\title{
ULTRAFILTRATION FOULING: IMPACT OF BACKWASH FREQUENCY AND AIR SPARGING
}

By

Lan Li

A thesis submitted in conformity with the requirements

for the degree of Master of Applied Science

Graduate Department of Civil Engineering

University of Toronto

C Copyright by Lan Li 2014 


\section{ULTRAFILTRATION FOULING: IMPACT OF BACKWASH FREQUENCY AND AIR SPARGING}

Lan Li

Master of Applied Science, 2014

Graduate Department of Civil Engineering

University of Toronto

\section{ABSTRACT}

A bench-scale study was performed to optimize backwash frequency and air sparging conditions during ultrafiltration (UF) of natural surface waters in order to maximize water production and minimize irreversible fouling as well as operating and maintenance costs. Surface shear stress representing different air sparging conditions (continuous coarse bubble, discontinuous coarse bubble, and large pulse bubble sparging) was applied in combination with various backwash frequencies $(0.5,2$ and $6 \mathrm{~h})$ and fouling was assessed. Results indicated that air sparging with discontinuous coarse bubbles or large pulse bubbles significantly reduced the irreversible fouling rate while providing cost savings when compared to the baseline condition, which assumed a $0.5 \mathrm{~h}$-backwash frequency and no air sparging during filtration. Cost savings were more pronounced at lower backwash frequencies, due to value associated with extra water produced over longer filtration times and longer membrane life resulted from fewer recovery chemical cleans because of lower irreversible fouling. 


\section{ACKNOWLEDGEMENTS}

I would like to thank Professors Robert Andrews and Pierre Bérubé for their support and guidance on my research project. I would also like to thank Heather Wray for spending many, many hours teaching me and helping me troubleshoot during laboratory experiments.

I would also like to acknowledge several people who have helped me in various ways throughout my thesis study: Jim Wang for teaching me how to use the analytical instrument, Jennifer Lee for helping me with ordering materials and equipment, John Armour and Kari Anne Last for arranging and helping me with water sampling at Peterborough and Barrie, and Syed Zaki Abdullah for sending me the UF membrane from the University of British Columbia.

I would like to thank the Natural Sciences and Engineering Research Council of Canada (NSERC) Industrial Chair in Drinking Water Research for supporting me financially.

Finally, I am grateful for the love and support from my family and friends. Without them, I would not have been able to accomplish this milestone. 


\section{Table of Contents}

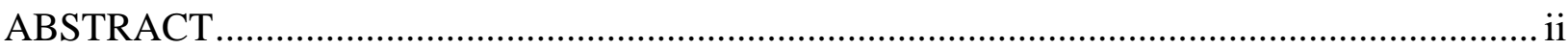

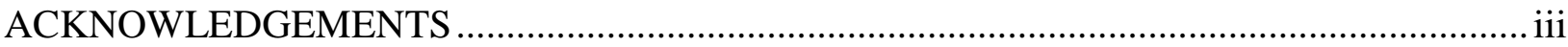

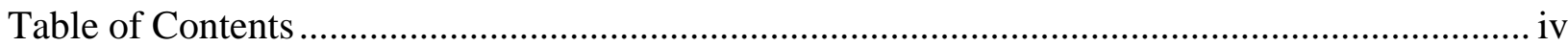

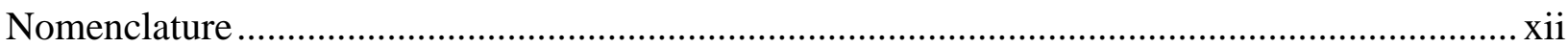

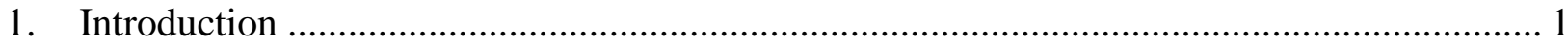

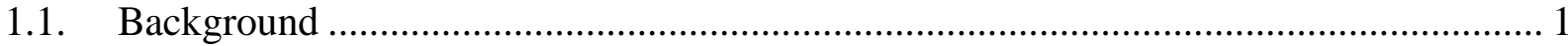

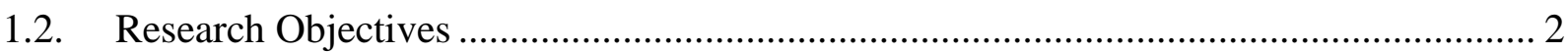

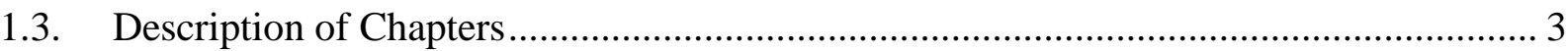

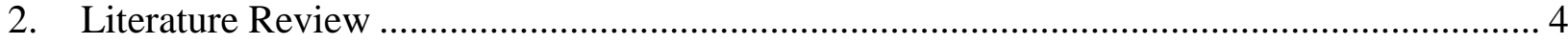

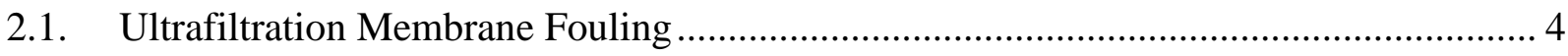

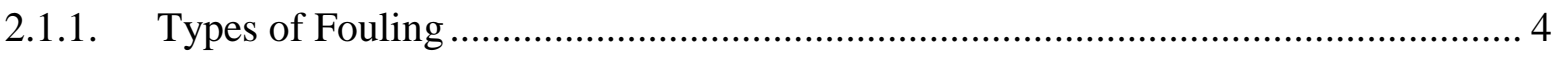

2.1.2. Fouling Mechanisms ……………………….............................................. 5

2.1.3. Factors that Influence Fouling ………………........................................... 5

2.1.3.1. Foulant Characteristics ........................................................................... 5

2.1.3.2. Water Chemistry ................................................................................

2.1.3.3. Membrane Properties........................................................................... 8

2.1.3.4. Operating Conditions................................................................................ 9

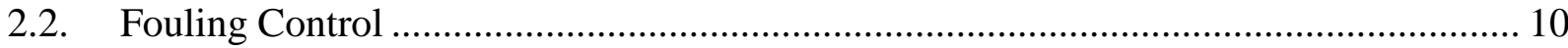

2.2.1. Pretreatment before Ultrafiltration................................................................ 10

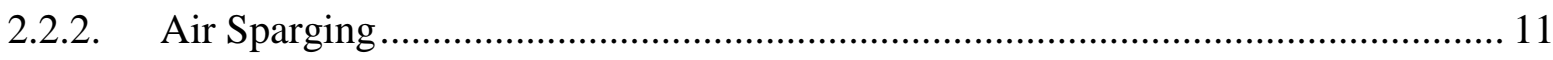

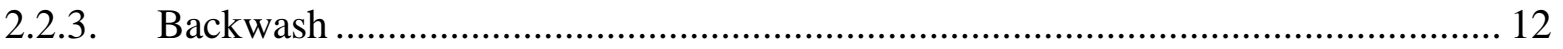

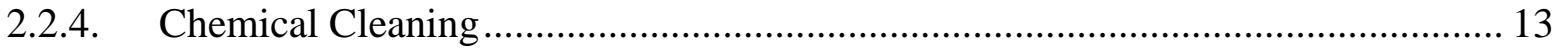

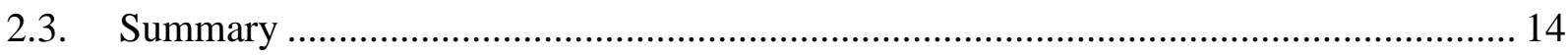

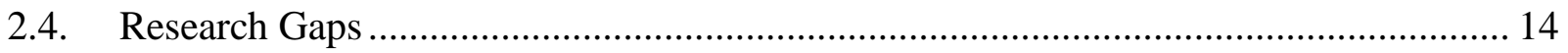

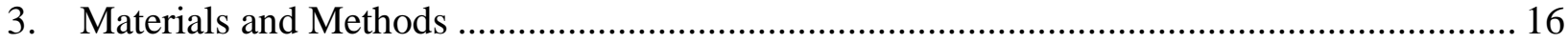

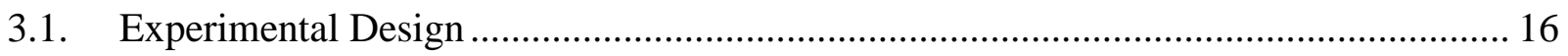

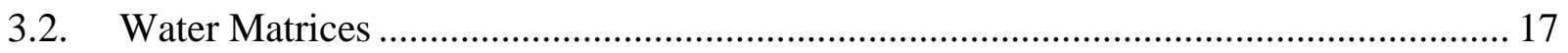

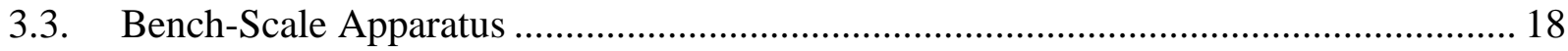

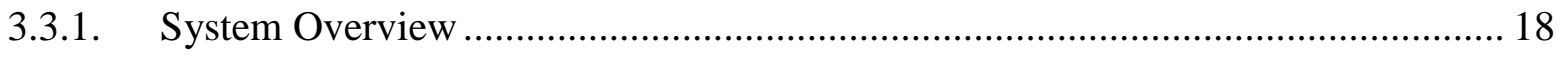




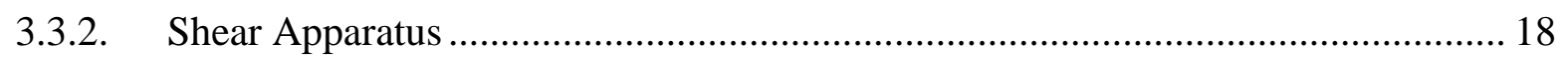

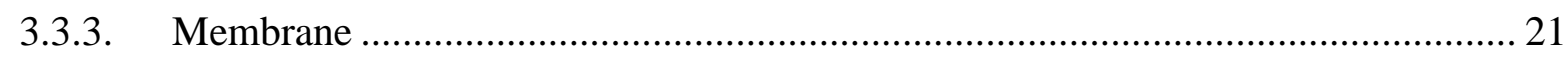

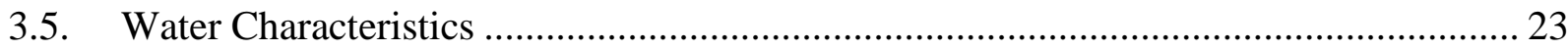

3.5.1. Liquid Chromatography - Organic Carbon Detection (LC-OCD) ......................... 23

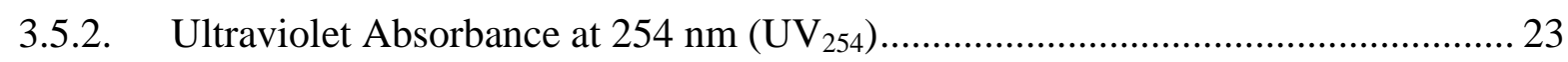

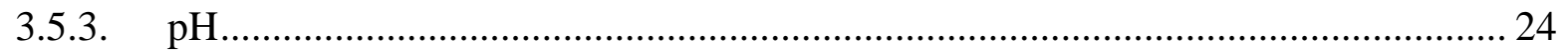

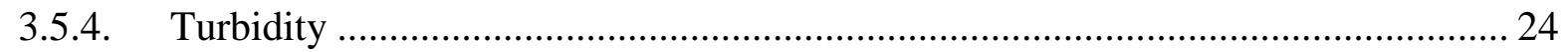

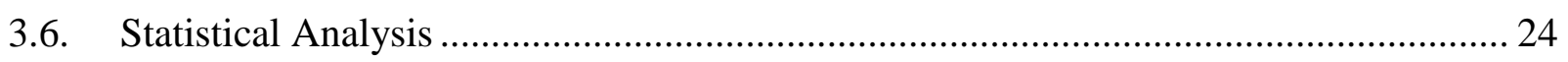

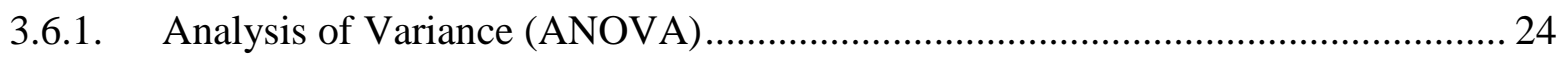

3.6.2. Post-Hoc Testing: Tukey’s Honestly Significant Difference (HSD) ...................... 25

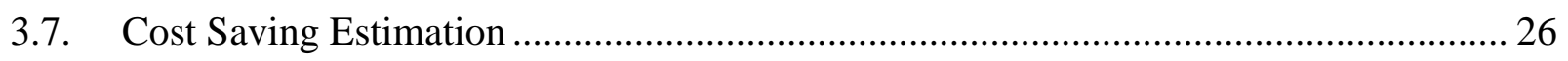

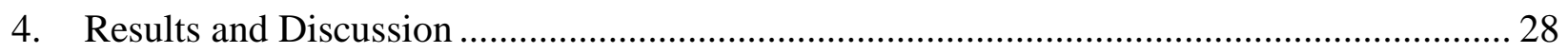

4.1. Effect of Backwash Frequency and Air Sparging Condition on Organic Matter Removal 28

4.2. Effect of Backwash Frequency and Air Sparging Condition on Membrane Fouling .... 28

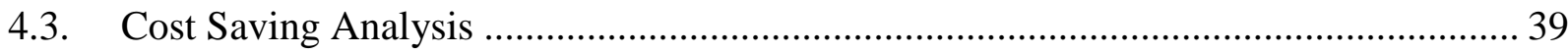

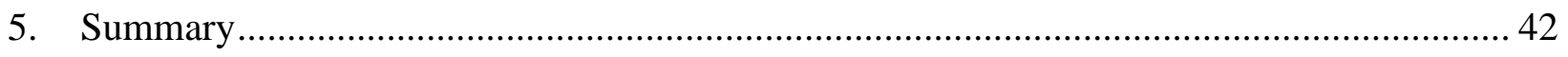

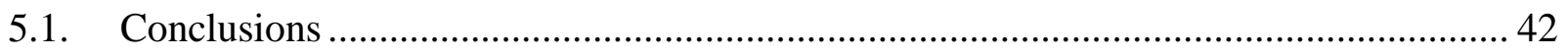

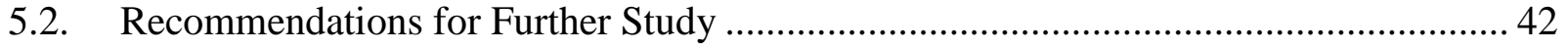

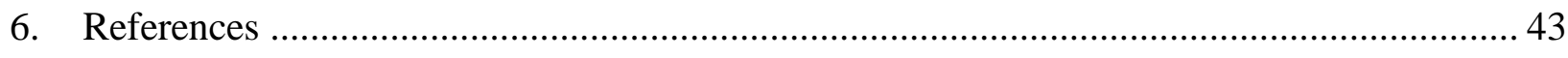

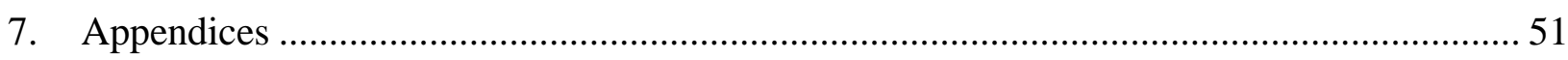

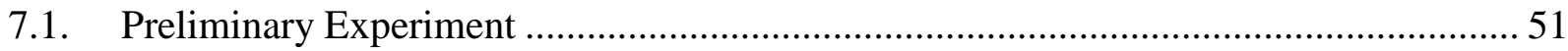

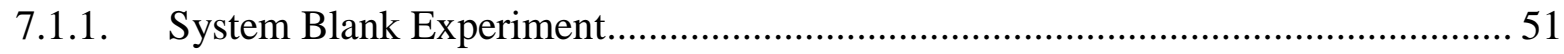

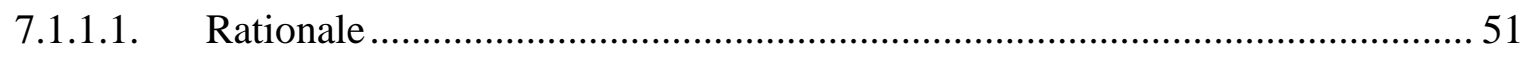

7.1.1.2. Objective ............................................................................................ 51

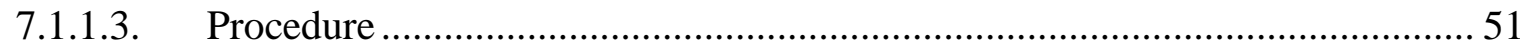

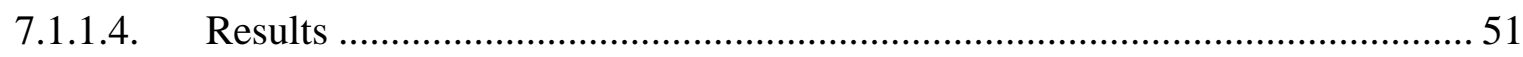

7.1.1.5. Conclusion ........................................................................................ 52

7.1.2. System Modification Experiment ……………................................................... 52

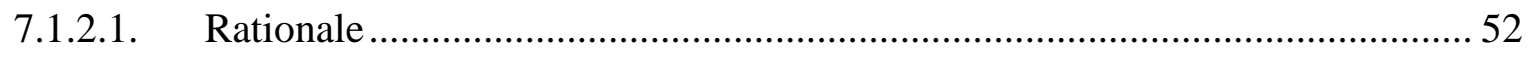

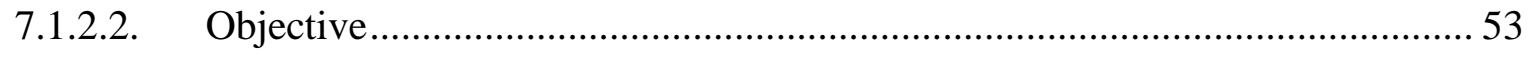

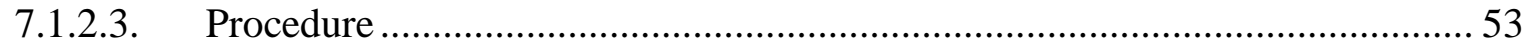




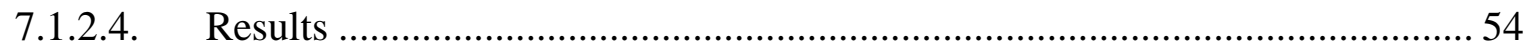

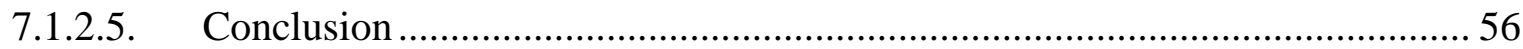

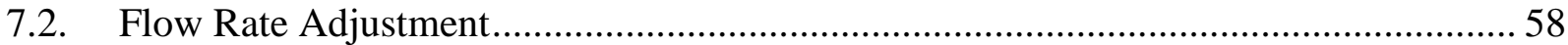

7.3. ANOVA Results of all experiments using natural water matrices.............................. 58

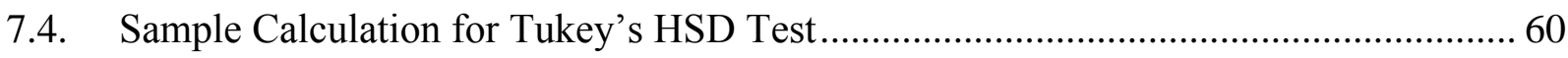

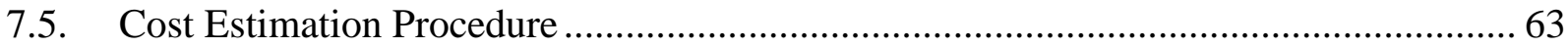

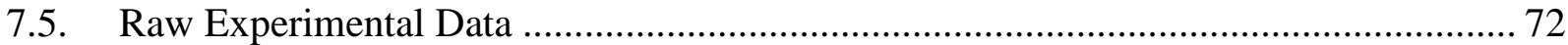




\section{List of Tables}

Table 3.1: Characteristics of surface shear stress conditions generated by the bench-scale shear

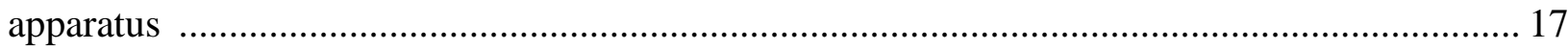

Table 3.2: Physical and chemical characteristics of the source waters in this study .................. 17

Table 3.3: Values used in cost estimation for a membrane train ........................................... 27

Table 4.1: Comparison of fouling and cost savings for a range of backwash and shear conditions

Table 7.1: Results of DOC analysis for the System Blank Experiment samples collected from permeate produced using the stainless steel holder and rubber backing fiber mounting methods

Table 7.2: Experimental conditions of system modification preliminary experiments performed in a $0.2 \mathrm{~g} / \mathrm{L}$ bentonite solution

Table 7.3: Fouling rates of filtration using the stainless steel holder and rubber backing fiber mounting methods under the no shear stress condition in a $0.2 \mathrm{~g} / \mathrm{L}$ bentonite solution 56

Table 7.4: ANOVA results of the stainless steel holder and the rubber backing fiber mounting

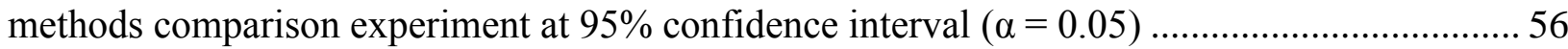
Table 7.5: Fouling rates of filtration using the stainless steel holder fiber mounting methods under different shear stress conditions in a $0.2 \mathrm{~g} / \mathrm{L}$ bentonite solution at the 60-80 min time

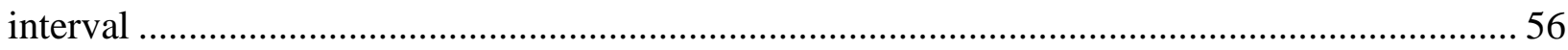

Table 7.6: Three-way ANOVA results for the experiments ................................................. 58

Table 7.7: Two-way ANOVA results for the experiments in Otonabee River water.................. 59

Table 7.8: One-way ANOVA comparing irreversible fouling rates at different backwash frequencies with the same shear stress conditions for experiments in Otonabee River water 59 Table 7.9: One-way ANOVA comparing irreversible fouling rates at different shear stress conditions with the same backwash frequency for experiments in Otonabee River water .......... 59 Table 7.10: Two-way ANOVA results for the experiments in Lake Simcoe water 59 Table 7.11: One-way ANOVA comparing irreversible fouling rates at different backwash frequencies with the same shear stress conditions for experiments in Lake Simcoe water 60 Table 7.12: One-way ANOVA comparing irreversible fouling rates at different shear stress conditions with the same backwash frequency for experiments in Lake Simcoe water 
Table 7.13: Tukey's HSD table for irreversible fouling rates at 0.5-h backwash frequency in

Otonabee River water

Table 7.14: Tukey's HSD table for irreversible fouling rates at 6-h backwash frequency in

Otonabee River water

Table 7.15: Tukey's HSD table for irreversible fouling rates under no shear condition in

Otonabee River water 62

Table 7.16: Tukey's HSD table for irreversible fouling rates under low peak shear condition in

Otonabee River water 62

Table 7.17: Tukey's HSD table for irreversible fouling rates at 2-h backwash frequency in Lake Simcoe water. 62

Table 7.18: Tukey's HSD table for irreversible fouling rates at 6-h backwash frequency in Lake

Simcoe water. 62

Table 7.19: Tukey's HSD table for irreversible fouling rates under no shear condition in Lake Simcoe water. 


\section{List of Figures}

Figure 3.1: Bench-scale submerged hollow fiber ultrafiltration experimental conditions .......... 16

Figure 3.2: Process flow diagram of bench-scale system .................................................. 19

Figure 3.3: Schematic of shear apparatus. (a) side view, (b) top view, (c) cross-section side view of the membrane tank showing the stainless steel fiber holder and the hollow fiber UF membrane 20

Figure 3.4: Impeller blades of shear apparatus. (a) low peak and high peak shear stress conditions, (b) sustained peak shear stress condition.... 21

Figure 3.5: Schematic of the side view of the membrane tank showing the relative position of different types of impellers to the fiber membrane surface. (a) high peak, (b) low peak, (c) sustained peak

Figure 3.6: Schematic representation of the variation in membrane resistance during filtrationbackwash cycles 22

Figure 4.1: Average (a) DOC and (b) biopolymer concentrations in feed (raw), permeate and backwash waters when considering all shear conditions and backwash frequencies .....

Figure 4.2: Typical resistance curves for UF experiments. Graphs show the resistance change during experiments at the 6 h-backwash frequency. (a) Otonabee River, (b) Lake Simcoe 30 Figure 4.3: Increase in resistance in each filtration cycle at different backwash frequencies and shear conditions during ultrafiltration for (a) Otonabee River, and (b) Lake Simcoe waters ...... 31 Figure 4.4: Reversible fouling as a percentage of total fouling for different backwash frequencies and shear conditions. (a) Otonabee River, (b) Lake Simcoe

Figure 4.5: Increase in resistance, $\Delta \mathrm{R}$, at different backwash frequencies and shear conditions during ultrafiltration of Otonabee River water. (a) 0.5 h-backwash frequency, (b) 2 h-backwash frequency, (c) 6 h-backwash frequency.....

Figure 4.6: Increase in resistance, $\Delta \mathrm{R}$, at different backwash frequencies and shear conditions during ultrafiltration of Lake Simcoe water. (a) 0.5 h-backwash frequency, (b) 2 h-backwash frequency, (c) 6 h-backwash frequency.....

Figure 4.7: Impact of backwash frequency and shear stress condition on irreversible fouling during ultrafiltration of Otonabee River water. (a) 0.5 h-backwash frequency, (b) 2 h-backwash frequency, (c) 6 h-backwash frequency . 
Figure 4.8: Impact of backwash frequency and shear stress condition on irreversible fouling during ultrafiltration of Lake Simcoe water. (a) 0.5 h-backwash frequency, (b) 2 h-backwash

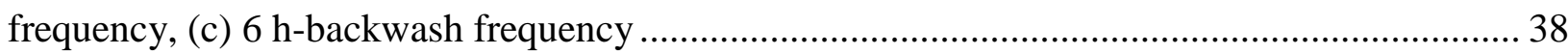
Figure 4.9: Estimation of operating and maintenance costs when considering various operating conditions for (a) Otonabee River, and (b) Lake Simcoe waters.

Figure 7.1: Resistance curves of filtration using the stainless steel holder fiber mounting method under the no shear stress condition in a $0.2 \mathrm{~g} / \mathrm{L}$ bentonite solution for the four membrane tanks

Figure 7.2: Resistance curves of filtration using the rubber backing fiber mounting method under the no shear stress condition in a $0.2 \mathrm{~g} / \mathrm{L}$ bentonite solution for the four membrane tanks 55 Figure 7.3: Resistance curves of filtration using the stainless steel fiber holder method under different shear stress conditions in a $0.2 \mathrm{~g} / \mathrm{L}$ bentonite solution.

Figure 7.5: Impact of backwash frequency and shear stress condition on irreversible fouling during ultrafiltration of Otonabee River water with respect to total filtration time. (a) 0.5 h, (b) 2 $\mathrm{h}$, and (c) $6 \mathrm{~h}$ 64 Figure 7.6: Impact of backwash frequency and shear stress condition on irreversible fouling during ultrafiltration of Lake Simcoe water with respect to total filtration time. (a) $0.5 \mathrm{~h}$, (b) $2 \mathrm{~h}$, and (c) $6 \mathrm{~h}$ 65

Figure 7.4: Relationship between additional power input and change in resistance 66 Figure 7.7: Resistance graphs showing the initial and final resistance of each cycle for experiments with the 0.5 h-backwash frequency in Otonabee River water. (a) no shear, (b) low peak, (c) sustained peak, (d) high peak

Figure 7.8: Resistance curves showing the initial and final resistance of each cycle for experiments with the 2 h-backwash frequency in Otonabee River water. (a) no shear, (b) low peak, (c) sustained peak, (d) high peak...... 75

Figure 7.9: Resistance curves showing the initial and final resistance of each cycle for experiments with the 6 h-backwash frequency in Otonabee River water. (a) no shear, (b) low peak, (c) sustained peak, (d) high peak...... 77

Figure 7.10: Resistance curves showing the initial and final resistance of each cycle for experiments with the 0.5 h-backwash frequency in Lake Simcoe water. (a) no shear, (b) low peak, (c) sustained peak, (d) high peak 
Figure 7.11: Resistance curves showing the initial and final resistance of each cycle for experiments with the 2 h-backwash frequency in Lake Simcoe water. (a) no shear, (b) low peak,

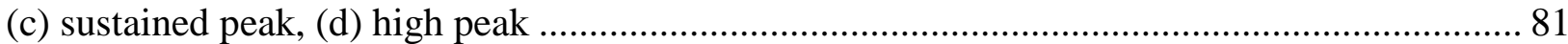

Figure 7.12: Resistance curves showing the initial and final resistance of each cycle for experiments with the 6 h-backwash frequency in Lake Simcoe water. (a) no shear, (b) low peak,

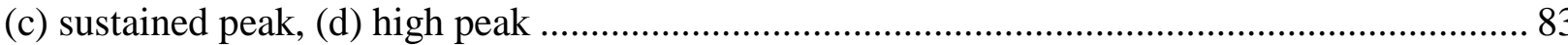




\section{Nomenclature}

\begin{tabular}{|c|c|}
\hline ANOVA & Analysis of variance \\
\hline${ }^{\circ} \mathrm{C}$ & Degree Celsius \\
\hline $\mathrm{Ca}$ & Calcium \\
\hline CEB & Chemically enhanced backwash \\
\hline CIP & Cleaning in place \\
\hline $\mathrm{cm}$ & Centimeter(s) \\
\hline DBP & Disinfection by-product \\
\hline DOC & Dissolved organic carbon \\
\hline EPS & Extracellular polymeric substances \\
\hline$f$ & Degrees of freedom for error \\
\hline $\mathrm{h}$ & Hour(s) \\
\hline HPLC & High-performance liquid chromatography \\
\hline HSD & Honestely significant difference \\
\hline i.d & Innver diameter \\
\hline IEP & Isoelectric point \\
\hline $\mathrm{J}$ & Flux \\
\hline $\mathrm{k}$ & Number of factor levels \\
\hline $\mathrm{kg}$ & Kilogram(s) \\
\hline $\mathrm{kW}$ & Kilowatt(s) \\
\hline $\mathrm{L}$ & Litre(s) \\
\hline LC-OCD & Liquid chromatography-organic carbon detection \\
\hline LMW & Low molecular weight \\
\hline $\mathrm{m}$ & Metre(s) \\
\hline MF & Microfiltration \\
\hline $\mathrm{Mg}$ & Magnesium \\
\hline $\mathrm{mg}$ & Milligram(s) \\
\hline $\min$ & Minute(s) \\
\hline $\mathrm{mL}$ & Millilitre(s) \\
\hline
\end{tabular}




\begin{tabular}{|c|c|}
\hline $\mathrm{mm}$ & Millimeter(s) \\
\hline MSE & Mean square error \\
\hline MWCO & Molecular weight cut-off \\
\hline $\mathrm{n}$ & Number of replicates in means \\
\hline NOM & Natural organic matter \\
\hline NTU & nephelometric turbidity units \\
\hline o.d & Outter diameter \\
\hline $\mathrm{P}$ & Pressure \\
\hline $\mathrm{p}$ & Statistical significance (p-value) \\
\hline PAC & Powdered activated carbon \\
\hline $\mathrm{PACl}$ & Plyaluminium chloride \\
\hline $\mathrm{pH}$ & Power of hydrogen \\
\hline Q & Studentized range critical value \\
\hline $\mathrm{R}$ & Resistance \\
\hline $\mathrm{R}_{0}$ & Initial resistance of virgin membrane \\
\hline $\mathrm{R}_{\mathrm{f}}$ & Final resistance of a filtration cycle \\
\hline $\mathrm{R}_{\mathrm{i}}$ & Initial resistance of a filtration cycle \\
\hline Rirr & Irreversible fouling \\
\hline $\mathrm{rpm}$ & Rotation(s) per minute \\
\hline $\mathrm{R}_{\text {rev }}$ & Reversible fouling \\
\hline $\mathrm{s}$ & Second(s) \\
\hline $\mathrm{t}$ & Number of replicates \\
\hline TMP & Transmembrane pressure \\
\hline TOC & Total organic carbon \\
\hline UF & Ultrafiltration \\
\hline $\mathrm{UV}_{254}$ & Ultraviolet absorbance at $254 \mathrm{~nm}$ \\
\hline Y & Measured variable (irreversible fouling rate) \\
\hline$\alpha$ & Effect of the ith level of factor A (shear condition) \\
\hline$\beta$ & Effect of the jth level of factor B (backwash frequency) \\
\hline$\Delta \mathrm{P}$ & Change in transmembrane pressure \\
\hline$\varepsilon$ & Random error component \\
\hline
\end{tabular}


$\mu$

$\mu$
Overall mean of measured variable

Viscosity 


\section{Introduction}

\subsection{Background}

Low pressure membrane filtration, especially ultrafiltration (UF), is commonly employed for drinking water treatment (Kabsch-Korbutowicz, 2005). However, membrane fouling remains a major constraint for UF applications, particularly for the treatment of surface water which contains natural organic matter (NOM) (Coasta et al., 2006), i.e., the major foulant in membrane filtration (Amy, 2008, Howe and Clark, 2002). In particular, biopolymers (polysaccharide- and protein-like NOM) have been identified as the primary UF foulant (Amy, 2008, Kimura et al., 2004).

Membrane fouling can be generally classified as either reversible or irreversible, defined operationally in terms of the specific backwashing and cleaning processes. Reversible fouling can be further categorized into hydraulically reversible or chemically reversible fouling. Hydraulically reversible foulant can be removed through physical cleaning, e.g., backwashing (Amy, 2008), that which remains after backwashing is hydraulically irreversible fouling. Some of the hydraulically irreversible foulant may be removed via chemical cleaning, i.e., chemically reversible fouling (Abrahamse et al., 2008). Reversible fouling can become increasingly difficult to remove by physical and chemical means over the course of a membrane's lifetime due to a transition to irreversible fouling (Smith et al., 2006). Hence, reversible fouling control can affect the extent of irreversible fouling.

Membrane fouling results in higher operation and maintenance costs, due to consumption of permeate during backwashing (Serra et al., 1999), increased energy consumption by permeate pumps to overcome increased resistance, and chemical cleaning processes which shorten membrane lifetime (Qu et al., 2012, Gahleitner et al., 2014). Usually, backwashing is applied every 30-90 minutes (Sutzkover-Gutman et al., 2010). Two types of chemical cleaning procedures are commonly performed at drinking treatment plants: maintenance cleaning and recovery cleaning. Maintenance cleaning refers to chemically enhanced backwash (CEB), which is normally performed daily using an oxidant such as sodium hypochlorite. Recovery cleaning is also known as cleaning in place (CIP), which uses caustic solutions (e.g. citric acid) to remove irreversible fouling and restore the membrane permeability. CIP is only performed a few times a year, typically < 10 times/year (Barrie Surface Water Treatment Plant, Ontario, Canada). Fouling control strategies that could result in longer permeation times between backwashing and reduced 
chemical cleaning would therefore be valuable and potentially lead to cost savings associated with extended membrane lifetime, and thus results in cost savings, since membrane replacement usually accounts for 25-40\% of plant costs (Regula et al, 2013).

Recent research has also indicated that the application of air sparging during filtration may be a promising fouling control strategy for UF membranes (Chan et al., 2011; Wray et al., 2013). Injecting air on the feed side creates a shear force on the membrane surface as bubbles rise along the membrane (Cui et al., 2003, Cabassud et al., 2001), which enhance the backtransport of foulants from the membrane surface, thus preventing deposition (Cabussud et al., 2001, Ducom et al., 2002). In an air-sparged UF system, bubble size and frequency result in different shear stresses at the membrane surface which can impact hydrodynamics and mass transfer (Zhang et al., 2009) and therefore fouling (Chan et al., 2011). Typically air sparging is applied only during backwash for UF production of drinking water. Several studies have shown that the use of air-assisted backwash can improve foulant removal efficiency and shorten the backwash time required to completely remove the cake layer (Remize et al., 2010, Bessiere et al., 2009, Serra et al., 1999). In particular, the application of large pulse bubbles (i.e., volume > 100 $\mathrm{mL}$ ) may provide an energy- and cost-efficient means of controlling membrane fouling (Jankhah and Bérubé, 2013). However, studies to-date have considered only particulate (reversible) fouling with lab-synthesized waters (Chan et al., 2011), or total fouling in natural waters (Wray et al., 2013), and have not distinguished between the impacts of air sparging on hydraulically reversible and irreversible fouling. The purpose of this research was therefore to provide a quantitative analysis regarding the effect of backwash frequency and air sparging condition on UF membrane fouling, particularly the hydraulically irreversible fouling.

\subsection{Research Objectives}

The main objectives of this research were to:

1. Examine the effects of different backwash frequencies and/or air-sparging conditions on fouling during ultrafiltration of natural surface waters (Otonabee River and Lake Simcoe), and

2. Identify the backwash frequencies and/or air sparging conditions that could result in the greatest cost savings with respect to fouling control for full-scale operation. 


\subsection{Description of Chapters}

- Chapter 2 provides background information on UF membrane fouling as well as strategies to minimizing fouling.

- Chapter 3 describes the methodology used to study the effect of backwash frequency and shear stress condition on UF membrane fouling. Details regarding water selection, experimental design, bench-scale apparatus, methods for sample collection and analysis, and statistical analysis are provided.

- Chapter 4 presents the results of bench-scale filtration experiments, including the effect of backwash frequency and air-sparging induced shear stress condition on DOC removal, membrane fouling rate and costs savings associated with fouling.

- Chapter 5 provides a summary, conclusions and recommendations for further studies.

- Chapter 6 lists the references consulted in this study

- Chapter 7 presents the appendices, including methodology and results of preliminary experiments for equipment development and modification, raw data from filtration experiments that were used in the analysis, selected LC-OCD results, and addition information associated with statistical analysis and costs analysis. 


\section{Literature Review}

\subsection{Ultrafiltration Membrane Fouling}

Low pressure membrane filtration, especially ultrafiltration (UF), is one of the commonly used processes in drinking water treatment (Kabsch-Korbutowicz, 2005). However, membrane fouling is still one of the major constraints in UF application, particularly in filtration of natural surface water, since it contains considerable amount of natural organic matter (NOM), which is the main UF foulant (Costa et al., 2006, Amy, 2008, Howe and Clark, 2002). Membrane fouling has become one of the main concerns in UF because it lowers the permeate flux and reduces water production due to the consumption of permeate during backwash (Serra et al., 1999). Fouling can also lead to high energy consumption, as it increases pumping power and number of cleaning processes (Qu et al., 2012).

\subsubsection{Types of Fouling}

Membrane fouling can be generally classified as reversible or irreversible, which is defined operationally in terms of the specific backwashing and cleaning processes. Reversible fouling can be further categorized into hydraulically or chemically reversible fouling. Hydraulically reversible fouling can be removed through physical cleaning, such as backwashing (Amy, 2008). Hydraulically reversible foulant usually does not cause severe problems to the membrane, since it can be removed at the end of each backwash cycle. The remaining foulant after backwashing is hydraulically irreversible. Some of the hydraulically irreversible foulant can be removed by regular chemical cleaning. This foulant is regarded as chemically reversible (Abrahamse et al., 2008). Chemically reversible fouling is caused by strong adsorption of macromolecules onto the membrane, resulting in pore blocking, gel layer or biofilm formation (Huyskens et al., 2008). Typical chemical cleaning processes include soaking the membrane in caustic solution to dissolve the foulant (Amy, 2008).

Irreversible fouling is mainly the result of membrane pore blockage, which is caused by substances that cannot be removed through either physical or chemical cleaning. This leads to membrane damage and permanent permeate flux reduction (Neubrand et al. 2010, Nguyen et al., 2011). 
Reversible foulant can become increasingly difficult to remove physically and chemically over the course of a membrane's lifetime, since transition from reversible to irreversible fouling is possible (Smith et al., 2006). Hence, reversible fouling control can affect the extent of irreversible fouling. Although the extent of hydraulically irreversible fouling is not affected by the number of backwash cycles, periodic backwash can help maintaining adequate permeability and productivity throughout the membrane lifetime (Amy, 2008).

\subsubsection{Fouling Mechanisms}

Fouling is caused by substances in the water that adsorb reversibly or irreversibly onto the membrane surface or within the membrane pores (Jones and O’Melia, 2000). There are three main membrane fouling mechanisms: pore constriction due to particle adsorption onto membrane pores, pore blocking at the membrane surface, and cake formation due to rejected particle deposition on the membrane surface (Katsoufido et al., 2005). Campinas and Rosa (2010) introduced another fouling mechanism in addition to the three main ones, which was the gel formation. It represented an extreme case of concentration polarization. NOM adsorption and gel-layer formation influence permeate flux and solute rejection (Cho et al., 2000). A study performed by Taniguchi et al. (2003) showed that cake formation was the dominant fouling mechanism in ultrafiltration. Other studies showed that pore blocking occurred in the earlier stage during filtration followed by cake formation (Hwang et al., 2008, Costa et al., 2006).

\subsubsection{Factors that Influence Fouling}

\subsubsection{Foulant Characteristics}

Membrane fouling can be generally classified into four categories in terms of the foulant characteristics: colloidal fouling, biofouling, organic fouling and inorganic fouling (Amy, 2008). NOM characteristics, such as aromaticity, charge, hydrophobic-hydrophilic property and molecular configuration, can affect membrane fouling (Jones and O’Melia, 2000, Neubrand, 2010, Fan et al., 2001, Lee at al., 2004). Larger NOM compounds can cause more fouling than smaller ones (Abrahamse et al., 2008). The colloidal fraction of NOM causes the most significant flux reduction in membrane filtration (Lee and Amy et al., 2006, Costa et al., 2006). NOM is usually classified as non-humic substances (relatively simple substances of known structures, such as carbohydrates, proteins, amino acids, fats, etc.) and humic substances (Choudhry, 1984). 
Choudhry (1984) described that humic substances were abundant in the environment and were generally divided into three fractions: humic acid, fulvic acid and humin. Humic substances are relatively large in molecular size (molecular weights range from a few hundred to several millions). Humic acids in water are classified in the colloidal range due to their molecular sizes. The colloidal fraction of NOM ranging between 3 and $20 \mathrm{~nm}$ represent the major fouling component in UF treatment associated with natural surface water (Howe and Clark, 2002). The humic acid concentration, solution $\mathrm{pH}$ and ionic strength control the colloidal structure, and thus affect the extent of fouling. At high concentration $(>3.5 \mathrm{~g} / \mathrm{L})$, low $\mathrm{pH}(<3.5)$ and high ionic strength $(>0.05 \mathrm{M})$, humic acid compounds are rigid, uncharged colloidal substances, but they become flexible linear polyelectrolytes at low concentration $(<3.5 \mathrm{~g} / \mathrm{L})$, high pH $(>3.5)$ and low ionic strength $(<0.05 \mathrm{M})$ (Sutzkover-Gutman et al., 2010). In addition, humic acids contribute to irreversible fouling ( $\mathrm{Li}$ et al., 2011). Fouling caused by humic acid is developed by initial rapid irreversible fouling due to internal pore adsorption followed by pore blocking and cake formation (Katsoufidou et al., 2008).

Polysaccharide- and protein-like NOM substances are believed to be the major membrane foulant. They have both macromolecular and colloidal forms (Amy, 2008). Amy (2008) stated that the polysaccharide-like NOM compounds were neutral and could interact with the membrane through hydrogen bonding, or form a cake/gel layer when they presented in the colloidal form, whereas the protein-like NOM compounds were amphoteric (i.e. have both negatively and positively charged functional groups) and could interact with the membrane surface through dipole interaction, or could form a cake/gel layer in their colloidal state. A study performed by Kimura et al. (2004) showed that organic matter did not uniformly adsorb onto the membrane and were the major cause of irreversible fouling. This study also demonstrated that some metals (e.g. iron and manganese) contributed to the irreversible fouling to some extent and polysaccharides had greater affinity for the hydrophobic polysulfone UF membrane. These compounds caused irreversible fouling through pore blocking. Kimura et al. (2004) suggested a database should be established to facilitate people selecting the appropriate membrane for a given water characteristics, so that to minimize irreversible fouling.

In addition to NOM, extracellular polymeric substances (EPS) represent another group of membrane foulant. EPS includes polysaccharides, and other biopolymers such as nucleic acids and proteins that are produced by microorganisms (Katsoufidou et al., 2010, Lee et al., 2006, Ang et al., 2006, Neubrand et al., 2010). In a study performed by Katsoufidou et al. (2008), 
sodium alginate, which was used as a representative of EPS, was found to cause more severe fouling than humic acid (a representative of NOM). The same study indicated that sodium alginate was associated with a fouling mechanism that was different from humic acid, in which sodium alginate would initially cause internal pore constriction followed by cake layer formation. Hydrophobicity/hydrophilicity of the foulant can also affecting membrane fouling.

Neutral hydrophilic compounds are often the more severe foulant than hydrophobic compounds (Abrahamse et al., 2008). There is a preferential rejection of aromatic/hydrophobic NOM by the membrane (Cho et al., 2000). Relatively high molecular weight (> $1 \mathrm{kDa}$ ) hydrophobic NOM fractions contribute to a rapid flux decline (flux dropped to $20 \%$ of pure water flux at the end of 60-minute filtration) and the lower molecular weight ( $<1 \mathrm{kDa})$ neutral hydrophilic compounds are responsible for slow flux decline (approximately 40-50\% drop from the pure water flux at the end of the 60-minute filtration) (Dong et al., 2007).

\subsubsection{Water Chemistry}

The rate of membrane fouling can be influenced by water chemistry parameters such as ionic strength, divalent ion concentration and $\mathrm{pH}$. Polymeric UF membranes and NOM molecules are usually negatively charged at neutral pH (Abrahamse et al., 2008). Increasing ionic strength lowers the zeta-potential of the membrane and NOM molecules, resulting less repulsion between them (Cho et al., 2000). Increasing ionic strength also causes macromolecule electrical double layer compression and leads to their aggregation and deposition on the membrane surface, and thus lowers the membrane rejection coefficient (Costa et al., 2005).

Divalent ion (e.g. $\mathrm{Ca}$ and $\mathrm{Mg}$ ions) concentration affects membrane fouling due to bridging caused by divalent ions and their ability to form complexes with organic molecules. Irreversible fouling is linearly dependent on $\mathrm{Ca}$ and $\mathrm{Mg}$ ion concentrations. An increase in $\mathrm{Ca}$ ion concentration enhances fouling by neutralizing the negatively charged NOM molecules, especially the charged humic substances and promotes molecule aggregation. Cake formation is also more dominant as $\mathrm{Ca}$ ion concentration increases (Amy, 2008, Abrahamse et al., 2008, Katsoufidou et al., 2008).

Studies have shown that fouling caused by humic acids is more severe at low $\mathrm{pH}$ (e.g. pH 3), high ionic strength (e.g. > $0.05 \mathrm{M}$ ) and at the presence of divalent ions (Sutzkover-Gutman et al., 2010). A study performed by Jones and O’Melia (2000) showed that fouling caused by adsorption of proteins onto membrane surface was the greatest at the protein isoelectric point 
( $\mathrm{pH}$ 4.7). This was because the electrostatic repulsion force between humic acid compounds and protein molecules decreased as the solution $\mathrm{pH}$ decreased, resulting an increase in adsorption. Jones and O'Melia (2000) also reported that the increase in ionic strength shielded some of the repulsive charges between the molecules, causing increasing adsorption onto the membrane.

\subsubsection{Membrane Properties}

Membrane fouling is also dependent on the physical and chemical characteristics of the membrane, including molecular weight cut-off (MWCO), pore size distribution, material composition, pure water permeability, surface roughness, surface charge and hydrophobicity index (Amy, 2008, Peeva et al., 2011, Cho et al., 2000). The relative sizes of colloidal foulant and membrane pores affect the rate of pore blocking and membrane fouling mechanisms (Costa et al., 2006). Many studies have found that fouling is more severe for membranes with higher permeability and MWCO, since larger pore size allows pore constriction instead of cake formation (cake formation is more common for membranes with smaller pores) (Costa et al., 2005, Suzkover-Gutman et al, 2010). Costa et al. (2006) also found that transition from pore blocking to cake formation occurred earlier for the more permeable membrane than less permeable membranes during filtration. This explains why microfiltration (MF) membranes are more prone to hydraulically irreversible fouling than UF membranes (Amy, 2008). The selection of membrane with the most effective MWCO is also dependent on the NOM characteristics in the source water (Cho et al., 2000).

UF membranes with greater negative surface charge can reduce fouling (Amy, 2008). However, membrane surface charge can be affected by the water chemistry. For example, in the case of a cellulose acetate membrane, the surface becomes more negative as the $\mathrm{pH}$ of the solution increases, but an increase in ionic strength makes the surface less negative (Elimelech et al., 1994). Humic substances adsorbed onto the cellulose acetate membrane also have impact on the surface charge (Childress et al., 1996) and the humic acid molecule adsorption is the strongest at $\mathrm{pH} 3$, which is near the isoelectric point of humic acid (Ruohomaki, 1998).

A study performed by Jung and Kang (2003) showed that the permeate flux decline rate was higher in hydrophobic membrane than hydrophilic membrane (a 10-30\% more flux drop for hydrophobic membranes than for hydrophilic membranes under the same coagulation pretreatment conditions at the end of the 30-minute UF). 


\subsubsection{Operating Conditions}

Membrane fouling lowers the filtration performance and increase the operating as well as maintenance costs, due to consumption of permeate during backwashing (Serra et al., 1999), increased energy consumption by permeate pumps to overcome increased resistance, and chemical cleaning processes which shortens membrane lifetime (Qu et al., 2012, Gahleitner et al., 2014). Therefore, it is necessary to identify the operating conditions that can optimize full-scale operation (Bérubé et al., 2008). There have been several techniques that are commonly applied to minimize membrane fouling, including pretreatment of the feed water to reduce potential foulant, air sparging to create shear stress on the membrane surface, and periodic backwash to remove fouling (Guo et al., 2009, Belfort et al., 1994). The three aforesaid techniques are discussed in detail in Section 2.2. Some membrane fouling control studies were focused on optimizing system conditions such as feed flow velocity, feed operating mode (e.g. dead-end or cross-flow filtration) and transmembrane pressure (TMP) (Gui et al., 2003).

Field et al. (1995) introduced the critical flux concept. Critical flux is used to distinguish between low fouling region and high fouling region in direct- and cross-flow systems (Field and Pearce, 2011). In theory, when a membrane filtration system is operated below the critical flux, no or negligible surface fouling should be observed (Bérubé et al., 2008, Wicaksana et al., 2005). A study performed by Bérubé et al. (2008) showed that under sub-critical flux operation, membrane fouling was predominantly caused by internal fouling; under super-critical flux operation, membrane fouling was mainly due to surface fouling. The same study also showed that when the system was operated under the transition zone (between "true" sub-critical flux conditions and super-critical flux conditions), fouling was increasingly due to surface fouling. The sustainable flux represents the flux condition under which an acceptable amount of fouling occurs, and the fouling is reversible during cleaning at an acceptable frequency (Field and Pearce, 2011).

Membrane filtration can be operated at a constant flux or a constant pressure. Constant flux operation minimizes extensive membrane fouling and is cost effective for submerged membrane systems (Defrance and Jaffrin, 1999). When the membrane is operated at a constant pressure, rapid flux decline occurs at the beginning followed by gradual decrease until a steady state or pseudo-steady state is reached (Le-Clech et al, 2006). Stepwise increase in filtration pressure can mitigate membrane internal fouling (Hwang et al., 2008). A review study performed by Le-Clech et al. (2006) stated that fouling rate was generally lower when constant flux 
operation was applied. Le-Clech et al. (2006) explained that this was because under constant flux condition, higher particle deposit rate may occur at the beginning of the filtration process in comparison to systems that were operated at constant TMP. This early formation of cake layer could act as a pre-filter for particles that may penetrate deeper into the membrane pores.

\subsection{Fouling Control}

\subsubsection{Pretreatment before Ultrafiltration}

Membrane filtration usually does not remove colour or NOM when used alone (Best et al., 2001). Reduction of NOM before disinfection in drinking water treatment is important since it minimizes the formation of disinfection by-products (DBPs) (Kabsch-Korbutowicz, 2005). Therefore, membrane process should combine with other pretreatment processes, such as activated carbon adsorption and coagulation, to improve the permeate water quality (Best et al., 2001, Choi and Dempsey, 2004). Some studies have shown that pretreatment before membrane filtration can either removed the potentially absorbable molecules or changed their physical and chemical properties to reduce fouling, particularly irreversible fouling (Kweon and Lawler, 2004, Jung and Kang, 2003). Coagulation before UF has been proven to have beneficial effect on minimizing membrane fouling by increasing the removal efficiency of NOM and enhancing membrane rejection (Lee et al., 2007, Kim et al., 2005, Kabsch-Korbutowicz, 2005, KabschKorbutowicz, 2006).

Coagulation is a more commonly used pretreatment, since it is inexpensive and easy to apply (Dong et al., 2007). In-line coagulation has been shown to be an effective UF pretreatment process (Guigui et al., 2002, Choi and Dempsey, 2004). In-line coagulation refers to the application of coagulation without a sedimentation or pre-filtration step before membrane filtration (Guigui et al., 2002). The effectiveness of coagulation is dependent on the coagulant type and dosage, since the characteristics (e.g. shape, size) of flocs affect the cake structure. Coagulation can be optimized to prevent the formation of a sticky and compact NOM gel layer on the membrane surface (Bergamasco et al., 2011, Li et al., 2011). Bench- and pilot-scale experiments have shown that aluminum-based coagulants were more effective in achieving high overall dissolved organic carbon (DOC) removal and had the potential to remove humic acids, (Neubrand et al., 2010). In addition, Zouboulis et al. (2008) reported that polyaluminum chloride $(\mathrm{PACl})$ was a more efficient coagulant than alum, due to its higher overall positive charge. 
Zouboulis et al., (2008) also showed that PACl worked better at high pH (i.e. > pH 7.4), low winter temperature conditions and at smaller quantity than alum. $\mathrm{PACl}$ also has higher DBP precursor removal efficiency than alum (Jung and Kang, 2003). There are three mechanisms of NOM removal by coagulation: charge neutralization, adsorption and entrapment. The required operating conditions (e.g. pH, temperature) for each mechanism are different (Gregor et al., 1997, Kabsch-Korbutowicz, 2005), and thus the efficiency of coagulation-UF process is also dependant on the operating conditions (Zouboulis et al., 2008, Kabsch-Korbutowicz, 2005). In addition, NOM removal efficiency is influenced by coagulant dosage. Excess coagulants are also potential membrane foulant (Cheng et al., 2010).

\subsubsection{Air Sparging}

Air sparging is commonly used in submerged membrane systems to reduce and remove particle deposition on membrane surface by injecting air on the feed side. Air sparging creates shear force at the membrane surface as bubbles rise along the membrane (Cui et al., 2003, Cabassud et al., 2001). The air-sparging induced shear force helps keeping particles that are near the membrane in suspension and enhances particle back-transport from the membrane surface, thus preventing particle deposition and enhances permeate flux (Cabassud et al., 2001, Ducom et al., 2002). A study performed by De Souza et al., (2013) showed that air sparging dominated UF fouling control. Other studies also showed that membrane fouling was significantly lower (20-60\% fouling reduction) under air-sparging conditions (Ghosh, 2006, Bérubé and Lei, 2006). On the other hand, a study performed by Hwang et al. (2008) reported that air-sparging could reduce particle deposition on membrane surface but did not have significant beneficial effects on membrane internal fouling.

In an air-sparged UF system, both the bubble size and frequency can affect the hydrodynamics and mass transfer at the membrane surface (Zhang et al., 2009). Different airsparging conditions produce bubbles with different geometries, resulting in various shear stress profiles (Chan et al., 2007). Shear stress profile parameters, including shear stress magnitude, duration and frequency, have different impacts on membrane fouling rate (Chan et al., 2011). Studies have shown that slug bubbles had desirable hydrodynamic characteristics in fouling control and enhancing permeate flux and selectivity for different membrane modules in various membrane filtration processes (Zhang et al., 2011, Cui et al., 2003, Yamanoi and Kageyama, 2010, Mercier et al., 1997). The interactions between bubbles and membrane surface are the 
major shear stress mechanism working on hollow fiber membrane, especially for the verticallyset modules. The fluctuation in shear and drag forces are a result of bubble flow velocity fluctuation (Nagaoka et al., 2006). Non-uniform and transient shear stress have shown to be more effective in fouling control than constant shear conditions (Ochoa et al., 2007, Chan et al., 2011). Chan et al. (2011) simulated various shear stress profiles to investigate the relationship between shear stress and fouling for the submerged UF hollow fiber membrane. The shear stress profiles tested in that study were similar to those observed in the pilot-scale study performed by Fulton et al. (2011). Results reported by Chan et al. (2011) showed that a high peak shear stress profile, which represented large pulse bubble sparging, had the best fouling control among the shear stress profiles examined in that study. Long duration shear events were more effective in fouling control than frequent short shear events for a given maximum peak shear value (Chan et al., 2011). The application of large pulse bubbles (i.e., volume > $100 \mathrm{~mL}$ ) may provide an energyand cost-efficient means membrane fouling control (Jankhah and Bérubé, 2013).

Membrane module configuration, including fiber packing density, air sparger design and tank dimensions, can also affect the bubble distribution and shear stress profile at the membrane surface, and thus influence fouling rate (Fulton et al, 2011). Culfaz et al. (2011) showed that vertical membrane modules had better performance than horizontal modules when coarse bubble sparging was applied, but no significant differences when fine bubbles were used. Several studies on the air-sparged submerged hollow fiber membranes showed that fouling control of tightly packed multi-fiber modules was poorer than the modules with some degree of looseness, since some parts in the more densely packed modules were not exposed to air-sparging and bulk liquid flow (Bérubé et al., 2006, Chan et al., 2007, Yeo et al., 2007). Although the lateral movement of the hollow fiber membrane resulted from the swaying of fibers also produces some shear force, the contribution to the surface shear stress is not significant in comparison to the air-sparing induced shear stress (Bérubé et al., 2006).

Energy costs from air sparging are also the major component in operating costs in UF (Le-Clech et al., 2006, Judd, 2008). Enhancement of air sparging effectiveness is influenced by air flow rate and the frequency of bubbling (Zhang et al., 2009).

\subsubsection{Backwash}

Full-scale UF in water treatment is a process of cycling between the filtration and backwashing steps (Remize et al., 2010). Backwash enables the membrane to operate for a 
longer time before it needs to be shut down for intensive physical and/or chemical cleaning, since the periodic backwash can reduce both internal and surface membrane fouling (Smith et al., 2006, Hwang et al., 2009). The frequency and intensity of backwash are some of the important parameters for maintaining good membrane operating conditions (Smith et al., 2006, Judd, 2006). During backwash, the permeate flux direction is reversed and this backward flow lifts off the accumulated foulant and flush it out of the system (Serra et al., 1999). The long-term decrease in membrane permeability is caused by the irreversible fouling after backwashing (Remize et al., 2010). While backwash loosens and detaches the fouling layer, it may also provide opportunities for macromolecules to infiltrate into the membrane pores. This is because the cake layer can serve as a pre-coat or secondary layer to protect the membrane from internal fouling by macromolecules (Ye et al., 2011, Wu et al., 2008). In addition, backwash requires temporary shutdown of the filtration process and consumes some permeate (Serra et al., 1999). Therefore, the effectiveness of backwash is important for maintaining the membrane permeability. The effectiveness of backwash is determined by the frequency and duration of the backwash cycle (Sutzkover-Gutman et al., 2010).

Optimal backwash frequency and duration depend on many parameters and it is impossible to pre-determine these parameters. A backwash operation with optimized effectiveness may not be the most economical operation (Smith et al., 2006). Usually, backwash is applied after every 30-90 minutes of filtration (Sutzkover-Gutman et al., 2010). A study performed by Kim and DiGiano (2006) reported that backwash frequency was more important than backwash duration in fouling control. Several studies have shown that the use of air-assisted backwash can improve foulant removal efficiency and shorten the backwash duration required to remove the cake layer (Remize et al., 2010, Bessiere et al., 2009, Serra et al., 1999). On the other hand, studies performed by Metzger et al. (2007) showed that air-assisted backwash could encourage irreversible fouling through pore blocking, because foulant that caused irreversible fouling mainly consisted of soluble molecular products, featuring high concentration and strongly bound proteins, which attached to the membrane and its pores, especially in the absence of the cake layer.

\subsubsection{Chemical Cleaning}

A commonly used method to remove hydraulically irreversible fouling and restore membrane permeability is chemical cleaning. There are two procedures of chemical cleaning that 
are usually applied at water treatment plants: chemically enhanced backwash (CEB) and cleaning in place (CIP). CEB is often performed daily using oxidants such as sodium hypochlorite. CIP is performed less frequent ( $<10$ times/year) using two types of chemicals: sodium hypochlorite to remove organic matter and citric acid to burn of the inorganic substances (Barrie Surface Water Treatment Plant, Ontario, Canada, Woo et al., 2013, Porcelli and Judd, 2010). Frequent chemical cleaning can shorten membrane lifetime and increase membrane replacement costs. Membrane replacement costs usually account for $25-40 \%$ of the membrane plant costs (Regula et al, 2013).

\subsection{Summary}

Low pressure membrane filtration, especially UF, is commonly used in drinking water treatment, because it is easy to apply and has the ability to produce high quality permeate while reducing the use of chemicals. However, membrane fouling still remains as one of the major obstacles in optimization of the filtration process. Studies have shown that NOM is the major membrane foulant which can cause both reversible and irreversible fouling through pore constriction, pore blocking and cake formation. Foulant characteristics, solution chemistry, membrane properties and operating conditions all have impacts on the membrane fouling behaviour.

There have been several operational techniques that are commonly applied to minimize membrane fouling and improve the process efficiency, including pretreatment of feed water by coagulation to reduce potential foulant concentration, air-sparging to create shear force at the membrane surface to enhance particle back-transport from the membrane, and periodic backwash to hydraulically remove foulant. Studies have shown that air-assisted backwash was more effective in removing foulant than backwashing alone.

\subsection{Research Gaps}

There have been some studies on the fouling control efficiency of techniques including coagulation pretreatment, air sparging and backwash, but not many of them have studied the level of significance of these techniques on reversible and irreversible fouling control, particularly for the submerged hollow fibre UF membrane systems (i.e. membranes that are operated under suction-driven outside-in mode). Submerged hollow fiber processes have become popular since they are easy to operate and manufacture (Jeison and van Lier, 2006, Le-Cletch et 
al., 2003, Wicaksana et al., 2006). It was found that many studies to-date on the optimization of UF were performed on flat sheet membranes or hollow fibre membranes that are operated in the inside-out mode. In addition, some of the studies used lab-synthesized water instead of natural surface water, so that the results may not be representative of full-scale operation, since the labsynthesized water in the previous studies mainly caused particulate fouling, which was mostly reversible, but the biopolymers in natural waters can also cause irreversible fouling. Some other studies using natural waters only considered total fouling and had not distinguished between the impact of air-sparging condition on hydraulically reversible and irreversible fouling (Wray et al., 2013). The study presented in this report examined the impacts of periodic backwash and airsparging induced shear stress on fouling of submerged hollow fiber UF membrane using natural surface water, with a focus on irreversible fouling control. 


\section{Materials and Methods}

\subsection{Experimental Design}

Bench-scale experiments were conducted to study the impact of different backwash frequencies $(0.5,2$ and $6 \mathrm{~h}$-permeation followed by 10 min-backwash) and four shear stress conditions, no shear, high peak, low peak and sustained peak, which represented four airsparging regimes, no air sparging, continuous coarse bubble, discontinuous coarse bubble and large pulse bubble sparging, respectively (Chan et al, 2011, Table 3.1), on fouling of the submerged hollow fiber UF membrane during filtration of two natural surface waters: Otonabee River and Lake Simcoe. A 10 min-backwash duration was selected because it is commonly applied at treatment plants associated with the surface waters studied. The four shear conditions were each applied during permeation at three backwash frequencies $(0.5,2$ and $6 \mathrm{~h})$ for Otonabee River and Lake Simcoe water, resulting in a total of 12 experimental conditions for each water matrix (Figure 3.1). The total filtration time (excluding backwash duration) for each experiment was $48 \mathrm{~h}$, resulting in 96, 24 and 8 filtration-backwash cycles, respectively, for the 0.5, 2 and 6 h-backwash frequencies. Each experiment was repeated twice. All conditions were performed in random order. The first cycle of each experiment was regarded as a system saturation, and the permeate and backwash water was discarded (permeate of the first 30 min was discarded for experiments with the 2 and $6 \mathrm{~h}$ backwash frequencies).

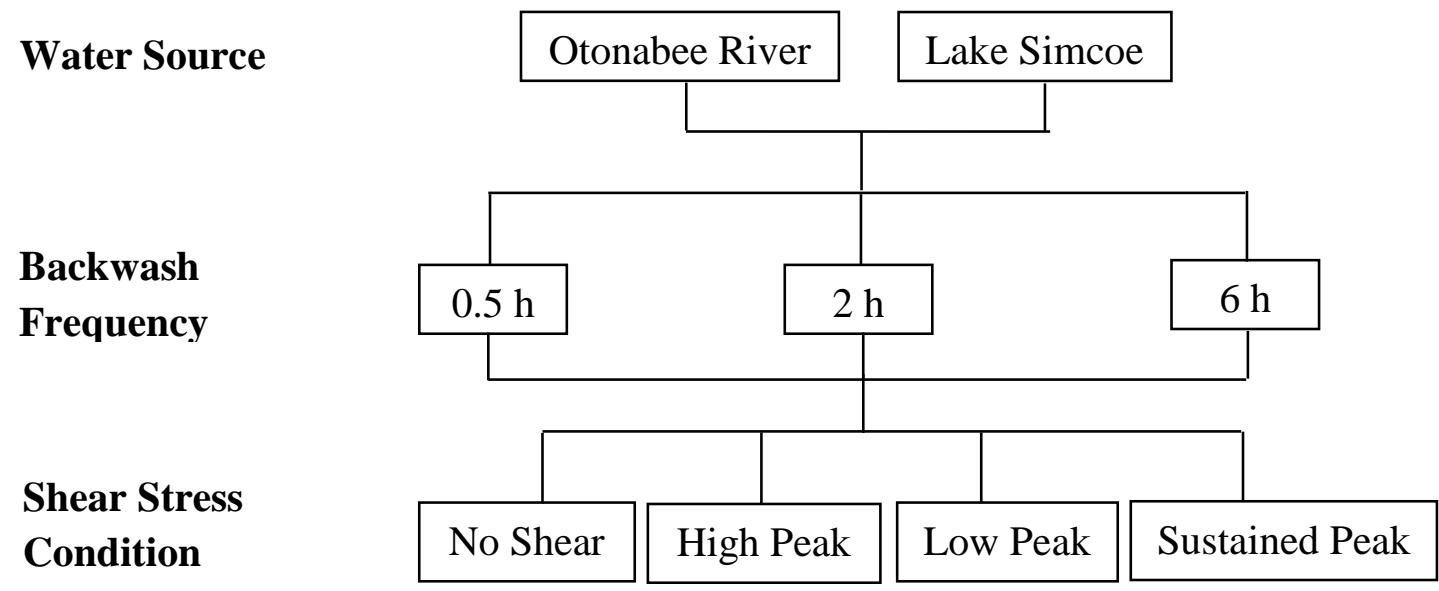

Figure 3.1: Bench-scale submerged hollow fiber ultrafiltration experimental conditions 
Table 3.1: Characteristics of surface shear stress conditions generated by the bench-scale shear apparatus (adapted from Chan et al., 2007, Chan et al., 2011)

\begin{tabular}{|c|l|l|}
\hline $\begin{array}{c}\text { Shear stress } \\
\text { condition }\end{array}$ & \multicolumn{1}{|c|}{$\begin{array}{c}\text { Description of air sparging } \\
\text { conditions }\end{array}$} & \multicolumn{1}{|c|}{$\begin{array}{c}\text { Equivalent full-scale } \\
\text { conditions }\end{array}$} \\
\hline No shear & Non-transient shear stress profile & No air sparging \\
\hline Low Peak & $\begin{array}{l}\text { Transient high shear stress of short } \\
\text { duration, followed by a period of } \\
\text { low shear stress mimicking } \\
\text { conditions of bubbles rising close } \\
\text { to but not in contact with fiber } \\
\text { surface }\end{array}$ & $\begin{array}{l}\text { Continuous coarse bubble } \\
\text { sparging }\end{array}$ \\
\hline Sustained Peak & $\begin{array}{l}\text { Transient high shear stress of long } \\
\text { duration, followed by a period } \\
\text { shear stress mimicking conditions } \\
\text { of bubbles rising close to but not } \\
\text { in contact with fiber surface }\end{array}$ & $\begin{array}{l}\text { Discontinuous coarse bubble } \\
\text { sparging }\end{array}$ \\
\hline High Peak & $\begin{array}{l}\text { Transient shear stress of short } \\
\text { duration, followed by a period of } \\
\text { high shear stress mimicking } \\
\text { conditions of bubbles rising in } \\
\text { contact with fiber surface }\end{array}$ & Large pulse bubble sparging \\
\hline
\end{tabular}

\subsection{Water Matrices}

Non-chlorinated, raw waters were collected at the intakes to the Peterborough water treatment plant (Otonabee River, Peterborough, ON) and Barrie south surface water treatment plant (Lake Simcoe, Barrie, ON). These waters were selected because they represent a range of DOC concentrations (Table 3.2) and are widely used as the drinking water sources in Ontario. The collected water was stored at $4^{\circ} \mathrm{C}$, and allowed to reach room temperature $\left(22^{\circ} \mathrm{C}\right)$ before use, within one week of collection.

Table 3.2: Physical and chemical characteristics of the source waters in this study

\begin{tabular}{|l|c|c|c|c|c|c|c|c|c|}
\hline Water & $\mathbf{p H}$ & $\begin{array}{c}\text { Turbidity } \\
(\mathbf{N T U})\end{array}$ & $\mathbf{U V}_{\mathbf{2 5 4}}$ & $\begin{array}{c}\text { DOC } \\
(\mathbf{m g} / \mathbf{L})\end{array}$ & $\begin{array}{c}\text { Biopolymers } \\
(\mathbf{m g} / \mathbf{L})\end{array}$ & $\begin{array}{c}\text { Humic } \\
\text { substances } \\
(\mathbf{m g} / \mathbf{L})\end{array}$ & $\begin{array}{c}\text { Building } \\
\text { blocks } \\
(\mathbf{m g} / \mathbf{L})\end{array}$ & $\begin{array}{c}\text { LMW } \\
\text { neutrals } \\
(\mathbf{m g} / \mathbf{L})\end{array}$ & $\begin{array}{c}\text { LMW } \\
\text { acids } \\
(\mathbf{m g} / \mathbf{L})\end{array}$ \\
\hline $\begin{array}{l}\text { Otonabee } \\
\text { River }\end{array}$ & 7.67 & 1.38 & 0.146 & 5.90 & 0.49 & 3.11 & 0.76 & 0.48 & 0.15 \\
\hline $\begin{array}{l}\text { Lake } \\
\text { Simcoe }\end{array}$ & 8.13 & 3.67 & 0.067 & 4.63 & 0.49 & 2.20 & 0.81 & 0.46 & 0.10 \\
\hline
\end{tabular}

${ }^{\mathrm{a}} \mathrm{LMW}=$ low molecular weight 


\subsection{Bench-Scale Apparatus}

\subsubsection{System Overview}

The bench-scale system allowed for automated filtration and backwash cycles (Figure 3.2). Briefly, the system consisted of a feed tank, single UF hollow fibers mounted in a stainless steel holder to the inner walls of membrane tanks, shear apparatus, peristaltic pumps and solenoid valves to control the filling and draining of the membrane tanks. Up to four membrane tanks could be operated in parallel in each experiment. The opening and closing of the solenoid valves as well as the pumping direction of the pumps were controlled by a PLC program (WinLDR V6, IDEC Corporation). Transmembrane pressure (TMP) on the permeate side of the membrane was measured and collected using a pressure transducer connected to a data logger and recorded automatically every $30 \mathrm{~s}$ using Labview software. Membrane tanks were filled and drained by gravity.

\subsubsection{Shear Apparatus}

The shear apparatus consisted of a cylindrical membrane tank (19 cm i.d), an impeller, a rig which secured the impeller, a motor which provided impeller rotation and a hollow fiber UF membrane that was mounted on the internal wall of the membrane tank by a stainless steel holder (Figure 3.3).

The shear apparatus is adapted from Chan et al., 2011 with a modification in the fiber mounting method. In Chan et al. 2011, the membrane fiber was attached to a piece of rubber backing using epoxy. Epoxy leaches LMW DOC during filtration and can interfere with the DOC measurement of water samples. A stainless steel fiber holder was installed for fiber mounting, and thus eliminated the use of epoxy and reduced leaching of LMW DOC (refer to Appendices, Section 7.1.1, for system blank experiment). The stainless steel holder was made from a stainless steel tubing ( $25 \mathrm{~cm}$ long, $3 \mathrm{~mm}$ o.d. and $2 \mathrm{~mm}$ i.d.) with a slot (1.57 $\mathrm{mm}$ wide) cut along its length. This tubing was embedded in the internal wall of the membrane tank along the circumference. Detailed description of this apparatus modification and related experiments that evaluate the system performance after modification is presented in Appendices, Section 7.1.2. 


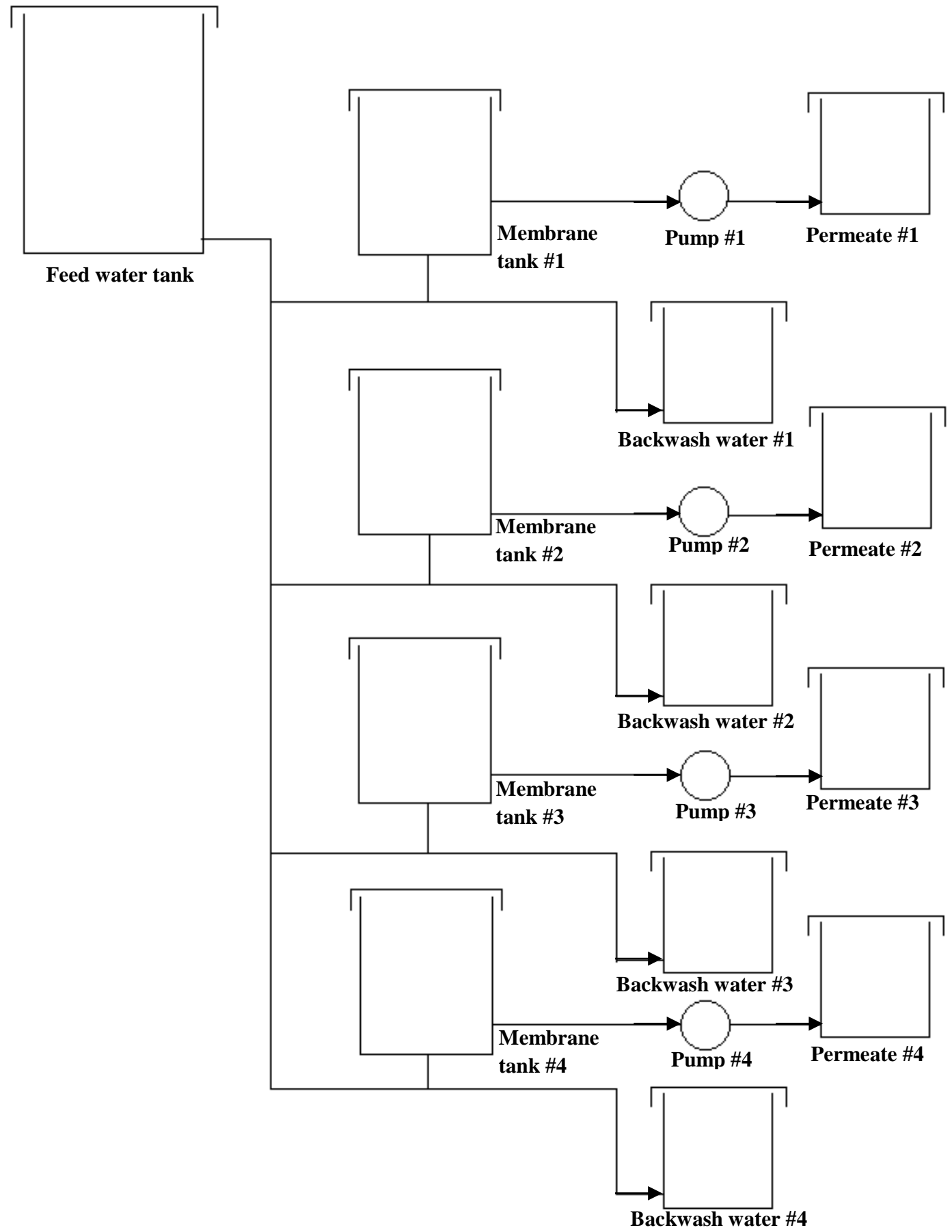

Figure 3.2: Process flow diagram of bench-scale system 


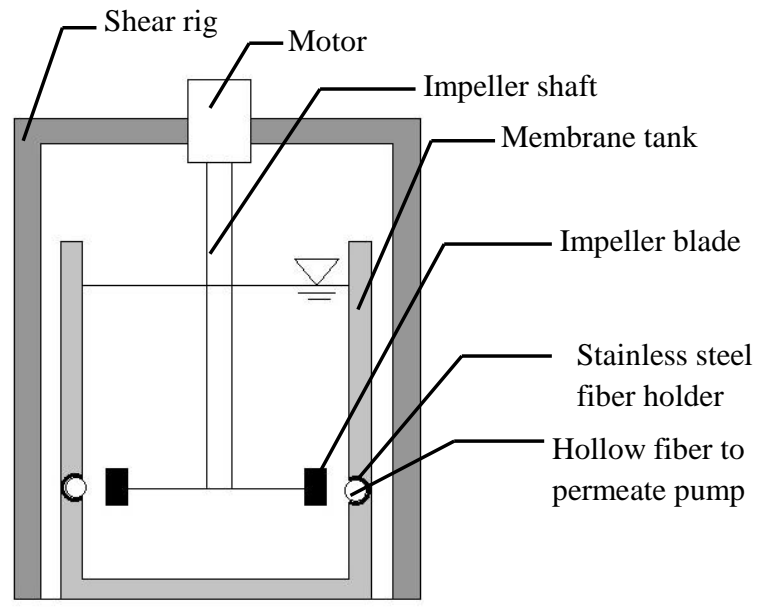

(a)

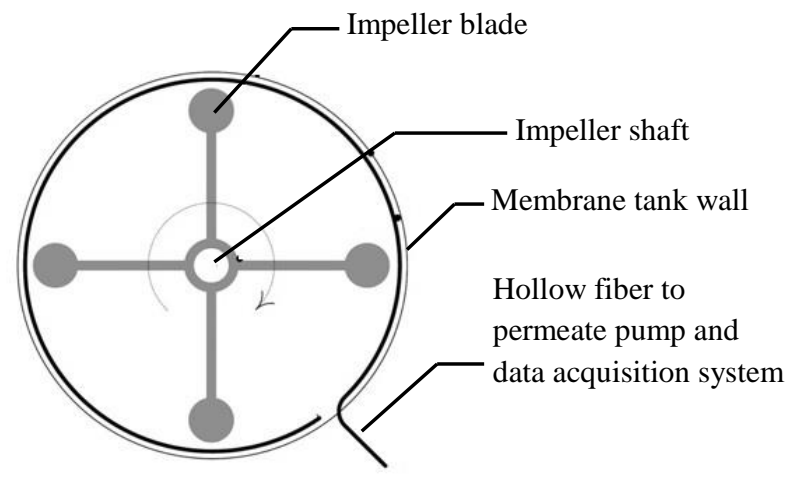

(b)

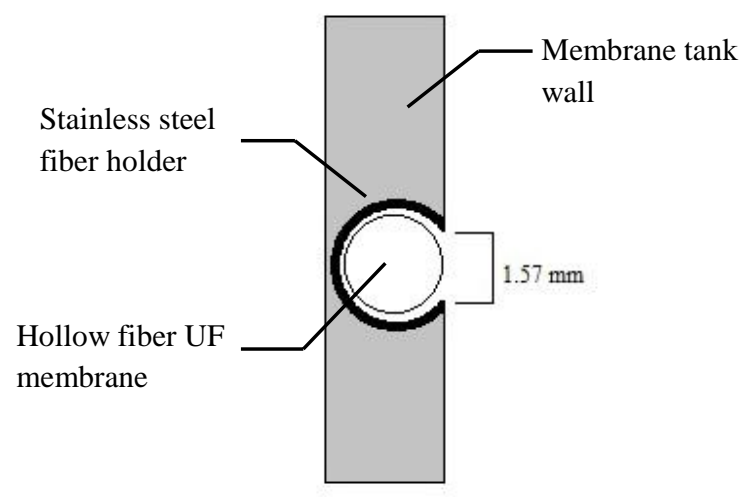

(c)

Figure 3.3: Schematic of shear apparatus. (a) side view, (b) top view (adapted from Chan et al., 2011), (c) cross-section side view of the membrane tank showing the stainless steel fiber holder and the hollow fiber UF membrane

The high peak (i.e. large pulse bubble sparging), low peak (i.e. continuous coarse bubble sparging) and sustained peak (i.e. discontinuous coarse bubble sparging) shear conditions were simulated by the rotating impeller blades with different geometry, rotational speeds and distances between the blade and the membrane surface (Figures 3.4 and 3.5 ). The no shear condition was simply a membrane tank without the impeller blades. It should be noted that there was no visible distance between the impeller blade and the membrane surface in the high peak shear condition apparatus configuration. The impeller rotational speed for the high peak and low peak shear conditions was $8.5 \mathrm{rpm}$ and for the sustained peak condition was $5 \mathrm{rpm}$ (Chan et al., 2011). 


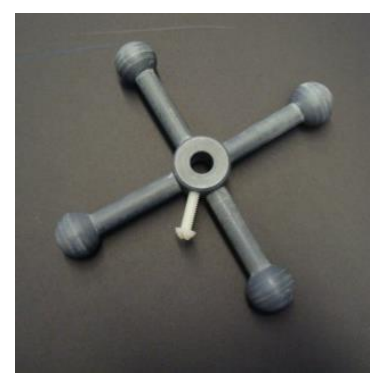

(a)

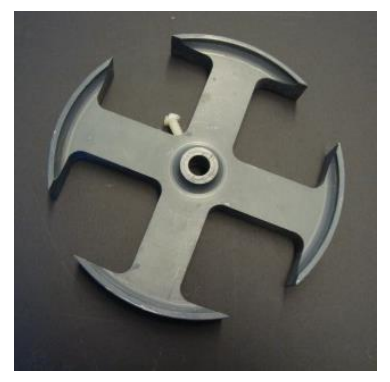

(b)

Figure 3.4: Impeller blades of shear apparatus. (a) low peak and high peak shear stress conditions, (b) sustained peak shear stress condition

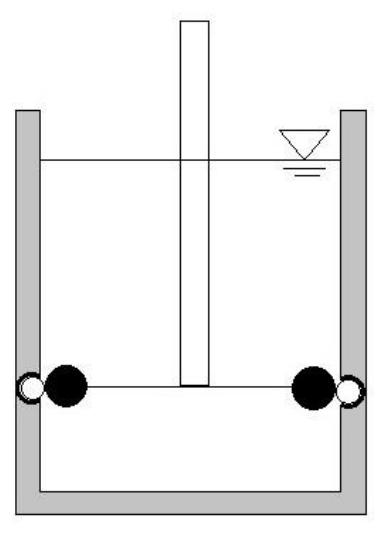

(a)

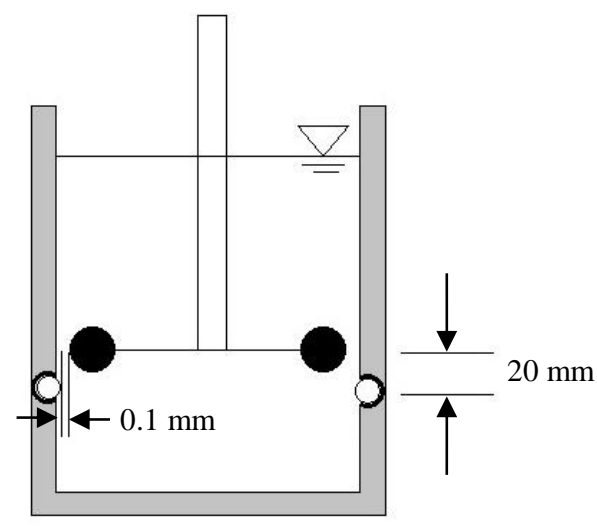

(b)

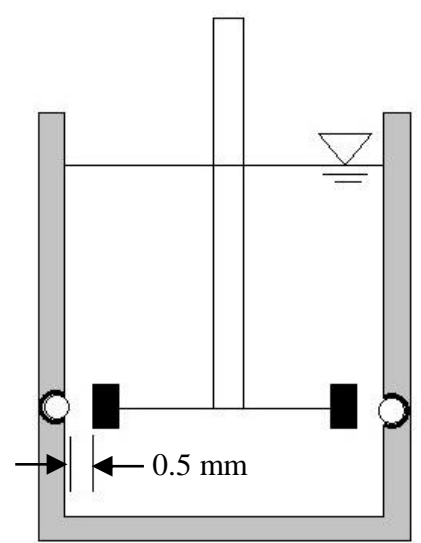

(c)

Figure 3.5: Schematic of the side view of the membrane tank showing the relative position of different types of impellers to the fiber membrane surface. (a) high peak, (b) low peak, (c) sustained peak (Adapted from Chan et al., 2011)

\subsubsection{Membrane}

The outside-in, polyvinylidene difluoride (PVDF) hollow fiber UF membranes (ZeeWeed ${ }^{\circledR} 500$, GE Water and Process Technologies, Oakville, Ontario) were used in this study. Virgin membrane fibers were used for all experiments. Fibers were first soaked in a $750 \mathrm{mg} / \mathrm{L}$ sodium hypochlorite solution for $24 \mathrm{~h}$ to remove glycerine preservative and then stored in a 50 $\mathrm{mg} / \mathrm{L}$ sodium hypochlorite solution until use. Prior to experiments, fibers were cleaned by filtering distilled water for approximately $1 \mathrm{~h}$. A $25 \mathrm{~cm}$ length of fiber was used for each experiment, resulting in a permeable area of approximately $1250 \mathrm{~mm}^{2}$. The membrane was 
secured in the stainless steel holder. One end of the membrane fiber was connected to the pumping system and the other end was sealed with a minimal amount of silicone (Shin-Etsu Silicone, Shin-Etsu Chemical Co. Ltd., Japan). The average permeate flowrate was $1 \mathrm{~mL} / \mathrm{min}$ to achieve a flux of $50 \mathrm{~L} / \mathrm{m}^{2} / \mathrm{h}$, which is a typical operating permeate flux for hollow fiber membranes (Chan et al., 2011, refer to Appendices, Section 7.2, for flowrate calculation). The backwash flow rate was also $1 \mathrm{~mL} / \mathrm{min}$.

\subsection{Fouling Quantification}

Membrane fouling was quantified as resistance $\left(\mathrm{m}^{-1}\right)$ in this thesis (Equation 3.1). This method has been used to quantify fouling of air-sparged hollow fiber UF membranes in previous studies (Wray et al., 2013; Park et al., 2010).

$$
R=\frac{\Delta P}{J \mu}
$$

where $\mathrm{R}$ is the resistance $\left(\mathrm{m}^{-1}\right), \Delta \mathrm{P}$ is the transmembrane pressure $(\mathrm{Pa}), \mathrm{J}$ is the flux $(\mathrm{m} / \mathrm{s})$ and $\mu$ is the fluid viscosity $\left(0.000995 \mathrm{~kg} / \mathrm{m} \cdot \mathrm{s}\right.$ at $\left.22^{\circ} \mathrm{C}\right)$.

Resistance vs. volume of permeate curves were plotted for each experiment (Figure 3.6). Hydraulically reversible fouling $\left(\mathrm{R}_{\mathrm{rev}}\right)$ of the $\mathrm{n}^{\text {th }}$ filtration-backwash cycle was quantified as the difference between the resistance at the end of filtration $\left(\mathrm{R}_{\mathrm{f}, \mathrm{n}}\right)$ and the resistance at the beginning of the $(n+1)^{\text {th }}$ filtration-backwash cycle $\left(R_{i, n+1}\right)$ (Equation 3.2). Hydraulically irreversible fouling $\left(\mathrm{R}_{\text {irr }}\right)$ of the $\mathrm{n}^{\text {th }}$ filtration-backwash cycle was quantified as the difference between the resistance at the beginning of the $(n+1)^{\text {th }}$ filtration-backwash cycle and the intrinsic resistance of the membrane at the beginning of an experiment $\left(\mathrm{R}_{0}\right)$ (Equation 3.3).

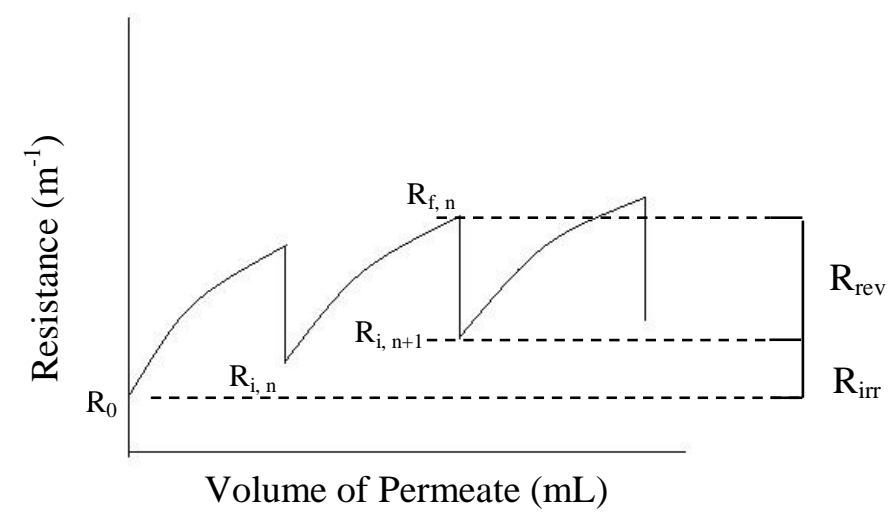

Figure 3.6: Schematic representation of the variation in membrane resistance during filtrationbackwash cycles 


$$
\begin{gathered}
R_{r e v}=R_{f, n}-R_{i, n+1} \\
R_{i r r}=R_{i, n+1}-R_{0}
\end{gathered}
$$

\subsection{Water Characteristics}

\subsubsection{Liquid Chromatography - Organic Carbon Detection (LC-OCD)}

DOC in the water samples were analyzed by liquid chromatography - organic carbon detection (LC-OCD) at the University of Waterloo, Ontario, Canada. The DOC fractions identified by LC-OCD include biopolymers, humic substances, building blocks, low molecular weight neutrals and low molecular weight acids. These fractions were characterized based on size, structural properties and concentration. The system and analytical method are described in detail by Huber et al. (2011). Water samples were filtered $(0.45 \mu \mathrm{m})$ and stored in $40-\mathrm{mL}$ amber glass vials with Teflon $®$-lined silicon septum screw caps at $4^{\circ} \mathrm{C}$ until analysis. An HPLC pump (S-100, Knauer, Berlin, Germany) delivered the mobile phase (a phosphate buffer purified by UV-irradiation in an annular UV-reactor) to an autosampler (MLE, Dresden, Germany, $1 \mathrm{~mL}$ injection volume $)$ and the weak cation exchange chromatographic column $(250 \mathrm{~mm} \times 20 \mathrm{~mm}$, TSK HW 50S, 3000 theoretical plates, Toso, Japan) at a flowrate of $1.1 \mathrm{~mL} / \mathrm{min}$. After chromatographic separation, samples were first detected by $\mathrm{UV}_{254}$ detector (UVD $254 \mathrm{~nm}$, type S-200, Knauer, Berlin, Germany) followed by the organic carbon detector (OCD). At the OCD inlet, the solution was acidified to convert carbonates to carbonic acids. The column was also bypassed to obtain a DOC value for each chromatographic run. OCD and UVD calibration was based on potassium hydrogen phthalate. A customised software program (ChromCALC, DOCLABOR, Karlsruhe, Germany) was used for data acquisition and data processing. LC-OCD results provided information on the types of foulant during UF of natural waters.

\subsubsection{Ultraviolet Absorbance at 254 nm $\left(\mathbf{U V}_{254}\right)$}

The ultraviolet absorbance at $254 \mathrm{~nm}$ wavelength was measured by a CE 3055 Single Beam Cecil UV/Visible Spectrophotometer (Cambridge, England) using $1 \mathrm{~cm}$ quartz cells (Hewlett Packard, Mississauga). The spectrophotometer was zeroed with Milli-Q® water. The 
quartz cells were rinsed twice with Milli-Q ${ }^{\circledR}$ water and once with the water sample before each measurement. All samples were filtered $(0.45 \mu \mathrm{m})$ prior to analysis.

\subsection{3. $\mathrm{pH}$}

A pH meter Model 8015(VWR Instrumental) was used for $\mathrm{pH}$ measurement. The

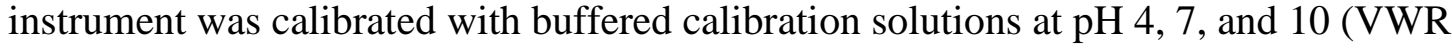
Instrumental) prior to the measurement.

\subsubsection{Turbidity}

Turbidity of the water samples was measured by a turbidimeter in NTU (nephelometric turbidity units) using a $40 \mathrm{~mL}$ clear glass vial. The vial was rinsed twice with Milli-Q® water and once with the water sample before each measurement.

\subsection{Statistical Analysis}

\subsubsection{Analysis of Variance (ANOVA)}

The significance of the effect of backwash frequency and shear condition (i.e. air sparing condition) on hollow fiber UF membrane irreversible fouling rate was assessed in two steps:

1. A two-way ANOVA was applied at a confidence interval of $95 \%$ to screen the data for possible effects of backwash frequency or shear condition

2. A one-way ANOVA was applied at a confidence interval of $95 \%$ for four shear conditions at the same backwash frequency, and then for three backwash frequencies at the same shear condition. If a significant difference existed in the irreversible fouling rates, the Tukey's post-hoc Honestly Significant Difference (HSD) test was then applied.

Design-Expert 8 (Stat-Ease Inc., Minneapolis, MN) was used for both two-way and oneway ANOVA tests. A two-way ANOVA model (Equation 3.4, Hines et al., 2003) allowed for the analysis of the effect of two main factors (backwash frequency and shear condition), as well as the effect of interaction between these two factors on membrane fouling. A statistically significant difference was defined as a p-value $<0.05$. 


$$
Y_{i j t}=\mu+\alpha_{i}+\beta_{j}+(\alpha \beta)_{i j}+\varepsilon_{i j t}
$$

where $\quad \mathrm{Y}=$ measured variable (irreversible fouling rate)

$\mu=$ overall mean of measured variable

$\alpha=$ effect of the $i^{\text {th }}$ level of factor A (shear condition)

$\beta=$ effect of the $j^{\text {th }}$ level of factor B (backwash frequency)

$\varepsilon=$ random error component

$\mathrm{i}=1-4$

$\mathrm{j}=1-3$

$\mathrm{t}=$ number of replicates $(1-2)$

The assumptions of this two-factor ANOVA model were that the error random variables were mutually independent, had equal variance and were normally distributed (Dean and Voss, 1999). When a significant effect of the backwash frequency and/or shear condition was detected by the two-way ANOVA, a one-way ANOVA was then applied using a model similar to the twoway ANOVA:

$$
Y_{i t}=\mu+\alpha_{i}+\varepsilon_{i t}
$$

where $\quad \mathrm{Y}=$ measured variable (irreversible fouling rate)

$\mu=$ overall mean of measured variable

$\alpha=$ effect of the $i^{\text {th }}$ level of factor (backwash frequency or shear condition)

$\varepsilon=$ random error component

$\mathrm{i}=1-3$ for backwash frequency, 1-4 for shear condition

$\mathrm{t}=$ number of replicates $(1-2)$

All ANOVA results are summarized in Appendices, Section 7.3.

\subsubsection{Post-Hoc Testing: Tukey's Honestly Significant Difference (HSD)}

ANOVA test only shows the response variables that are significantly affected by different factors but does not provide information of how the response variables are affected. Post-hoc tests are then applied after the ANOVAs. In the current study, Tukey's HSD was applied to the irreversible fouling rates at conditions which backwash frequencies or shear conditions were 
identified as significant by the one-way ANOVA. Fouling rates from different experimental conditions were compared pairwise to assess which sets of conditions produced fouling rates that were statistically different from each other at a 95\% confidence interval. HSD was calculated in Equation 3.6 (Hines et al., 2003)

$$
H S D=Q_{[\alpha, k, f]} \sqrt{\frac{M S E}{n}}
$$

Where $Q=$ the studentized range critical value

$\alpha=0.05$ (at $95 \%$ confidence interval)

$\mathrm{k}=$ number of factor levels (for shear condition: $\mathrm{k}=4$; for backwash frequency: $\mathrm{k}=3$ )

$\mathrm{f}=$ degrees of freedom for error

$\mathrm{n}=$ number of replicates in means (2)

MSE $=$ mean squared error (obtained from Design Expert)

If the difference between two means is greater than the HSD, then the means in the pair are considered significantly different from each other at $95 \%$ confidence interval (refer to Appendices, Section 7.4, for more information and Tukey’s HSD results).

\subsection{Cost Saving Estimation}

Annual operating and maintenance costs for one membrane train $\left(24,000 \mathrm{~m}^{2}\right.$ membrane permeable area, 29 MLD) of each experimental condition were estimated based on energy associated with permeation, backwashing and air sparging, as well as membrane replacement due to exposure to chemical cleaning. All costs were based on and compared to a baseline operating condition, which assumed that the backwash frequency is $0.5 \mathrm{~h}$ and coarse bubble air sparging only occurs during the 10 min-backwash. Both chemically enhanced backwash (CEB) and cleaning in place (CIP) were considered in membrane replacement costs associated with membrane life. In the baseline case, CEB was performed daily and CIP was performed 8.7 times per year (Barrie Surface Water Treatment Plant, Ontario, Canada). The membrane was assumed to require replacement when the chemical exposure reached 500,000 ppm·h (Cote et al., 2012). This baseline condition was a representative of full-scale UF drinking water treatment. 
Calculation of energy consumption during permeation included the extra power required to overcome the resistance increase due to fouling in order to maintain a constant flux of $50 \mathrm{~L} / \mathrm{m}^{2} \cdot \mathrm{h}$. It was assumed that the CEB was also performed daily for all the experimental conditions investigated in this study. CIP frequency was linearly extrapolated from baseline condition into equivalent longer or shorter operating times between CIP based on the irreversible fouling reduction or increase resulting from different air sparging conditions and backwash frequencies. Annual membrane replacement costs for each condition were the costs of one membrane train averaged over the estimated membrane lifetime (expressed in years). The total cost estimated for an experimental condition was then subtracted from the value of the water produced in the corresponding condition to determine an annual cost savings (or loss). All values used in the cost calculations are presented in Table 3.3. Refer to Appendices, Section 7.5, for more information on cost estimation.

Table 3.3: Values used in cost estimation for a membrane train

\begin{tabular}{|c|c|}
\hline Parameter & Value \\
\hline Pump power usage in permeation $(\mathrm{kW})$ & 75 \\
\hline Pump power usage in backwash $(\mathrm{kW})$ & 112 \\
\hline Power usage in continuous coarse bubble air sparging $(\mathrm{kW})^{\mathrm{a}}$ & 30 \\
\hline Power usage in discontinuous coarse bubble air sparging $(\mathrm{kW})^{\mathrm{a}}$ & 15 \\
\hline Power usage in large pulse bubble air sparging $(\mathrm{kW})^{\mathrm{a}}$ & 9 \\
\hline $\begin{array}{l}\text { Concentration of sodium hypochlorite used in chemically enhanced } \\
\text { backwash }(\mathrm{mg} / \mathrm{L})^{\mathrm{b}}\end{array}$ & 100 \\
\hline Duration of chemically enhanced backwash $(\min )^{b}$ & 30 \\
\hline Frequency of chemically enhanced backwash (numbers per day) ${ }^{b}$ & 1 \\
\hline Concentration of sodium hypochlorite used in recovery cleaning $(\mathrm{mg} / \mathrm{L})^{\mathrm{b}}$ & 500 \\
\hline Concentration of citric acid used in recovery cleaning $(\mathrm{mg} / \mathrm{L})^{\mathrm{b}}$ & 200 \\
\hline Duration of recovery cleaning $(\mathrm{h})^{\mathrm{b}}$ & 6 \\
\hline Frequency of recovery cleaning (numbers per year) ${ }^{b}$ & 8.7 \\
\hline Membrane flux $\left(\mathrm{L} / \mathrm{m}^{2} / \mathrm{h}\right)$ & 50 \\
\hline Membrane area $\left(\mathrm{m}^{2} /\right.$ train $)$ & 24000 \\
\hline Cost of electricity $(\$ / \mathrm{kWh})^{\mathrm{c}}$ & 0.118 \\
\hline Cost of water $\left(\$ / \mathrm{m}^{3}\right)$ & 0.08 \\
\hline Cost of one membrane train $(\$)^{\mathrm{d}}$ & 1428571 \\
\hline
\end{tabular}

${ }^{a}$ Based on assumption that power usage of discontinuous coarse bubble and large pulse bubble air sparging are 0.5 and 0.3 , respectively, relative to continuous coarse bubble air sparging (GE Water and Process

Technologies, Oakville, Ontario)

${ }^{\mathrm{b}}$ Barrie Surface Water Treatment Plant

${ }^{\mathrm{c}}$ York Region Environmental Service Committee, 2011

${ }^{\mathrm{d}}$ Estimated based on costs per UF membrane module 


\section{Results and Discussion}

\subsection{Effect of Backwash Frequency and Air Sparging Condition on Organic Matter Removal}

LC-OCD results showed that DOC was not well removed in either water matrix by UF alone, i.e., < 6\% removal for the Otonabee River and $<12 \%$ removal for Lake Simcoe (Figure 4.1(a)). Biopolymers were the only fraction of DOC removed by the membrane to a measurable degree, regardless of the shear condition and backwash frequency that was applied. Biopolymers were removed by an average of $80 \% \pm 6 \%$ for Otonabee River and $63 \% \pm 6 \%$ for Lake Simcoe (Figure 4.1(b)). As such, biopolymers represented the main foulant. Previous studies by PeterVarbanets et al. (2011) and Tian et al. (2013) also reported biopolymers to be the primary membrane foulant when filtering natural waters. Results also indicated that the application of different shear conditions did not affect the rejection of organic matter fractions. This was consistent with a previous study by Wray et al., 2013.

\subsection{Effect of Backwash Frequency and Air Sparging Condition on Membrane Fouling}

Typical resistance curves for the UF experiments were shown in Figure 4.2. Raw data of the experiments is presented in Appendices, Section 7.6. In general, total fouling (i.e. change in resistance, $\Delta \mathrm{R}$ ) in a filtration cycle increased as the backwash frequency decreased (Figure 4.3), irrespective to the type of air sparging applied. This was attributed to a higher accumulation of foulant, including biopolymers, on the membrane surface over a longer filtration time. At low backwash frequency, especially at $6 \mathrm{~h}, \Delta \mathrm{R}$ in conditions with shear (i.e. air sparging) applied was lower than $\Delta \mathrm{R}$ in the condition without shear (i.e. no air sparging). This showed that air sparging could provide fouling control by enhancing particle back-transport from the membrane surface, so that deposition was minimized. The results were consistent with previous studies (Wray et al., 2013, Chan et al., 2011). 
(a)

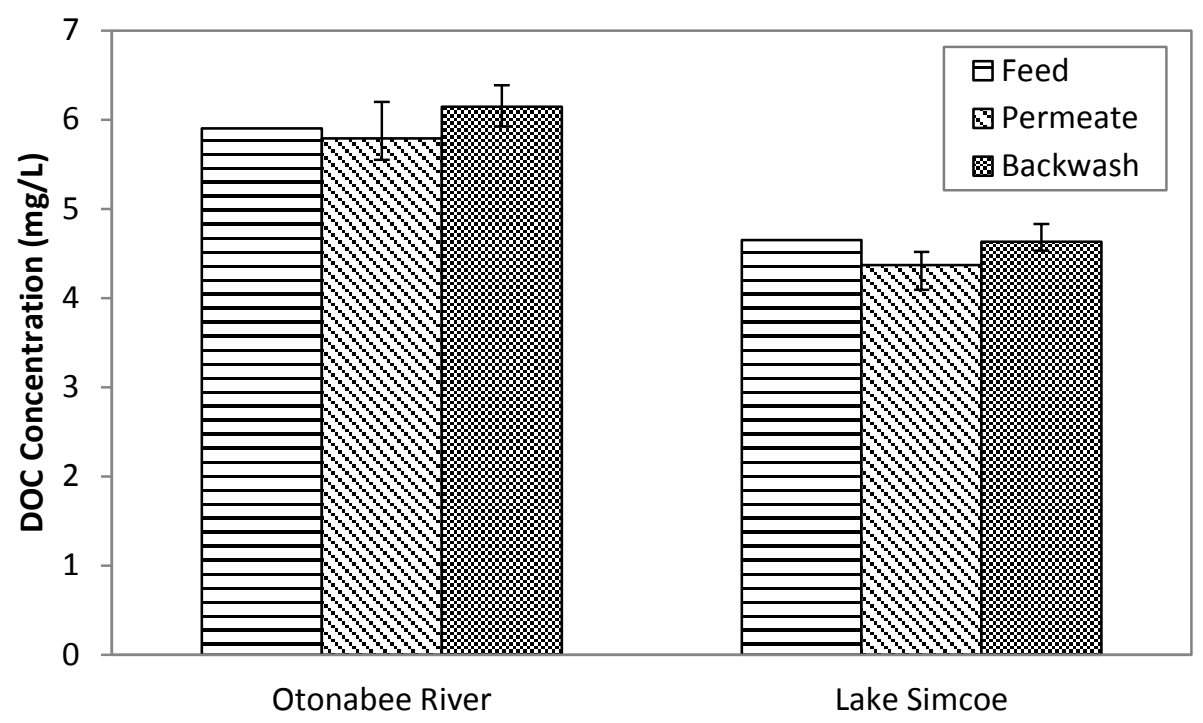

(b)

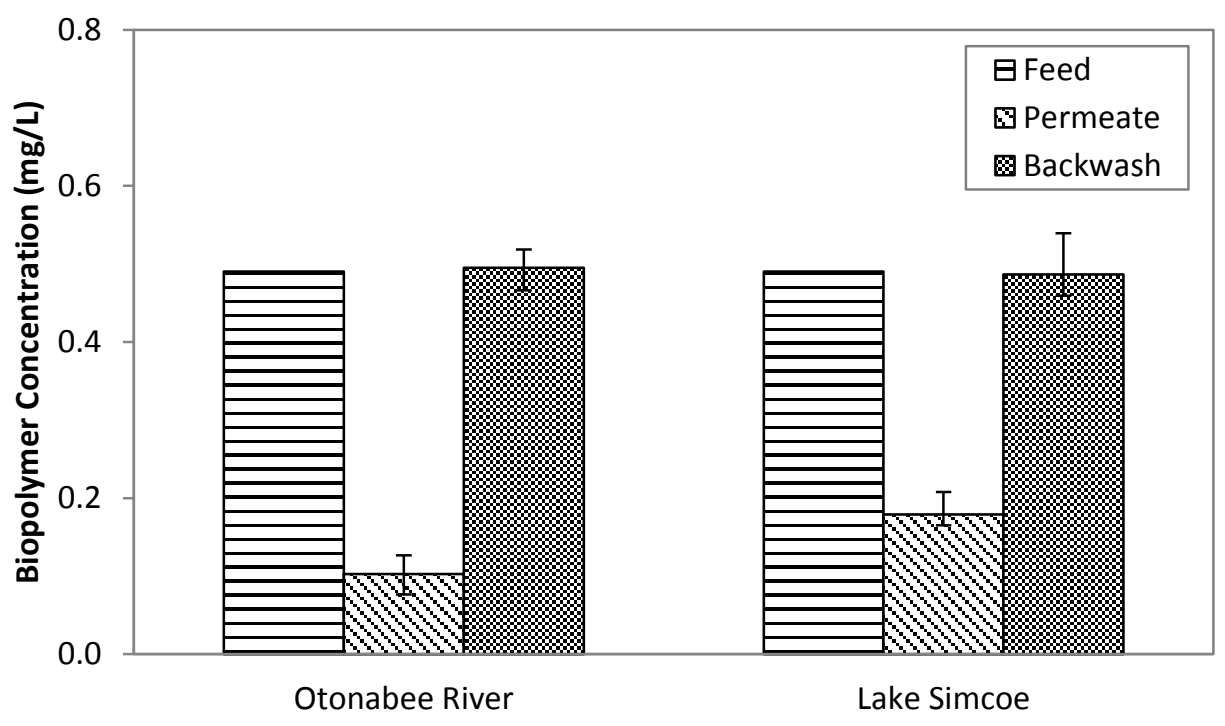

Figure 4.1: Average (a) DOC and (b) biopolymer concentrations in feed (raw), permeate and backwash waters when considering all shear conditions and backwash frequencies (vertical bars represent maximum and minimum values observed) 
(a)

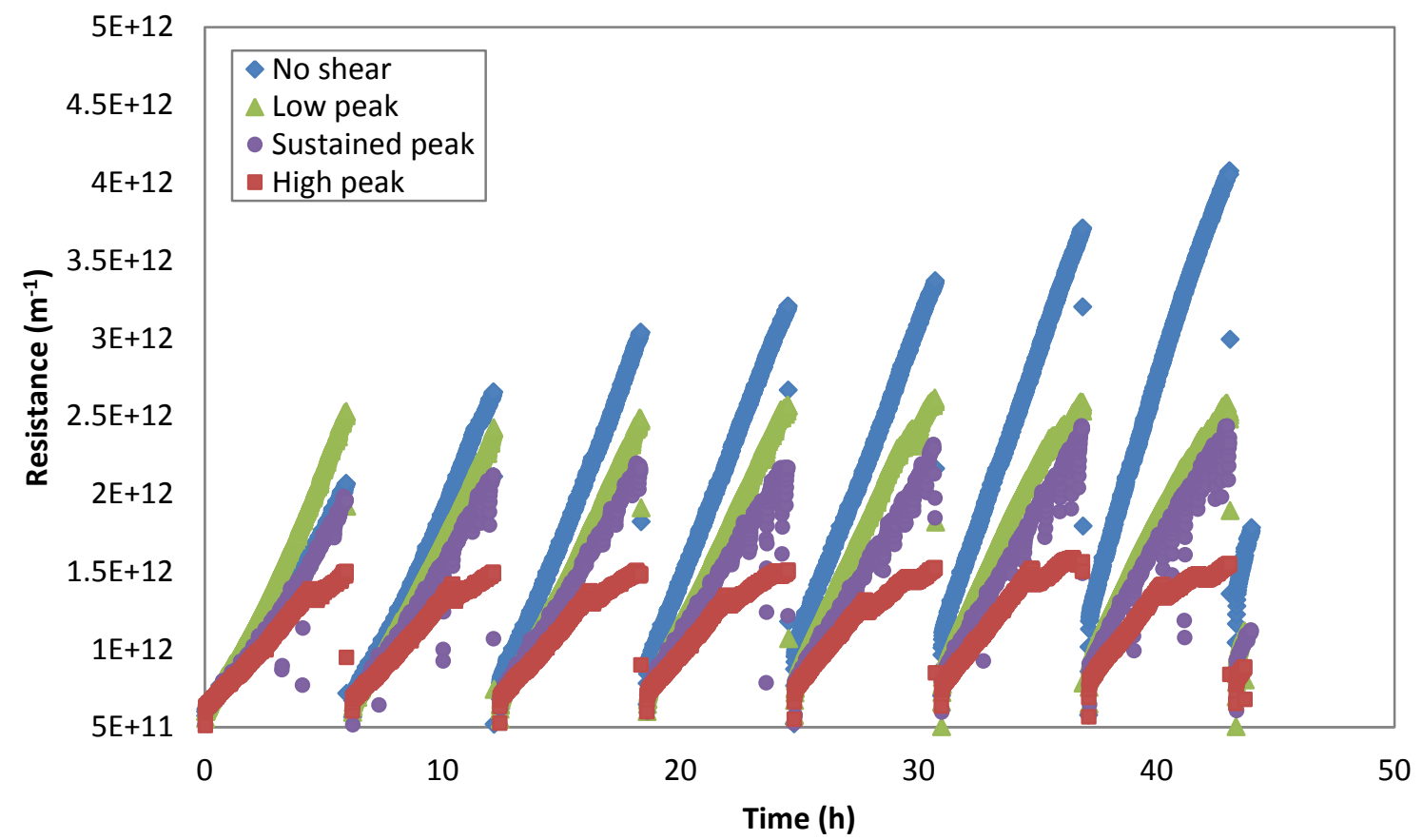

(b)

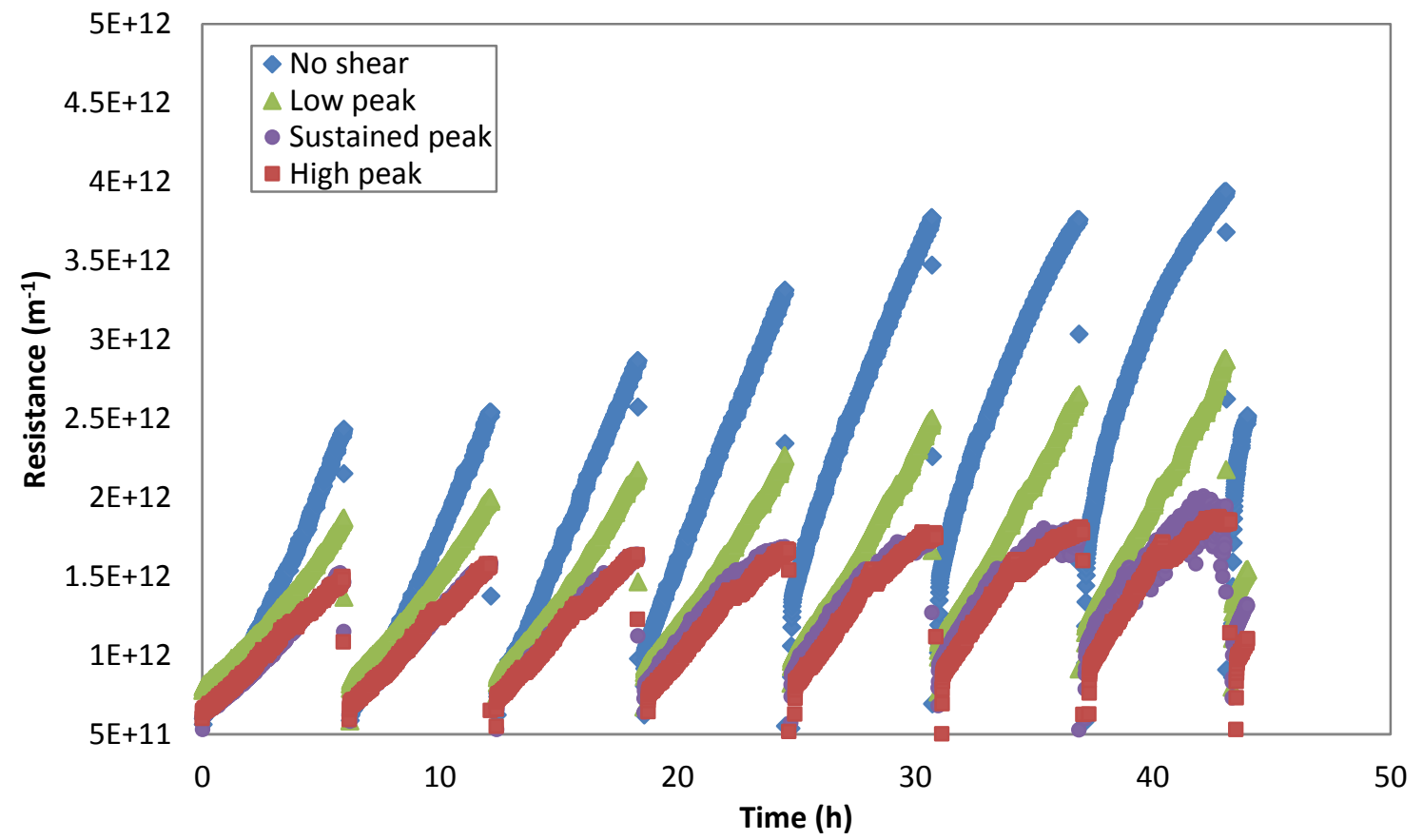

Figure 4.2: Typical resistance curves for UF experiments. Graphs show the resistance change during experiments at the 6 h-backwash frequency. (a) Otonabee River, (b) Lake Simcoe 
(a)

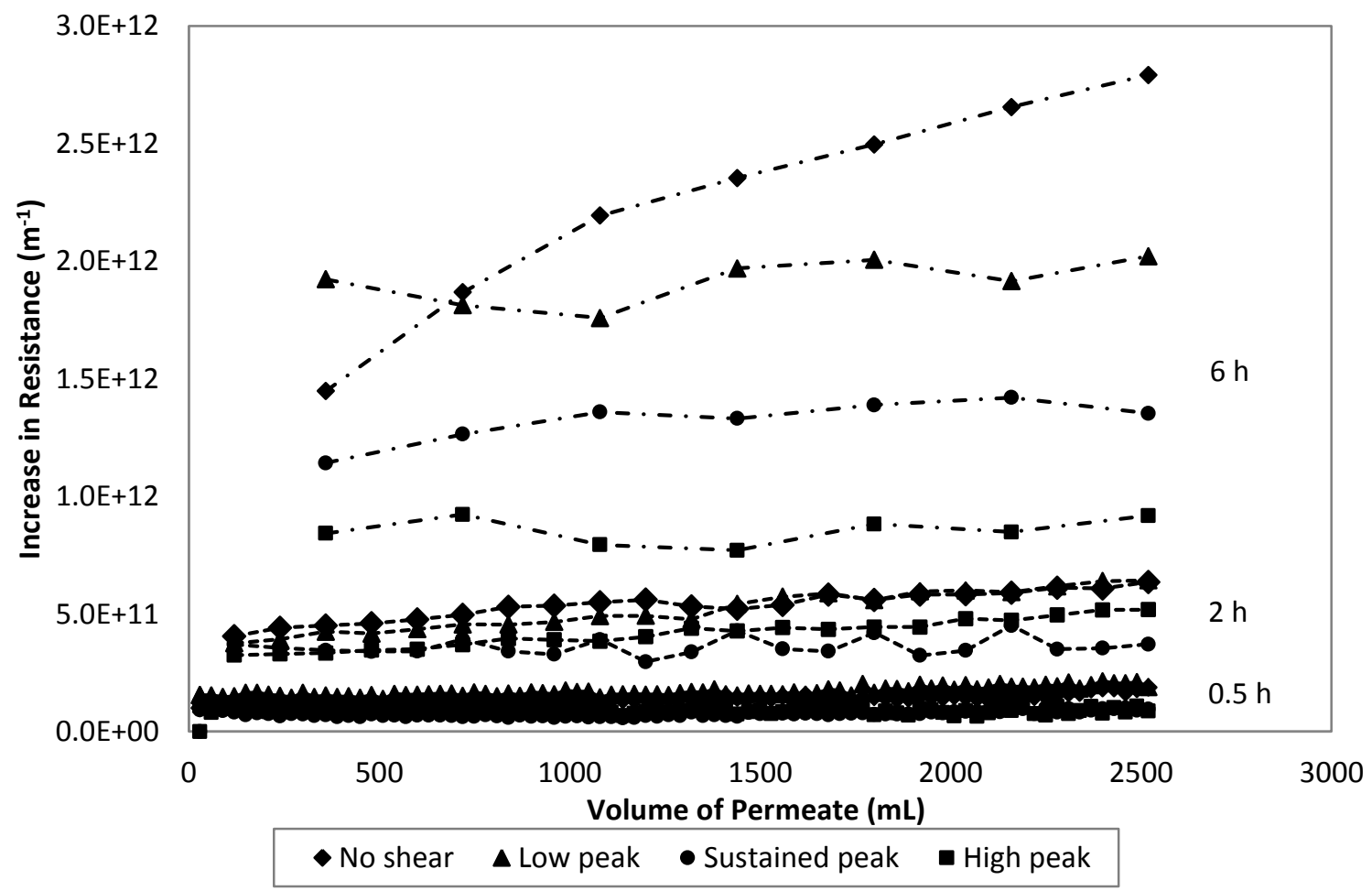

(b)

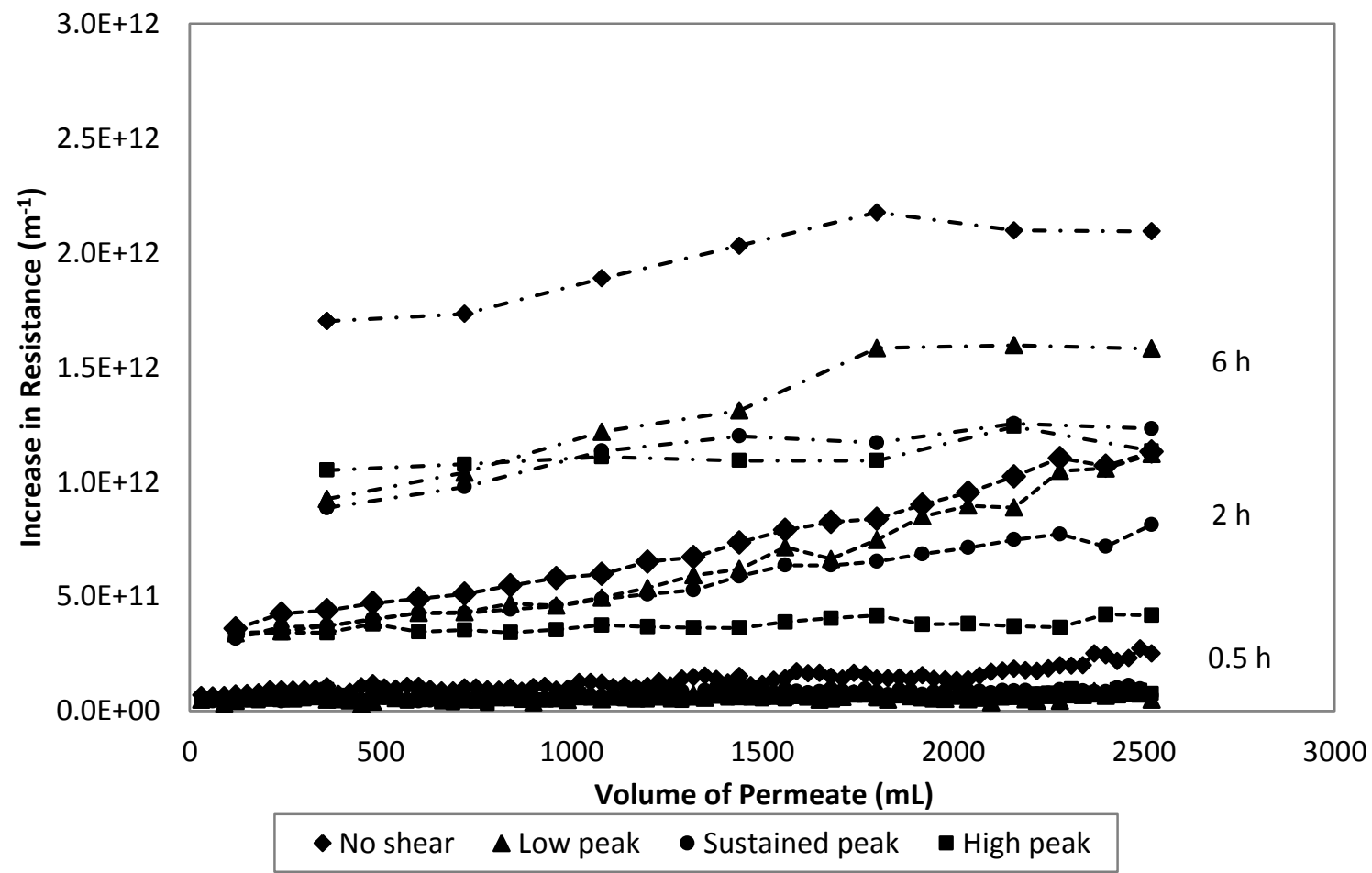

Figure 4.3: Increase in resistance in each filtration cycle at different backwash frequencies and shear conditions during ultrafiltration for (a) Otonabee River, and (b) Lake Simcoe waters (data represents average values of duplicate runs for each condition) 
The average percentage of reversible fouling in each filtration cycle ranged between 8698\% of the total fouling for the conditions applied in this study (Figure 4.4). The proportions of hydraulically reversible fouling were similar for different shear (i.e. air sparging) conditions when the same backwash frequency was applied, as such higher $\Delta \mathrm{R}$ in a filtration cycle resulted in higher amount of foulant remained on the membrane after backwash (i.e. higher hydraulically irreversible fouling), since hydraulically irreversible fouling is the result of the hydraulically reversible fouling that is unable to be removed by backwashing (Amy, 2008) and transition from reversible fouling to irreversible fouling is possible (Peldszus et al., 2011). Consequently, higher amount of remaining hydraulically reversible fouling could lead to higher irreversible fouling rate. The rate of $\Delta \mathrm{R}$ increase was also positive for most of the conditions applied in both waters (Figures 4.5 and 4.6), indicating that there was more accumulation of foulant in each cycle over the course of UF operation. As shown in Figures 4.7 and 4.8, the irreversible fouling increased as the backwash frequency decreased for a given shear (i.e. air sparging) condition. This agreed to the earlier discussion that lower backwash frequency resulted in higher total fouling and led to higher irreversible fouling.

An analysis of irreversible fouling rates for different experimental conditions showed that both shear stress (i.e. air sparging) and backwash frequency significantly influenced irreversible fouling for both water matrices (ANOVA p-values < 0.05). For a given backwash frequency, the impact of varying shear conditions on irreversible fouling control showed a general relationship: no shear $=$ low peak $<$ sustained peak $=$ high peak. For the Otonabee River water, the irreversible fouling rate was reduced by up to $83 \%$ when considering high peak (i.e., large pulse bubble sparging) and $71 \%$ for sustained peak (i.e., discontinuous coarse bubble sparging). For Lake Simcoe water, the irreversible fouling rate was reduced by up to $73 \%$ when applying high peak and 59\% when applying sustained peak conditions (Table 4.1) versus a no shear condition. The difference in irreversible fouling rates among the four shear conditions became more pronounced as backwash frequency decreased. Air sparging not only reduced total fouling, but also provided irreversible fouling control.

Only sustained peak (i.e. discontinuous coarse bubble sparging) and high peak (i.e. large pulse bubble sparging) resulted in significant irreversible fouling reduction relative to a no shear condition for a given backwash frequency. The effect of fouling control by low peak (i.e. continuous coarse bubble sparging) condition was not significant when compared to no shear. This may be due to the low biopolymer concentration $(<0.5 \mathrm{mg} / \mathrm{L})$ in both Otonabee River and 
Lake Simcoe waters. Jankhah and Bérubé (2013) showed that the efficiency of the power transferred onto the membrane surface was higher for pulse bubble than for coarse bubble sparging, indicating that pulse bubble sparging could lead to better fouling control. This information helps explain why the application of high peak shear condition (i.e. large pulse bubble sparging) resulted in significant irreversible fouling reduction in this study.

Table 4.1: Comparison of fouling and cost savings for a range of backwash and shear conditions

\begin{tabular}{|c|c|c|c|}
\hline $\begin{array}{l}\text { Backwash } \\
\text { frequency (h) }\end{array}$ & $\begin{array}{l}\text { Shear } \\
\text { condition }\end{array}$ & $\begin{array}{c}\text { Irreversible } \\
\text { fouling } \\
\text { reduction }(\%)^{\mathrm{a}}\end{array}$ & 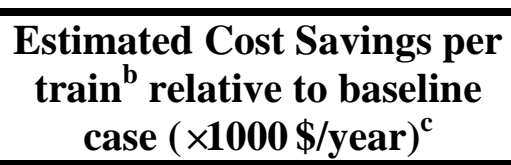 \\
\hline \multicolumn{4}{|c|}{ Otonabee River } \\
\hline 0.5 & Low peak & 1 & $(22.5)$ \\
\hline 0.5 & Sustained peak & 71 & 66.5 \\
\hline 0.5 & High peak & 83 & 85.7 \\
\hline 2 & No shear & (4) & 300.0 \\
\hline 2 & Low peak & (2) & 273.5 \\
\hline 2 & Sustained peak & 60 & 353.7 \\
\hline 2 & High peak & 64 & 363.9 \\
\hline 6 & No shear & (195) & 186.2 \\
\hline 6 & Low peak & $(69)$ & 289.3 \\
\hline 6 & Sustained peak & 10 & 387.7 \\
\hline 6 & High peak & 46 & 432.0 \\
\hline \multicolumn{4}{|c|}{ Lake Simcoe } \\
\hline 0.5 & Low peak & 65 & 44.6 \\
\hline 0.5 & Sustained peak & 59 & 53.9 \\
\hline 0.5 & High peak & 73 & 74.9 \\
\hline 2 & No shear & (102) & 196.5 \\
\hline 2 & Low peak & $(27)$ & 246.5 \\
\hline 2 & Sustained peak & (13) & 276.7 \\
\hline 2 & High peak & 69 & 369.3 \\
\hline 6 & No shear & (154) & 388.4 \\
\hline 6 & Low peak & (129) & 378.9 \\
\hline 6 & Sustained peak & 18 & 395.9 \\
\hline 6 & High peak & 63 & 449.4 \\
\hline
\end{tabular}

${ }^{1}$ Percent increases are shown in parentheses

${ }^{2}$ Each train has $24000 \mathrm{~m}^{2}$ membrane area

${ }^{3}$ Cost losses are shown in parentheses 
(a)

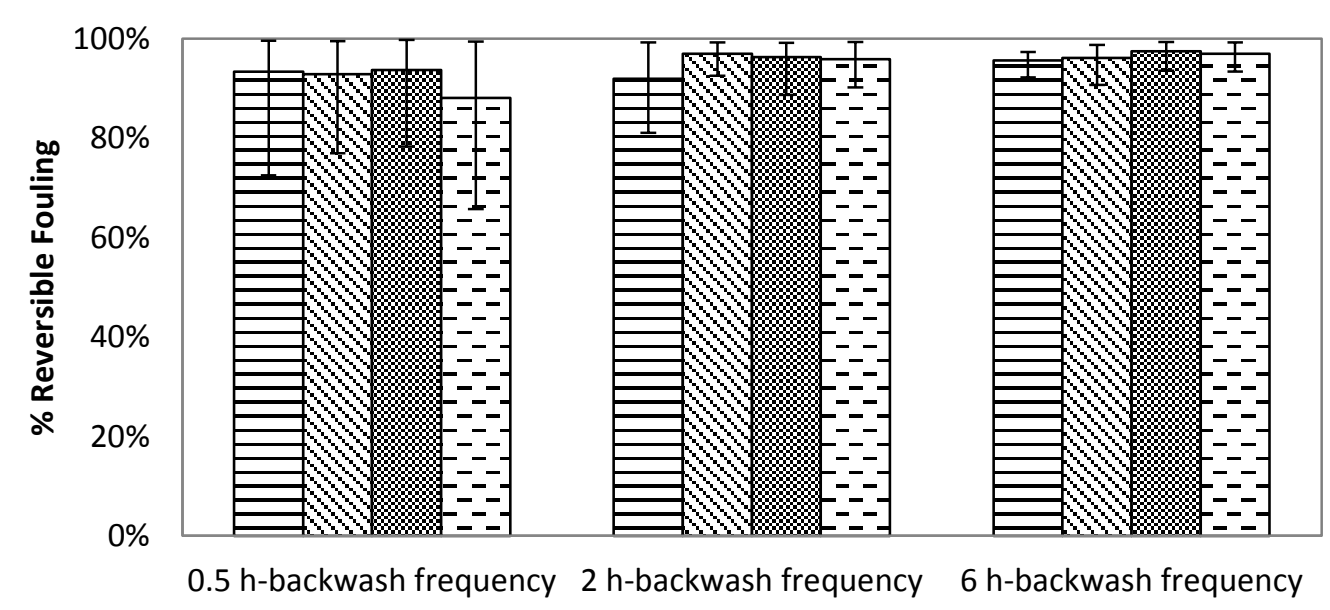

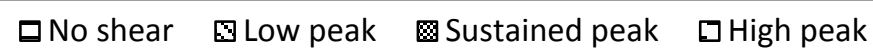

(b)

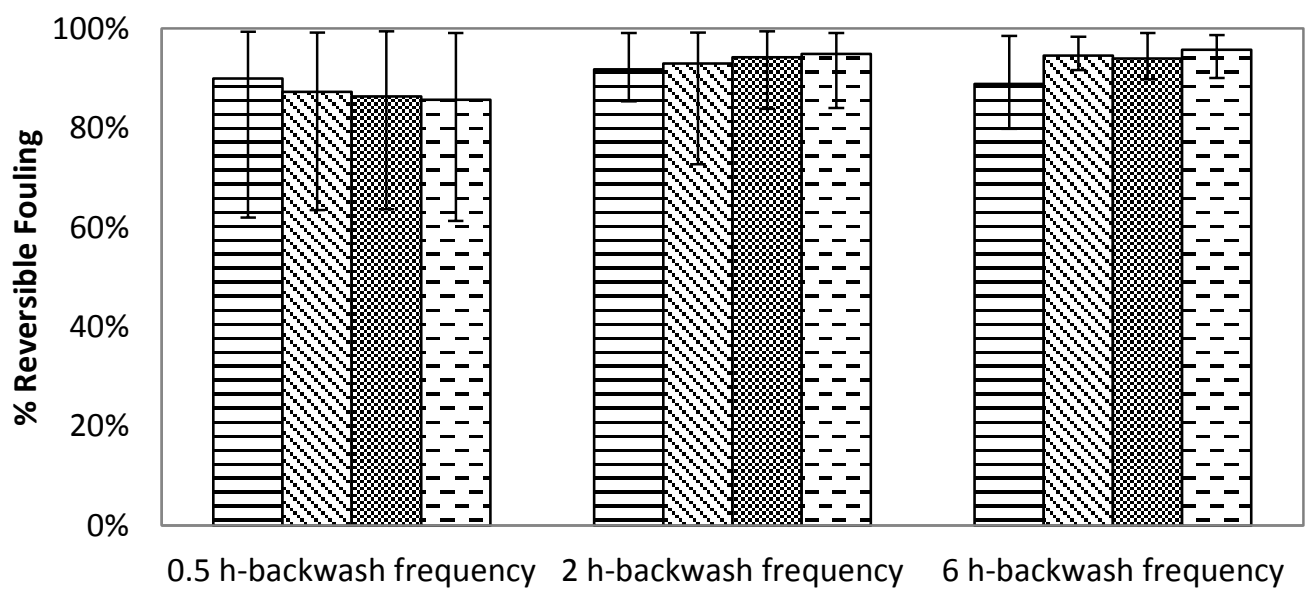

日No shear $\mathrm{QLow}$ peak Sustained peak घHigh peak

Figure 4.4: Reversible fouling as a percentage of total fouling for different backwash frequencies and shear conditions. (a) Otonabee River, (b) Lake Simcoe (vertical bars represent maximum and minimum values) 
(a)

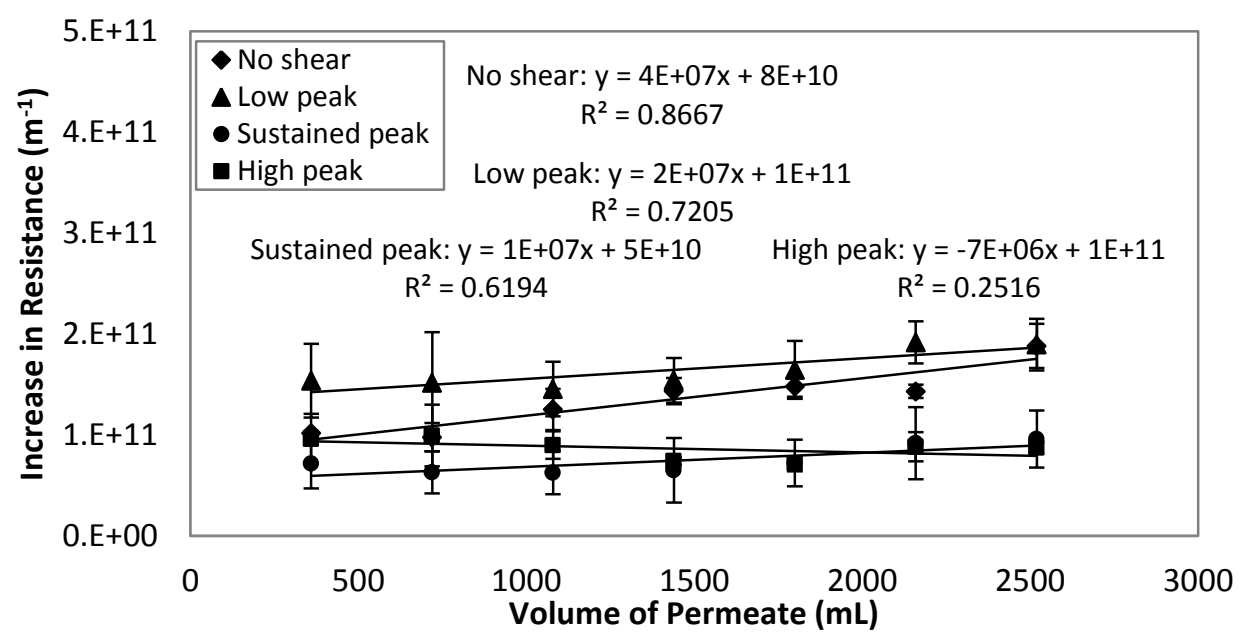

(b)

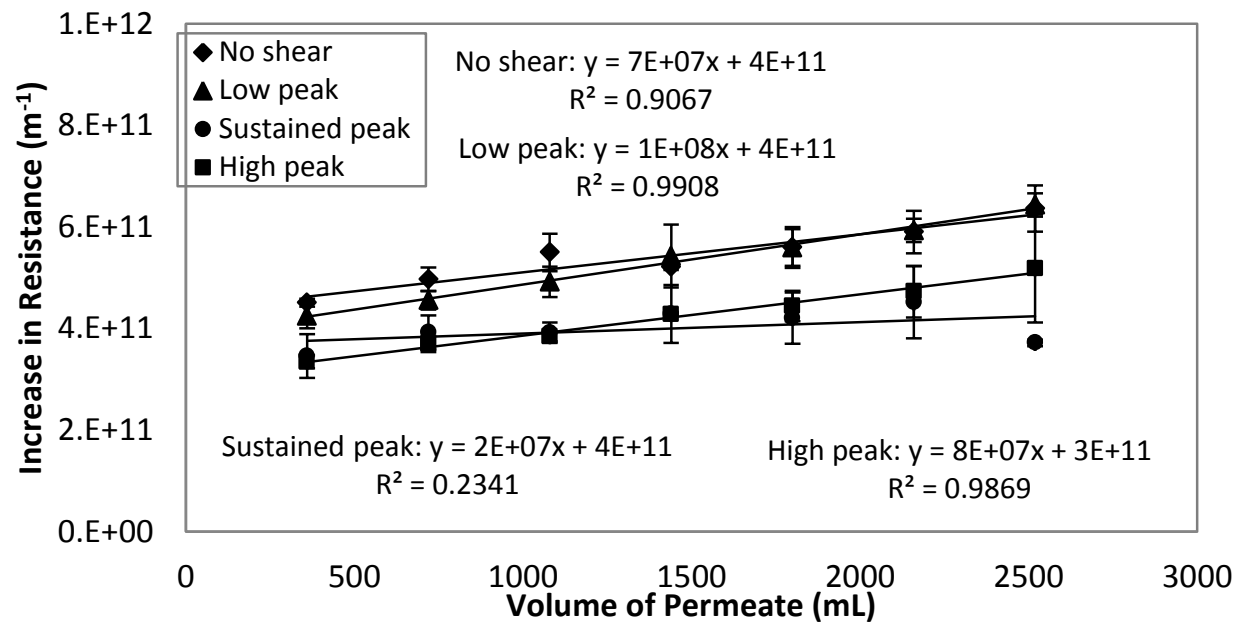

(c)

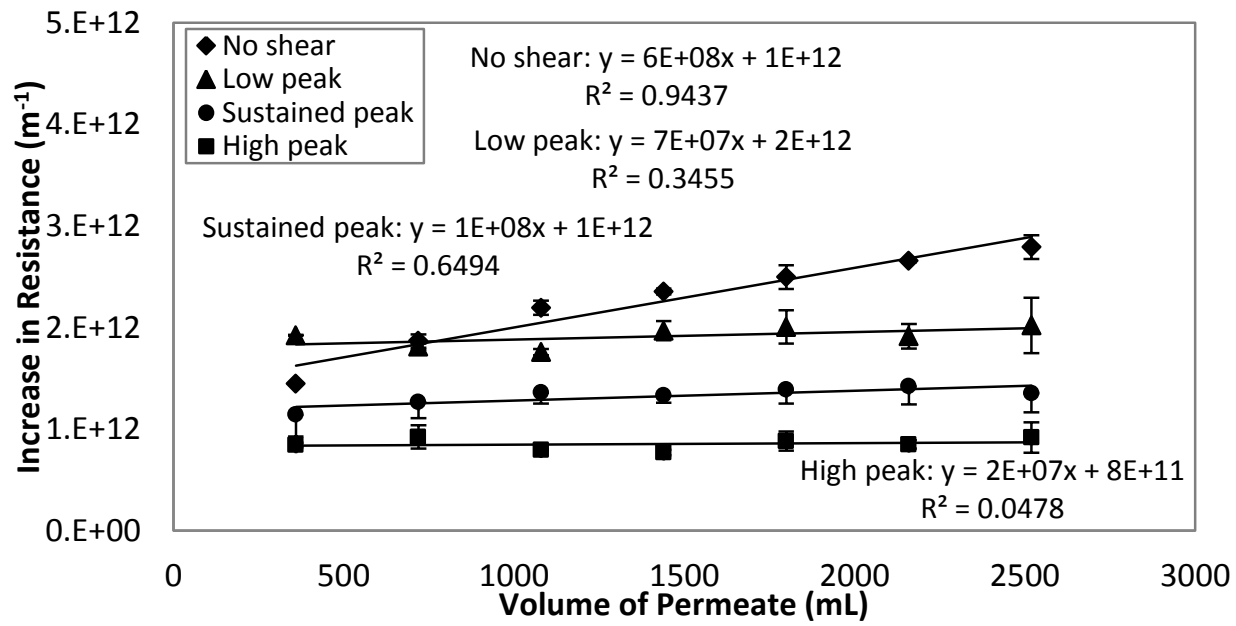

Figure 4.5: Increase in resistance, $\Delta \mathrm{R}$, at different backwash frequencies and shear conditions during ultrafiltration of Otonabee River water. (a) 0.5 h-backwash frequency, (b) 2 h-backwash frequency, (c) 6 h-backwash frequency (data represents average values of duplicate runs for each condition, vertical bars represent maximum and minimum values observed) 
(a)

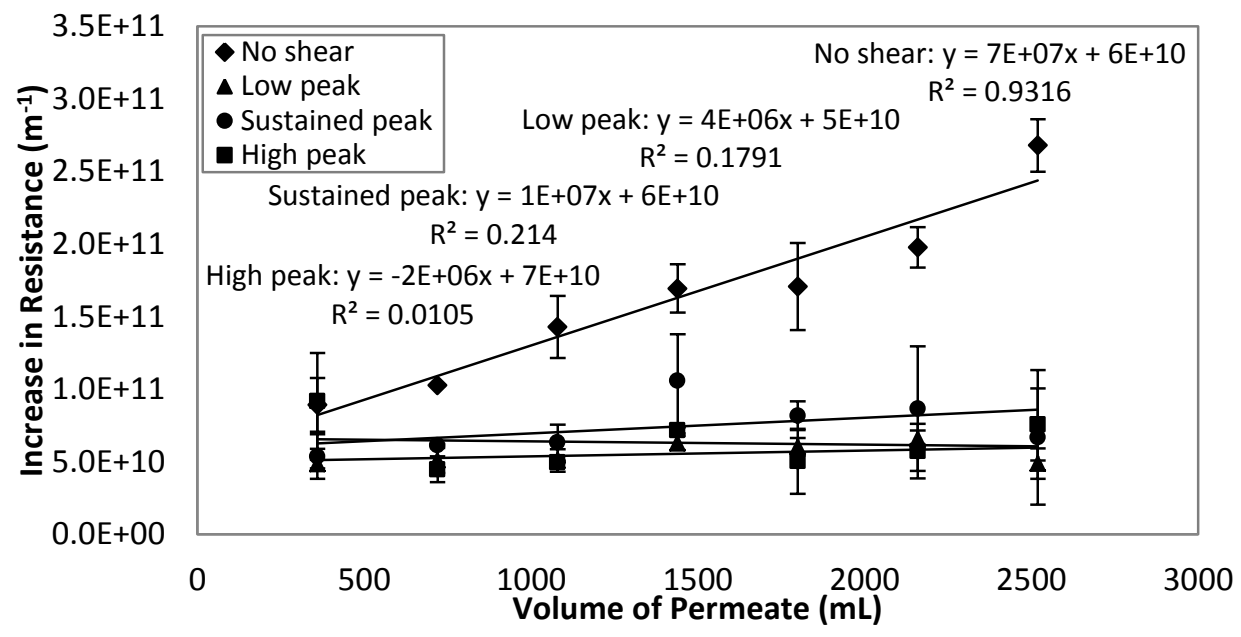

(b)

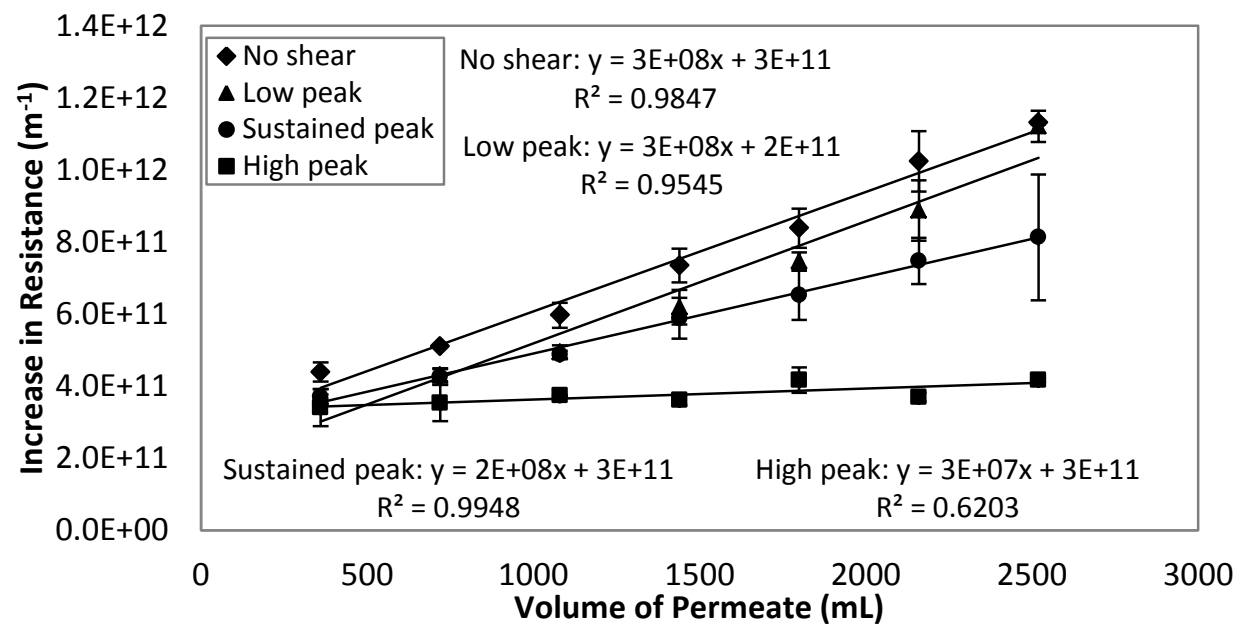

(c)

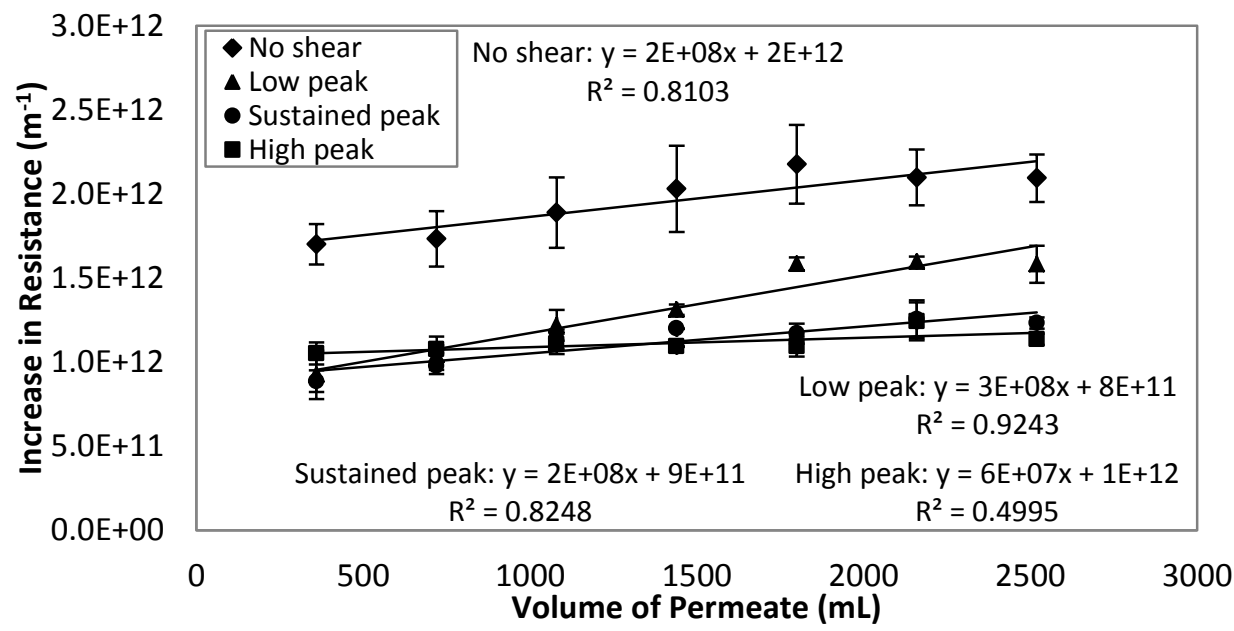

Figure 4.6: Increase in resistance, $\Delta \mathrm{R}$, at different backwash frequencies and shear conditions during ultrafiltration of Lake Simcoe water. (a) $0.5 \mathrm{~h}$-backwash frequency, (b) $2 \mathrm{~h}$-backwash frequency, (c) 6 h-backwash frequency (data represents average values of duplicate runs for each condition, vertical bars represent maximum and minimum values observed) 
(a)

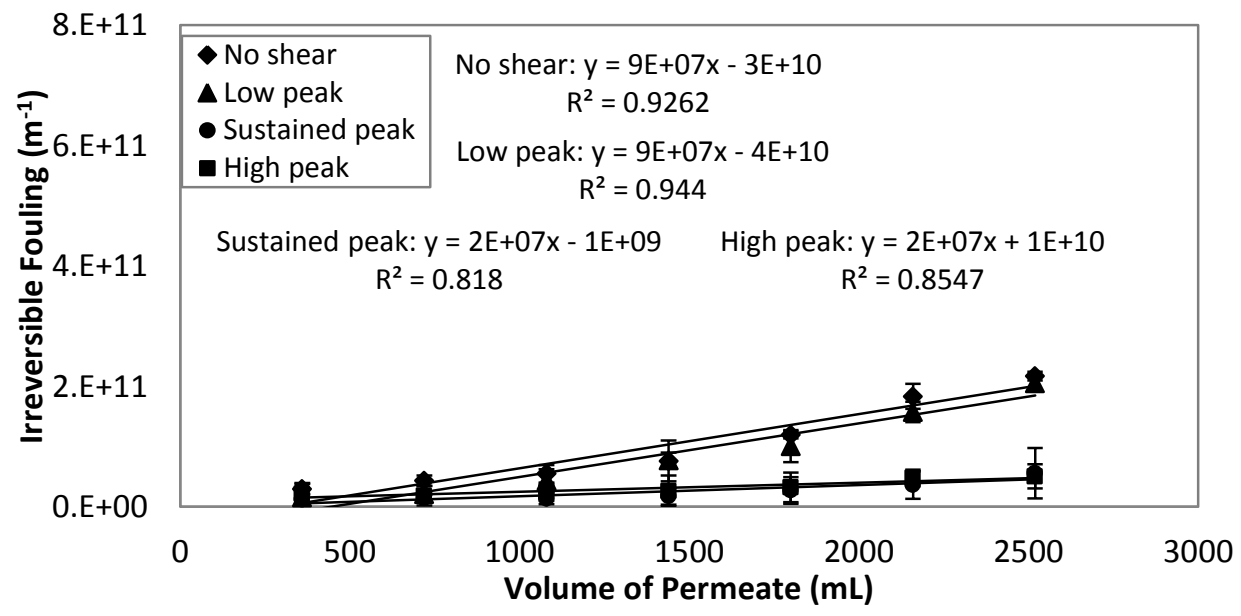

(b)

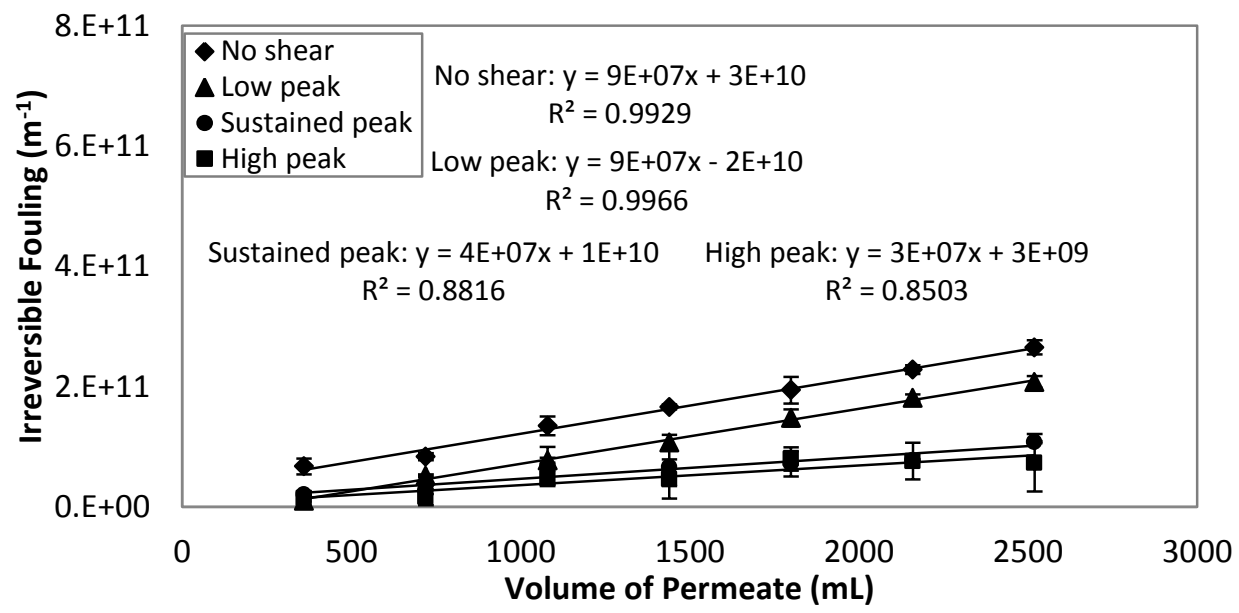

(c)

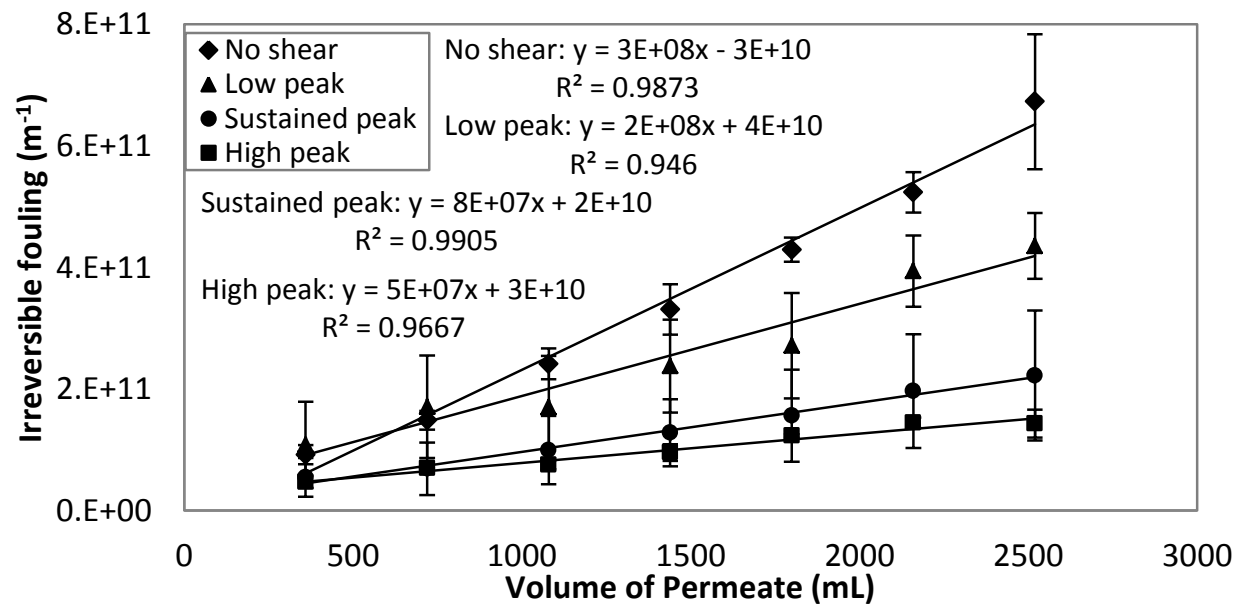

Figure 4.7: Impact of backwash frequency and shear stress condition on irreversible fouling during ultrafiltration of Otonabee River water. (a) $0.5 \mathrm{~h}$-backwash frequency, (b) $2 \mathrm{~h}$-backwash frequency, (c) 6 h-backwash frequency (data represents average values of duplicate runs for each condition, vertical bars represent maximum and minimum values observed) 
(a)

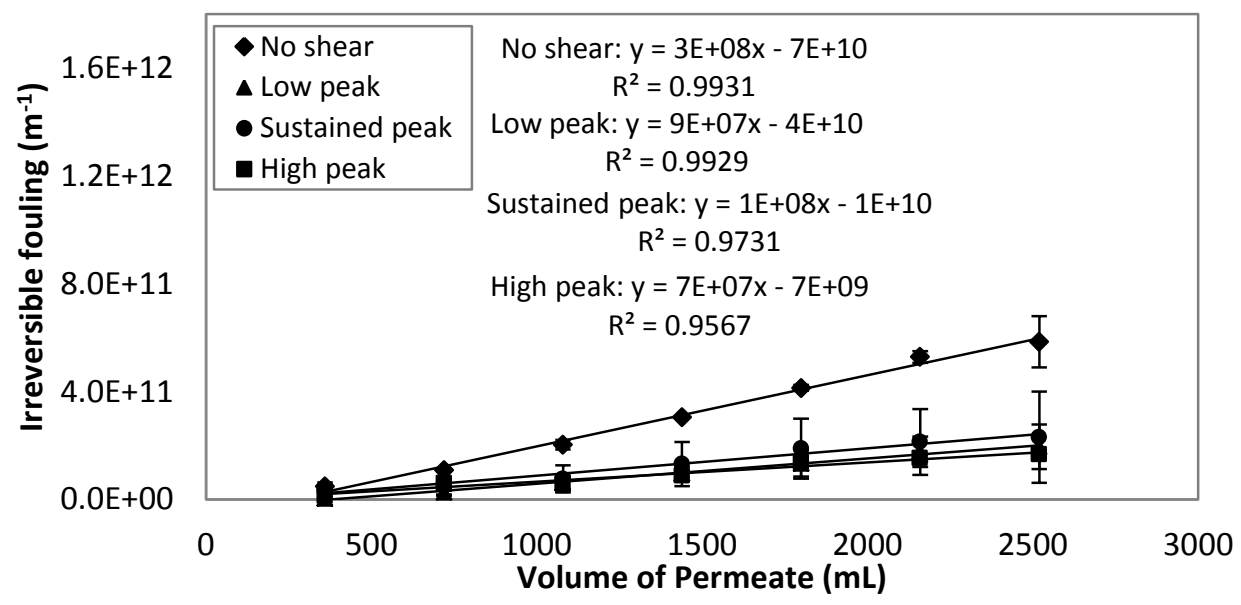

(b)

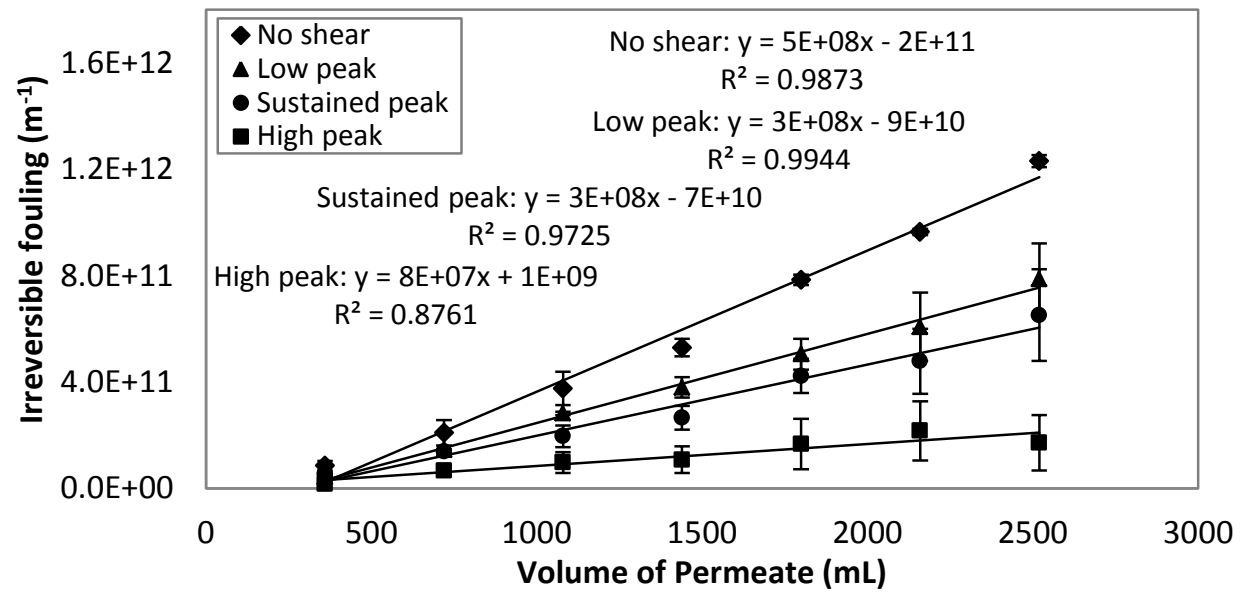

(c)

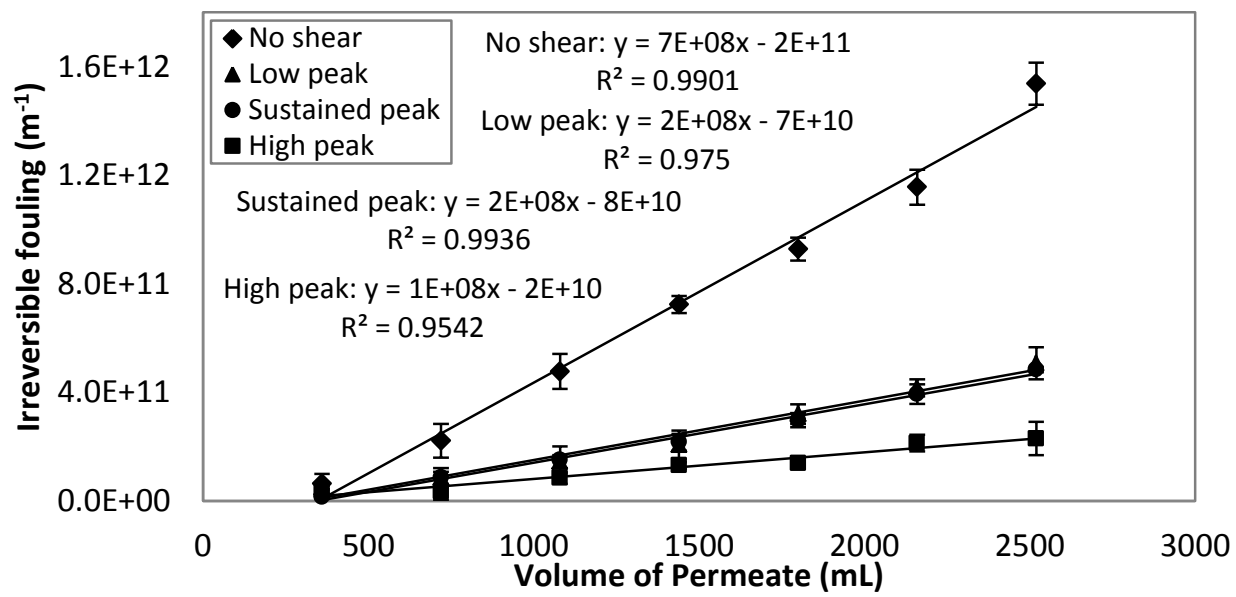

Figure 4.8: Impact of backwash frequency and shear stress condition on irreversible fouling during ultrafiltration of Lake Simcoe water. (a) 0.5 h-backwash frequency, (b) 2 h-backwash frequency, (c) 6 h-backwash frequency (data represents average values of duplicate runs for each condition, vertical bars represent maximum and minimum values observed) 
Results also showed that the irreversible fouling rates in the absence of shear for Lake Simcoe water was significantly higher than for Otonabee River water when the same backwash frequency was applied (ANOVA p-values < 0.05). In contrast, the irreversible fouling rates between the two water matrices were generally similar statistically when the same air sparging condition and backwash frequency was applied. However, Otonabee River and Lake Simcoe had similar dissolved biopolymer concentrations, which represent the primary UF foulant (Table 3.2). Higher irreversible fouling rates for Lake Simcoe water may be due to a higher colloidal concentration (turbidity, Table 3.2) in Lake Simcoe. Colloidal fraction of NOM has been reported to cause the most significant fouling (Lee et al., 2006, Costa et al., 2006). Higher irreversible fouling rates in Lake Simcoe for other shear conditions were not observed and could be the result of an air-sparging induced shear stress that kept the particles at the membrane surface in suspension as well as enhancing particle back-transport from the surface, such that deposition was minimized (Braak, et al, 2011, Cabassud et al., 2001).

\subsection{Cost Saving Analysis}

Membrane replacement was assumed to contribute to the largest proportion of costs (40$80 \%$ ) for the conditions examined in this study (Figure 4.9). Permeation costs increased by approximately $20 \%$ and $30 \%$ for $2 \mathrm{~h}$ - and $6 \mathrm{~h}$-backwash frequencies, respectively, when compared to the baseline case due to a longer permeation time at lower backwash frequency. Additional costs associated with increased energy required for pumping due to an increase in resistance during permeation only accounted for up to $4 \%$ of the total permeation costs. Backwash costs were largely reduced as the backwash frequency decreased (80\% and 90\% reduction at $2 \mathrm{~h}$ - and $6 \mathrm{~h}$-backwash frequencies, respectively, when compared to the baseline case). Filtration with sustained peak and high peak shear conditions were always associated with irreversible fouling reduction and cost savings irrespective of the backwash frequency applied when taking into account of the value of the water produced (Table 4.1). As discussed in the previous section, high peak shear conditions were more effective for irreversible fouling control, allowing longer permeation times (up to $6 \mathrm{~h}$ ) prior to backwashing. A lower irreversible fouling rate would also be reflected in less frequent chemical cleaning (i.e., CIP), thus reducing chemical exposure, extending the lifetime of the membrane and decreasing replacement costs. As shown in Figure 4.9, a high peak shear condition could lead to reduction in membrane replacement costs by up to $55 \%$. In addition, longer permeation times result in greater water production and 
(a)

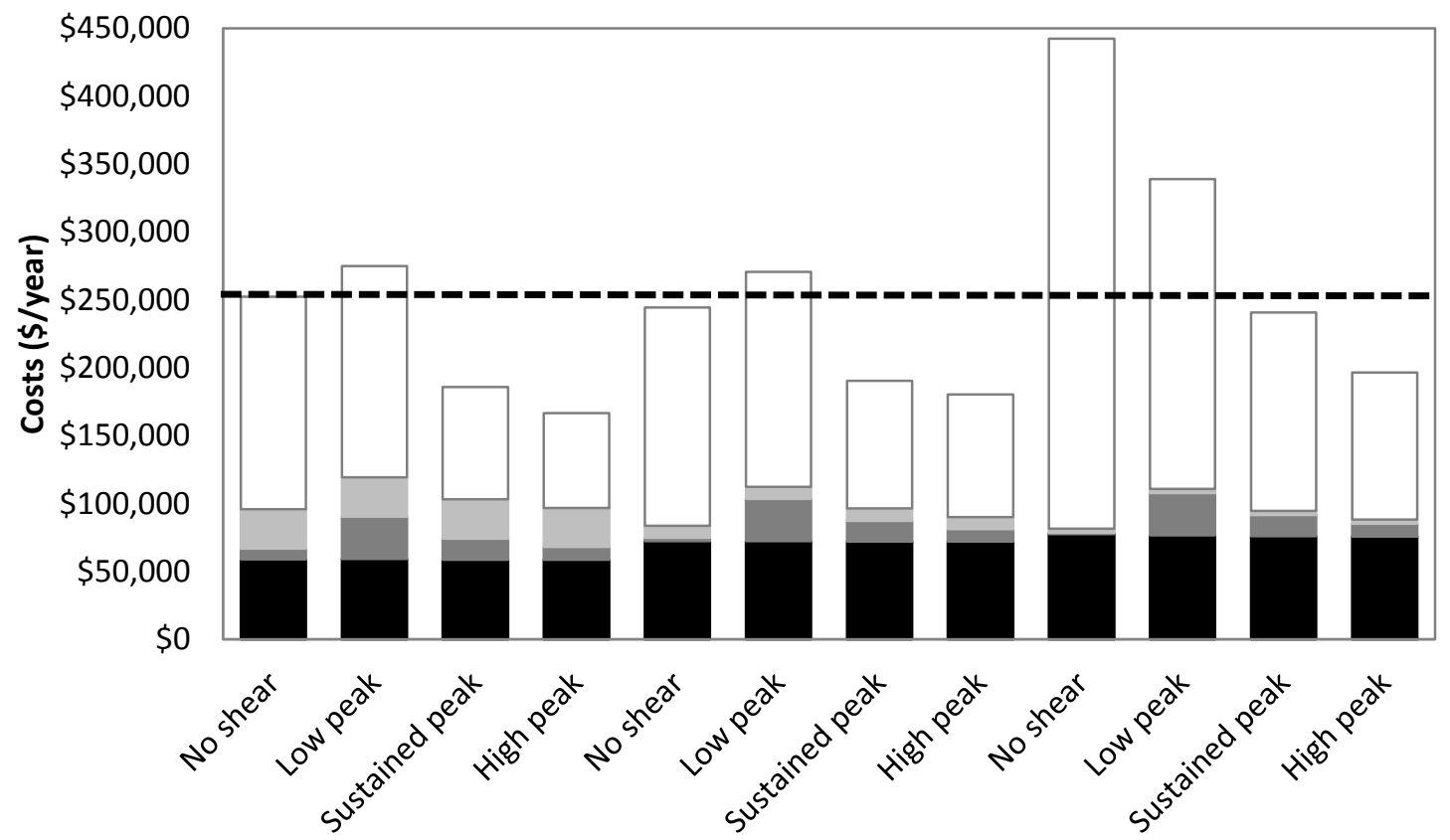

$0.5 \mathrm{~h}$-Backwash Frequency $2 \mathrm{~h}$-Backwash Frequency $6 \mathrm{~h}$-Backwash Frequency

- Permeation cost $\quad$ Aeration cost Backwash cost $\square$ Membrane replacement cost

(b)

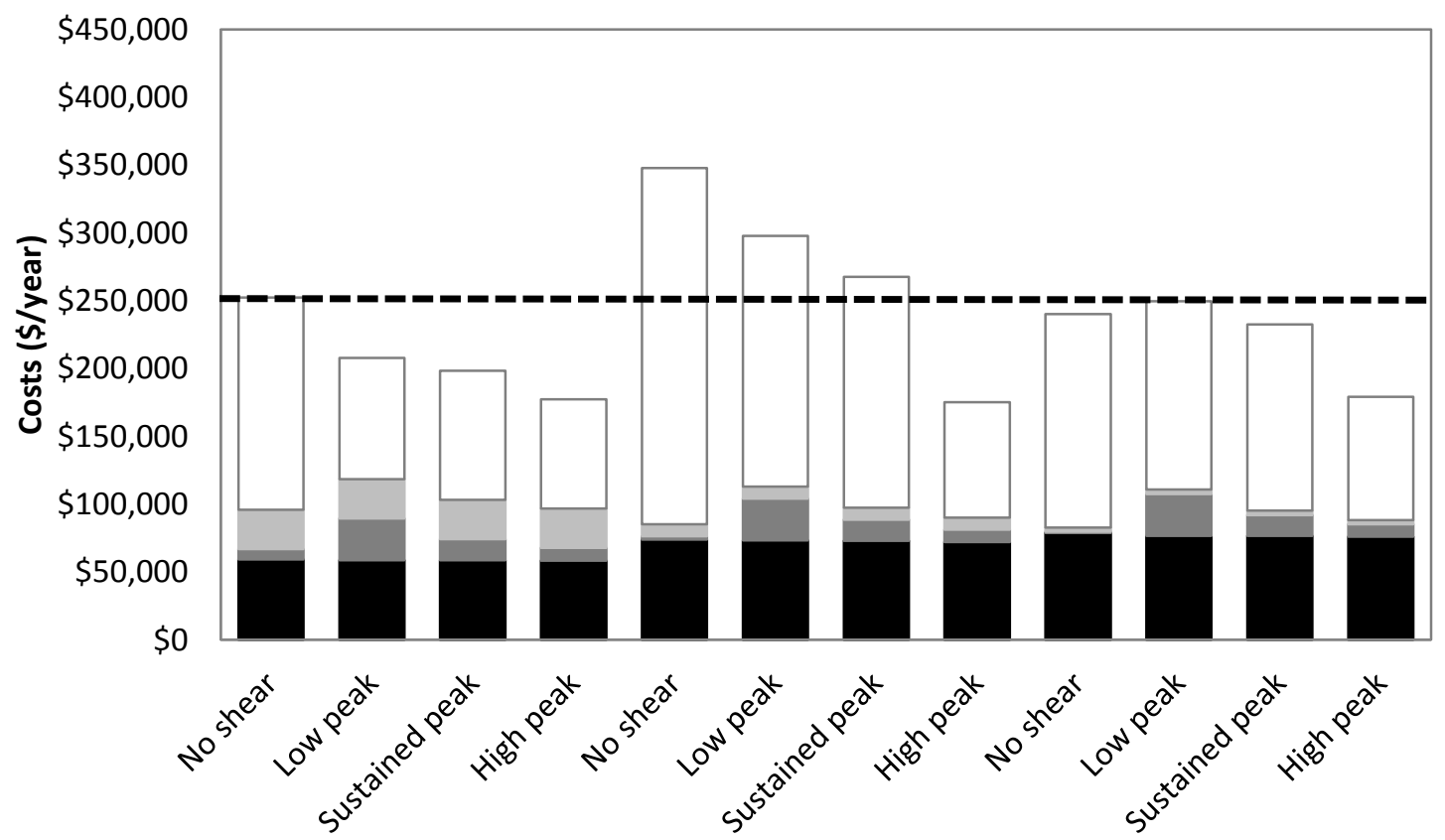

0.5 h-Backwash Frequency $2 \mathrm{~h}$-Backwash Frequency

6 h-Backwash Frequency

- Permeation cost Aeration cost Backwash cost $\square$ Membrane replacement cost

Figure 4.9: Estimation of operating and maintenance costs when considering various operating conditions for (a) Otonabee River, and (b) Lake Simcoe waters (horizontal dash line represents costs at the baseline condition ( 0.5 h-backwash frequency and no shear applied) 
reduced permeate consumption during backwash, such that cost savings were more pronounced for lower backwash frequencies when high peak shear was applied. However, longer permeation duration may lead to high total fouling during filtration cycles, as such total fouling should be monitored during each cycle to ensure it does not exceed operational limits. 


\section{Summary}

Bench-scale experiments using a single hollow fiber submerged UF membrane were conducted to examine the impact of backwash frequency and air-sparging induced shear stress condition on fouling for two natural surface waters: Otonabee River and Lake Simcoe. Three backwash frequencies (0.5, 2 and 6 h-filtration followed by $10 \mathrm{~min}$ backwash) and four shear stress conditions which simulated different air sparging regimes (no air sparging, continuous coarse bubble, discontinuous coarse bubble and large pulse bubble sparging) were examined. Fouling was quantified as resistance $\left(\mathrm{m}^{-1}\right)$. Concentrations of DOC fractions in raw, permeate and backwash water samples were analyzed using LC-OCD to determine if different experimental conditions had an impact on DOC removal. Cost analyses were performed to estimate potential savings with respect to fouling control.

\subsection{Conclusions}

The current study yielded the following conclusions:

- UF membranes removed $<12 \%$ of total DOC, irrespective of the backwash frequency and/or air-sparging condition applied

- Large pulse bubble and discontinuous coarse bubble air sparging significantly reduced irreversible fouling rate (up to $80 \%$ reduction for a $0.5 \mathrm{~h}$-backwash frequency), when compared to a baseline operating condition of no air sparging and a $0.5 \mathrm{~h}$-backwash frequency.

- Annual cost savings of up to $\$ 450,000$ for a 29 MLD membrane train were estimated when applying pulse bubble sparging applied with a $6 \mathrm{~h}$ backwash frequency, when compared to a baseline operating condition. Major cost savings are attributed to higher permeate production and reduced irreversible fouling which resulted in fewer required chemical cleans and extended membrane life

\subsection{Recommendations for Further Study}

Based on the current work, pilot studies should be considered for future research, since they may better simulate continuous operation at full-scale water treatment plants. Incorporation of coagulation and flocculation prior to UF should also be examined. 


\section{References}

Abrahamse, A.J., Lipreau, C., Li, S. and Heijman, S.G.J. (2008) Removal of divalent cations reduces fouling of ultrafiltration membranes. Journal of Membrane Science 323(1), 153-158.

Amy, G. (2008) Fundamental understanding of organic matter fouling of membranes. Desalination 231(1-3), 44-51.

Belfort, G., Davis, R.H. and Zydney, A.L. (1994) The behavior of suspensions and macromolecular solutions in crossflow microfiltration. Journal of Membrane Science 96(1), 1-58.

Bergamasco, R., Konradt-Moraes, L.C., Vieira, A.M.S, Vieira, M.F. and FagundesKlen, M.R. (2011) Performance of a coagulation-ultrafiltration hybrid process for water supply treatment. Chemical Engineering Journal 166(2), 483-489.

Bérubé, P.R. and Lei, E. (2006) The effect of hydrodynamic conditions and system configurations on the permeate flux in a submerged hollow fiber membrane system. Journal of Membrane Science 271(1), 29-37.

Bérubé, P.R., Lin, H. and Watai, Y. (2008) Fouling in air sparged submerged hollow fiber membranes at sub- and super-critical flux conditions. Journal of Membrane Science 307(2), 169-180.

Bessiere, Y., Guigui, C., Remize, P.J. and Cabassud, C. (2009) Coupling air-assisted backwash and rinsing steps: a new way to improve ultrafiltration process operation for inside-out hollow fibre modules. Desalination 240(1), 71-77.

Best. G, Singh, M., Mourato, D. and Chang, Y.J. (2001) Application of immersed ultrafiltration membranes for organic removal and disinfection by-product reduction. Water Supply 1(5-6), 221-231.

Braak, E., Alliet, M., Schetrite, S. and Albasi, C. (2011) Aeration and hydrodynamics in submerged membrane bioreactors. Journal of Membrane Science 379(1), 118.

Cabassud, C., Laborie, S., Durand-Bourlier, L. and Laine, J.M. (2001) Air sparging in ultrafiltration hollow fibers: relationship between flux enhancement, cake characteristics and hydrodynamic parameters. Journal of Membrane Science 181(1), 57-69.

Campinas, M. and Rosa, M.J. (2010) Assessing PAC contribution to the NOM fouling control in PAC/UF systems. Water Research 44(5), 1636-1644.

Chan, C.C.V., Bérubé, P.R. and Hall, E.R. (2007) Shear profiles inside gas sparged submerged hollow fiber membrane modules. Journal of Membrane Science 297(1), 104-120.

Chan, C.C.V., Bérubé, P.R. and Hall, E.R. (2011) Relationship between types of surface shear stress profiles and membrane fouling. Water Research 45(19), 6403-6416. 
Cheng, Y.L., Wong, R.J., Lin, J.C.T., Huang, C., Lee, D.J. and Lai, J.Y. (2010) Pretreatment of natural organic matters containing raw water using coagulation. Separation Science and Technology 45(7), 911-919.

Childress, A.E. and Elimelech, M. (1996) Effect of solution chemistry on the surface charge of polymeric reverse osmosis and nanofiltration membranes. Journal of Membrane Science 119(2), 253-268.

Cho, J., Amy, G. and Pellegrino, J. (2000) Membrane filtration of natural organic matter: factors and mechanisms affecting rejection and flux decline with charged ultrafiltration (UF) membrane. Journal of Membrane Science 164(1), 89-110.

Choi, K.Y. and Dempsey, B.A. (2004) In-line coagulation with low-pressure membrane filtration. Water Research 38(19), 4271-4281.

Choudhry, G.G. (1984) Humic substances: Structural, photophysical, photochemical and free radical aspects and interactions with environmental chemicals. Gordon and Breach Science Publishers. New York

Costa, A.R. and de Pinho, M.N. (2005) Effect of membrane pore size and solution chemistry on the ultrafiltration of humic substances. Journal of Membrane Science 255(1), 49-56.

Costa, A.R., de Pinho, M.N. and Elimelech, M. (2006) Mechanisms of colloidal natural organic matter fouling in ultrafiltration. Journal of Membrane Science 281(1), 716-725.

Cote, P., Alam, Z. and Penny, J. (2012) Hollow fiber membrane life in membrane bioreactors (MBR). Desalination 288, 145-151.

Cui, Z.F., Chang, S. and Fane, A.G. (2003) The use of gas bubbling to enhance membrane processes. Journal of Membrane Science 221(1), 1-35.

Culfaz, P.Z., Wessling, M. and Lammertink, R.G.H. (2011) Fouling behaviour of microstructured hollow fiber membranes in submerged and aerated filtrations. Water Research 45(4), 1865-1871.

De Souza, N.P. and Basu, O.D. (2013) Comparative analysis of physical cleaning operations for fouling control of hollow fiber membranes in drinking water treatment. Journal of Membrane Science 436(5), 28-35.

Dean, A. and Voss, D. (1999) Design and Analysis of Experiments. Springer: New York.

Defrance, L. and Jaffrin, M.Y. (1999) Comparison between filtrations at fixed transmembrane pressure and fixed permeate flux: application to a membrane bioreactor used for wastewater treatment. Journal of Membrane Science 152(2), 203-210.

Dong, B., Chen, Y., Gao, N. and Fan, J. (2007) Effect of coagulation pretreatment on the fouling of ultrafiltration membrane. Journal of Environmental Science 19(3), 278-283. 
Ducom, G., Puech, F.P. and Cabassud, C. (2002) Air sparging with flat sheet nanofiltration: a link between wall shear stresses and flux enhancement. Desalination 145(1), 97-102.

Elimelech, M., Chen, W.H. and Waypa, J.J. (1994) Measuring the zeta (electrokinetic) potential of reverse osmosis membranes by a streaming potential analyzer. Desalination 95(3), 269-286.

Fan, L., Harris, J.L., Roddick, F.A. and Booker, N.A. (2001) Influence of the characteristics of natural organic matter on the fouling of microfiltration membranes. Water Research 38(18), 4455-4463.

Field, R.W. and Pearce, G.K. (2011) Critical, sustainable and threshold fluxes for membrane filtration with water industry applications. Advances in Colloid and Interface Science 164(1), 38-44.

Field, R.W., Wu, D., Howell, J.A. and Gupta, B.B. (1995) Critical flux concept for microfiltration fouling. Journal of Membrane Science 100(3), 259-272.

Fulton, B.G., Redwood, J., Tourais, M. and Bérubé, P.R. (2011) Distribution of surface shear forces and bubble characteristics in full-scale gas sparged submerged hollow fiber membrane modules. Desalination 281, 128-141.

Gahleitner, B., Loderer, C., Saracino, C., Pum, D. and Fuchs, W. (2014) Chemical foam cleaning as an efficient alternative for flux recovery in ultrafiltration process. Journal of Membrane Science 450, 433-439

Ghosh, R. (2006) Enhancement of membrane permeability by gas-sparging in submerged hollow fibre ultrafiltration of macromolecular solutions: role of module design. Journal of Membrane Science 274(1), 73-82.

Gregor, J.E., Nokes, C.J. and Fenton, E. (1997) Optimising natural organic matter removal from low turbidity waters by controlled $\mathrm{pH}$ adjustment of aluminium coagulation. Water Research 31(12), 2949-2958.

Gui, P., Huang, X., Chen, Y. and Qian, Y. (2003) Effect of operational parameters on sludge accumulation on membrane surfaces in a submerged membrane bioreactor. Desalination 151(2), 185-194.

Guigui, C., Rouch, J.C., Durand-Bourlier, L., Bonnelye, V. and Aptel, P. (2002) Impact of coagulation conditions on the in-line coagulation/UF process for drinking water production. Desalination 147(1), 95-100.

Guo, X., Zhang, Z., Fang, L. and Su, L. (2009) Study on ultrafiltration for surface water by a polyvinylchloride hollow fiber membrane. Desalination 238(1), 183191.

Hines, W.W., Montgomery, D.C., Goldsman, D.M. and Borror, C.M. (2003) Probability and Statistics in Engineering. John Wiley \& Sons Inc. USA

Howe, K.J. and Clark, M. (2002) Fouling of microfiltration and ultrafiltration membranes by natural waters. Environmental Science \& Technology 36(16), 3571-3576. 
Huber, S.A. Balz, A., Abert, M. and Pronk, W. (2011) Characterisation of aquatic humic and non-humic matter with size-exclusion chromatography-organic carbon detection-organic nitrogen detection (LC-OCD-OND). Water Research $45,879-885$.

Huyskens, C., Brauns, E., Van Hoof, E. and De Wever, H. (2008) A new method for the evaluation of the reversible and irreversible fouling propensity of MBR mixed liquor. Journal of Membrane Science 323(1), 185-192.

Hwang, K.J., Chan, C.S. and Chen, F.F. (2008) A comparison of hydrodynamic methods for mitigating particle fouling in submerged membrane filtration. Journalof the Chinese Institute of Chemical Engineers 39(3), 257-264.

Hwang, K.J., Chan, C.S. and Tung, K.L. (2009) Effect of backwash on the performance of submerged membrane filtration. Journal of Membrane Science 330(1), 349-356.

Jankhah, S. and Bérubé, P.R. (2013) Power induced by bubbles of different sizes and frequencies on to hollow fibers in submerged membrane systems. Water Research 47(17), 6516-6526.

Jeison, D. and van Lier, J.B. (2006) Cake layer formation in anaerobic submerged membrane bioreactors (AnSMBR) for wastewater treatment. Journal of Membrane Science 284(1), 227-236.

Jones, K. and O'Melia, C.R. (2000) Protein and humic acid adsorption onto hydrophilic membrane surfaces: effects of $\mathrm{pH}$ and ionic strength. Journal of Membrane Science 165(1), 31-46.

Judd, S. (2006) The MBR book of principles and applications of membrane bioreactors in water and wastewaters treatment, Elsevier, Oxford.

Jung, C.W. and Kang, L.S. (2003) Application of combined coagulation-ultrafiltration membrane process for water treatment. Korean Journal of Chemical Engineering 20(5), 855-861.

Kabsch-Korbutowicz, M. (2005) Effect of Al coagulant type on natural organic matter removal efficiency in coagulation/ultrafiltration process. Desalination 185(1), 327-333.

Kabsch-Korbutowicz, M. (2006) Removal of natural organic matter from water by inline coagulation/ ultrafiltration process. Desalination 200(1), 421-423.

Katsoufidou, K.S., Siotopoulos, D.C., Yiantsios, S.G. and Karabelas, A.J. (2010) UF membrane fouling by mixture of humic acids and sodium alginate: fouling mechanisms and reversibility. Desalination 265(3), 220-227.

Kim, J. and DiGiano, F.A. (2006) A two-fiber, bench-scale test of ultrafiltration (UF) for investigation of fouling rate and characteristics. Journal of Membrane Science 271(1-2), 196-204.

Kim, S.H., Moon, S.Y., Yoon, C.H., Yim, S.K. and Cho, J.W. (2005) Role of coagulation in membrane filtration of wastewater for reuse. Desalination 173(3), 301-307. 
Kimura, K., Hane, Y., Watanabe, Y., Amy, G. and Ohkuma, N. (2004) Irreversible membrane fouling during ultrafiltration of surface water. Water Research 38(1415), 3431-3441.

Kweon, J.H. and Lawler, D.F. (2004) Fouling mechanisms in the integrated system with softening and ultrafiltration. Water Research 38(19), 4164-4172.

Le-Clech, P., Chen, V. and Fane, T.A.G. (2006) Fouling in membrane bioreactors used in wastewater treatment. Journal of Membrane Science 284(1), 17-53.

Le-Clech, P., Jefferson, B. and Judd, S.J. (2003) Impact of aeration, solids concentration and membrane characteristics on the hydraulic performance of a membrane bioreactor. Journal of Membrane Science, 218(1), 117-129.

Lee, C.W., Bae, S.D., Han, S.W. and Kang, L.S. (2007) Application of ultrafiltration hybrid membrane processes for reuse of secondary effluent. Desalination 202(1), 239-246.

Lee, N., Amy, G. and Croué, J.P. (2006) Low-pressure membrane (MF/UF) fouling associated with allochthonous versus autochthonous natural organic matter. Water Research 40(12), 2357-2368.

Lee, N., Amy, G., Croué, J.P. and Buisson, H. (2004) Identification and understanding of fouling in low-pressure membrane (MF/UF) filtration by natural organic matter (NOM). Water Research 38(20), 4511-4523.

Lee, S., Ang, W.S. and Elimelech, M. (2006) Fouling of reverse osmosis membranes by hydrophilic organic matter: implications for water reuse. Desalination 187(1), 313-321.

Li, Y.H., Wang, J., Zhang, W., Zhang, X.J. and Chen, C. (2011) Effects of coagulation on submerged ultrafiltration membrane fouling caused by particles and natural organic matter (NOM). Chinese Science Bulletin 56(6), 584-590.

Mercier, M., Fonade, C. and Lafforgue-Delorme, C. (1997) How slug flow can enhance the ultrafiltration flux in mineral tubular membranes. Journal of Membrane Science 128(1), 103-113.

Metzger, U., Le-Clech, P., Stuetz, R.M., Frimmel, F.H. and Chen, V. (2007) Characterisation of polymeric fouling in membrane bioreactors and the effect of different filtration modes. Journal of Membrane Science 301 (1), 180-189.

Nagaoka, H., Kurosaka, M., Shibata, N. and Kobayashi, M. (2006) Effect of bubble flow velocity on drag-force and shear stress working on submerged hollow fibre membrane. Water Science and Technology 54(10), 185-192.

Neubrand, W., Vogler, S., Ernst, M. and Jekel, M. (2010) Lab and pilot scale investigations on membrane fouling during the ultrafiltration of surface water. Desalination 250(3), 968-972.

Nguyen, A.H., Tobiason, J.E. and Howe, K.J. (2011) Fouling indices for low pressure hollow fiber membrane performance assessment. Water Research 45(8), 26272637. 
Ochoa, J.C., Coufort, C., Escudie, R., Line, A. and Paul, E. (2007) Influence of nonuniform distribution of shear stress on aerobic biofilms. Chemical Engineering Science 62(14), 3672-3684.

Park, H., Lee, Y.H., Kim, K., Kim, H., Moon, J., Ahn, C. and Kang, M. (2010) Reduction of membrane fouling by simultaneous upward and downward air sparging in a pilot-scale submerged membrane bioreactor treating municipal wastewater. Desalination 251(1), 75-82.

Peeva, P.D., Palupi, A.E. and Ulbricht, M. (2011) Ultrafiltration of humic acid solutions through unmodified and surface functionalized low-fouling polyethersulfone membranes - effects of feed properties, molecular weight cutoff and membrane chemistry on fouling behavior and cleanability. Separation and Purification Technology 81(2), 124-133.

Peldszus, S., Halle, Cynthia, Peiris, R.H., Hamouda, M., Jin, X., Legge, R.L., Budman, H., Moresoli, C. and Huck, P.M. (2011) Reversible and irreversible low-pressure membrane foulants in drinking water treatment: Identification by principal component analysis of fluorescence EEM and mitigation by biofiltration pretreatment. Water Research 45, 5161-5170.

Peter-Varbanets, M., Margot, J., Traber, J. and Pronk, W. (2011) Mechanisms of membrane fouling during ultra-low pressure ultrafiltration. Journal of Membrane Science 377(1), 42-53.

Porcelli, N. and Judd, S. (2010) Chemical cleaning of potable water membranes: The cost benefit of optimisation. Water Research 44(5), 1389-1398.

Qu, F., Liang, H., Wang, H., Wang, Z., Yu, H. and Li, G. (2012) Ultrafiltration membrane fouling by extracellular organic matters (EOM) of microcystis aeruginosa in stationary phase: influences of interfacial characteristics of foulants and fouling mechanisms. Water Research, 46(5), 1490-1500.

Regula, C., Carretier, E., Wyart, Y., Sergent, M., Gésan-Guiziou, G., Ferry, D., Vincent, A., Boudot, D. and Moulin, P. (2013) Drinking water ultrafiltration: state of the art and experimental designs approach. Desalination and Water Treatment 51(25-27), 4892-4900.

Remize, P.J., Guigui, C. and Cabassud, C. (2010) Evaluation of backwash efficiency, definition of remaining fouling and characterisation of its contribution in irreversible fouling: Case of drinking water production by air-assisted ultrafiltration. Journal of Membrane Science 355(1), 104-111.

Ruohomaki, K., Vaisanen, P., Metsamuuronen, S., Kulovaara, M. and Nystrom, M. (1998) Characterization and removal of humic substances in ultra- and nanofiltration. Desalination 118(1-3), 273-283.

Serra, C., Durand-Bourlier, L., Clifton, M.J., Moulin, P., Rouch, J.C. and Aptel, P. (1999) Use of air sparging to improve backwash efficiency in hollow-fiber modules. Journal of Membrane Science 161(1), 95-113. 
Smith, P.J., Vigneswaran, S., Ngo, H.H., Ben-Aim, R. and Nguyen, H. (2006) A new approach to backwash initiation in membrane systems. Journal of Membrane Science 278(1), 381-389.

Sutzkover-Gutman, I., Hasson, D. and Semiat, R. (2010) Humic substances fouling in ultrafiltration processes. Desalination 261(3), 218-231.

Taniguchi, M., Kilduff, J.E. and Belfort, G. (2003) Modes of natural organic matter fouling during ultrafiltration. Environmental Science \& Technology, 37(8), 1676-1683.

Tian, J., Ernst, M., Cui, F. and Jekel, M. (2013) Correlations of relevant membrane foulants with UF membrane fouling in different waters. Water Research 47(3), 1218-1228.

Wicaksana, F., Fan, A.G. and Chen, V. (2005) The relationship between critical flux and fibre movement induced by bubbling in a submerged hollow fibre system. Water Science and Technology 51(6-7), 115-122.

Wicaksana, F., Fane, A.G. and Chen, V. (2006) Fibre movement induced by bubbling using submerged hollow fibre membranes. Journal of Membrane Science 271(1), 186-195.

Woo, Y.C., Lee, J.J., Oh, J.S. and Kim, H.S. (2012) Effect of chemical cleaning conditions on the flux recovery of MF membrane as pretreatment of seawater desalination. Desalination and Water Treatment 51(31-33), 6329-6337.

Wray, H.E., Andrews, R.C. and Bérubé, P.R. (2013) Surface shear stress and membrane fouling when considering natural water matrices. Desalination 330, 22-27.

Wu, J., L-Clech, P., Stuetz, R.M., Fane, A.G. and Chen, V. (2008) Novel filtration mode for fouling limitation in membrane bioreactors. Water Research 42(14), 3677-3684.

Yamanoi, I. and Kageyama, K. (2010) Evaluation of bubble flow properties between flat sheet membranes in membrane bioreactor. Journal of Membrane Science 360(1), 102-108.

Ye, Y., Chen, V. and Le-Clech, P. (2011) Evolution of fouling deposition and removal on hollow fibre membrane during filtration with periodical backwash. Desalination 283, 198-205.

Yeo, A.P.S., Law, A.W.K. and Fane, A.G. (2007) The relationship between performance of submerged hollow fibers and bubble induced phenomena examined by particle image velocimetry. Journal of Membrane Science 304(1), 125-137.

Zhang, K., Cui, Z. and Field, R.W. (2009) Effect of bubble size and frequency on mass transfer in flat sheet MBR. Journal of Membrane Science, 332(1), 30-37.

Zhang, K., Wei, P., Yao, M. Field, R.W. and Cui, Z. (2011) Effect of the bubbling regimes on the performance and energy cost of flat sheet MRBs. Desalination 
$283,221-226$.

Zouboulis, A., Traskas, G. and Samaras, P. (2008) Comparison of efficiency between poly-aluminium chloride and aluminium sulphate coagulants during full-scale experiments in a drinking water treatment plant. Separation Science and Technology 43(6), 1507-1519. 


\section{Appendices}

\subsection{Preliminary Experiment}

\subsubsection{System Blank Experiment}

\subsubsection{Rationale}

In the study performed by Chan et al., 2011, the membrane fiber was attached to a piece of rubber backing using epoxy. Epoxy leaches low molecular weight (LMW) DOC during filtration, which interferes with the water quality analysis. Therefore, a new fiber mounting method was introduced using the stainless steel fiber holder (Figure 3.3(c)), as such the membrane fiber could be fixed to the interior wall of the membrane tank without the use of epoxy. Experiment was performed to determine the amount of reduction in LMW DOC when using the stainless steel holder for fiber mounting.

\subsubsection{Objective}

The objectives of the System Blank Experiment were to:

1. Compare the amount of DOC addition to the system of the two fiber mounting methods: stainless steel holder and rubber backing, and

2. Determine the fractions of DOC that were added to the system by each fiber mounting method

\subsubsection{Procedure}

Two membrane fibers were each fixed to the interior wall of a membrane tank. One was mounted using the stainless steel holder and the other was mounted using the rubber backing method. Filtration was performed using Milli-Q® water. Feed and permeate samples were collected for LC-OCD analysis.

\subsubsection{Results}

LC-OCD results showed that approximately $1 \mathrm{mg} / \mathrm{L}$ and $3 \mathrm{mg} / \mathrm{L}$ of DOC was added to the permeate when using the stainless steel holder and the rubber backing fiber mounting method, respectively (Table 7.1). Results also showed that the largest amount of DOC addition was due to 
LMW neutrals fraction (approximately $33 \%$ and $41 \%$ of DOC for the stainless steel and rubber backing fiber mounting methods, respectively). The rubber backing method added approximately 3.6 times more LMW neutrals than the stainless steel holder method.

Table 7.1: Results of DOC analysis for the System Blank Experiment samples collected from permeate produced using the stainless steel holder and rubber backing fiber mounting methods (each fiber mounting method had two permeate samples produced from two different hollow fiber UF membranes)

\begin{tabular}{|l|c|c|c|c|c|c|}
\hline \multicolumn{1}{|c|}{ Water } & $\begin{array}{c}\text { DOC } \\
(\mathbf{m g} / \mathbf{L})\end{array}$ & $\begin{array}{c}\text { Biopolymers } \\
(\mathbf{m g} / \mathbf{L})\end{array}$ & $\begin{array}{c}\text { Humic } \\
\text { substances } \\
(\mathbf{m g} / \mathbf{L})\end{array}$ & $\begin{array}{c}\text { Building } \\
\text { blocks } \\
(\mathbf{m g} / \mathbf{L})\end{array}$ & $\begin{array}{c}\text { LMW } \\
\text { neutrals } \\
(\mathbf{m g} / \mathbf{L})\end{array}$ & $\begin{array}{c}\text { LMW } \\
\text { acids } \\
(\mathbf{m g} / \mathbf{L})\end{array}$ \\
\hline Blank feed & 0.28 & 0.001 & $\mathrm{n} . \mathrm{q}^{\mathrm{a}}$ & 0.015 & 0.074 & 0.013 \\
\hline $\begin{array}{l}\text { Stainless steel } \\
\text { holder }\end{array}$ & 1.13 & 0.007 & 0.041 & 0.12 & 0.38 & 0.063 \\
\hline Rubber backing & 2.90 & 0.071 & 0.39 & 0.34 & 1.18 & 0.066 \\
\hline
\end{tabular}

${ }^{a}$ n.q: not quantifiable $(<1 \mathrm{ppb})$

\subsubsection{Conclusion}

Both the stainless steel holder and rubber backing fiber mounting methods added extra DOC to the permeate during filtration. The stainless steel holder method leached less DOC (1.77 $\mathrm{mg} / \mathrm{L}$ less) than the rubber backing method, since only minimal amount of silicon instead of epoxy was applied at one end of the membrane fiber in the stainless steel holder method. A large proportion of the added DOC was attributed to the LMW neutrals when using the stainless steel holder fiber mounting method (33-41\%). The rubber backing method added approximately 3.6 times more LMW neutrals than the stainless steel holder method.

\subsubsection{System Modification Experiment}

\subsubsection{Rationale}

The application of the stainless steel holder fiber mounting method reduced the leaching of LMW DOC compared to the rubber backing method that was used in Chan et al., 2011 (refer to Section 7.1.1). However, the stainless steel holder embedded in the interior wall of the membrane tank increased the distance between the membrane surface and the impeller blade of the original apparatus design in Chan et al, 2011, due to the removal of the rubber backing. Therefore, a new set of impeller blades with the same geometry but larger radius were made to 
achieve the same distance between the membrane surface the impeller blade. Filtration experiment was then conducted to examine if this apparatus modification had changed the system performance of the original design.

\subsubsection{Objective}

The objectives of this experiment were to:

1. Determine if the fouling rate when using the stainless steel fiber holder was the same as the fouling rate when using the rubber backing fiber mounting method under the no shear condition in a $0.2 \mathrm{~g} / \mathrm{L}$ bentonite solution, and

2. Determine if the modified shear apparatus could produce the same shear conditions as reported by Chan et al. 2011 by comparing fouling using the stainless steel holder method to the results in Chan et al., 2011 in a $0.2 \mathrm{~g} / \mathrm{L}$ bentonite solution

\subsubsection{Procedure}

There were two sections in this experiment:

1. Filtration using the two fiber mounting methods, stainless steel holder and rubber backing, under the no shear condition in a $0.2 \mathrm{~g} / \mathrm{L}$ bentonite solution, and

2. Filtration using the stainless steel holder fiber mounting method under the four different shear conditions (Table 3.1) in a $0.2 \mathrm{~g} / \mathrm{L}$ bentonite solution.

Four membrane tanks were operated in parallel in each trial. Experimental conditions are summarized in Table 7.2. 
Table 7.2: Experimental conditions of system modification preliminary experiments performed in a $0.2 \mathrm{~g} / \mathrm{L}$ bentonite solution

\begin{tabular}{|c|c|c|c|c|}
\hline $\begin{array}{c}\text { Fiber Mounting } \\
\text { Method }\end{array}$ & $\begin{array}{l}\text { Flow Rate } \\
(\mathrm{mL} / \mathrm{min})\end{array}$ & Shear Condition & $\begin{array}{c}\text { Filtration } \\
\text { Duration (min) }\end{array}$ & $\begin{array}{c}\text { \# of Replicate } \\
\text { Runs }\end{array}$ \\
\hline \multicolumn{5}{|c|}{ Section 1 of Experiment } \\
\hline Stainless steel holder & 1 & No shear & 30 & 3 \\
\hline Rubber backing & $0.5^{\mathrm{a}}$ & No shear & 30 & 3 \\
\hline \multicolumn{5}{|c|}{ Section 2 of Experiment } \\
\hline Stainless steel holder & 1 & $\begin{array}{l}\text { No shear, high } \\
\text { peak, low peak, } \\
\text { sustained peak }^{\text {b }}\end{array}$ & 80 & 3 \\
\hline
\end{tabular}

\subsubsection{Results}

In Section 1 of the experiment, the resistance vs. time curves (Figures 7.1 and 7.2) were not linear with respect to time at the beginning of each test $(0-10 \mathrm{~min})$, fouling rates (increase in resistance over time) were then calculated for the 10-30 min interval (Table 7.3), where the resistance increase was approximately linear. The significance of difference in membrane fouling between the membrane tanks and between the two fiber mounting methods was evaluated using a two-way ANOVA model similar to the one described in Section 3.6.1. In this experiment, the dimension of the ANOVA model was $4 \times 2$ (4 levels of factor A, which was the number of membrane tank, and 2 levels of factor B, which was the fiber mounting method). Design-Expert 8 (Stat-Ease Inc., Minneapolis, MN) was used for the ANOVA. A statistically significant difference between the membrane tanks and between the fiber mounting methods was indicated by a p-value $<0.05$. ANOVA results (Table 7.4) showed that there was no significant difference in fouling rate between the two fiber mounting methods or between the membrane tanks ( $\mathrm{p}>$ $0.05)$.

In section 2 of the experiment, fouling rates were calculated near the end of each test run (60-80 $\mathrm{min})$ (Table 7.5), where the $95 \%$ confidence intervals generally did not overlap and the resistance curves appeared to be linear (Figure 7.3). The resistance vs. time plot (Figure 7.3) shows that different shear conditions resulted in different fouling rates and that the application of shear had better fouling control than filtration without shear. One-way ANOVA results showed that the impact of different shear conditions on fouling rate was significant at $95 \%$ confidence level $(\mathrm{F}$-value $=21.69, \mathrm{p}$-value $=0.0003)$. The impact of different shear conditions on fouling 
control had the general relationship: no shear < low peak < sustained peal < high peak, which was consistent with the study performed by Chan et al., 2011.

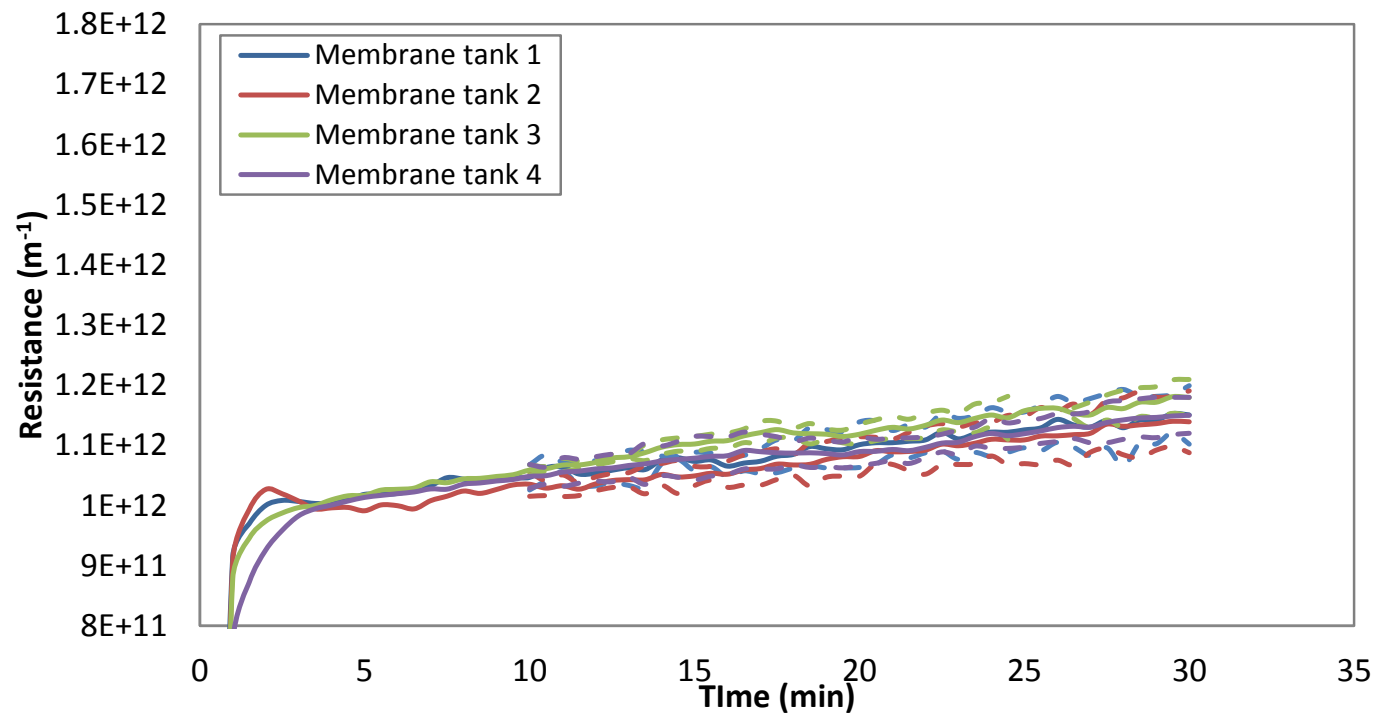

Figure 7.1: Resistance curves of filtration using the stainless steel holder fiber mounting method under the no shear stress condition in a $0.2 \mathrm{~g} / \mathrm{L}$ bentonite solution for the four membrane tanks (dash lines represent the $95 \%$ confidence interval for each membrane tanks at the 10-30 min filtration interval)

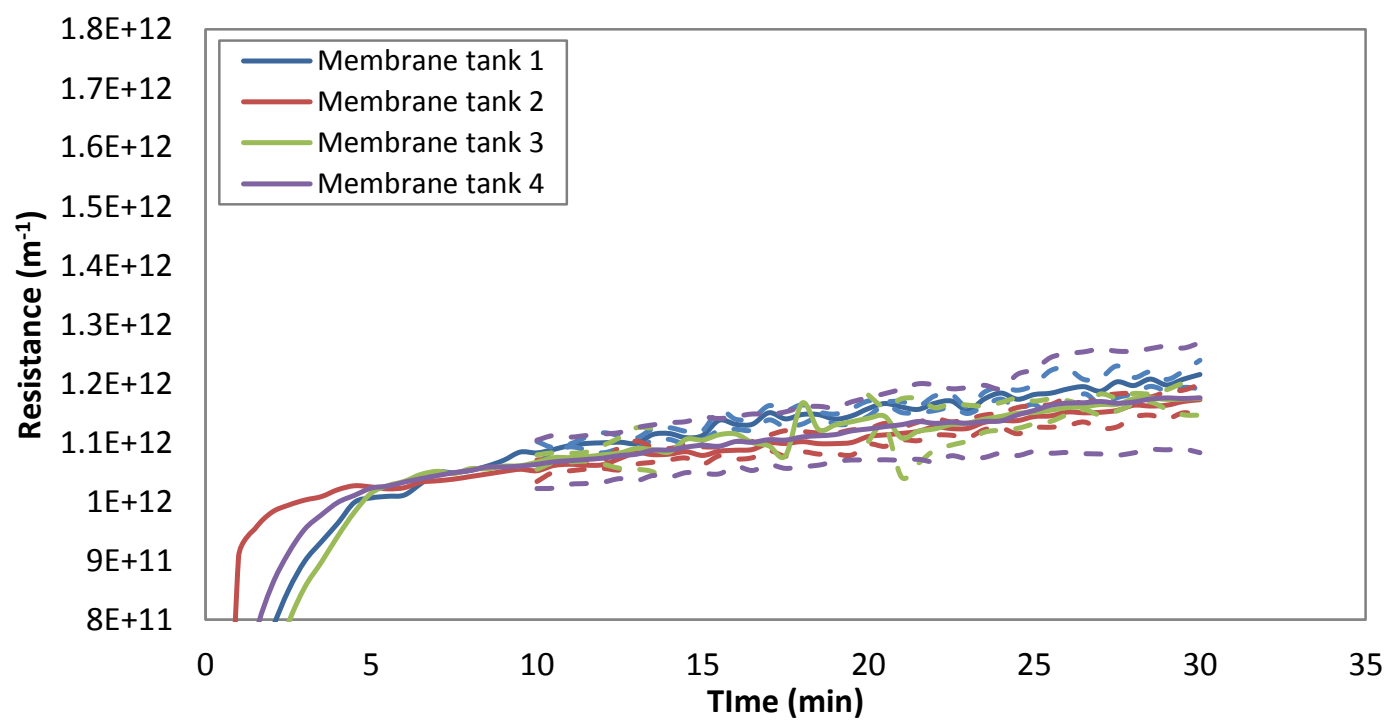

Figure 7.2: Resistance curves of filtration using the rubber backing fiber mounting method under the no shear stress condition in a $0.2 \mathrm{~g} / \mathrm{L}$ bentonite solution for the four membrane tanks (dash lines represent the $95 \%$ confidence interval for each membrane tanks at the 10-30 min filtration interval) 
Table 7.3: Fouling rates $\left(\times 10^{9} \mathrm{~m}^{-1} / \mathrm{min}\right)$ of filtration using the stainless steel holder and rubber backing fiber mounting methods under the no shear stress condition in a $0.2 \mathrm{~g} / \mathrm{L}$ bentonite solution

\begin{tabular}{|c|c|c|c|c|c|c|}
\hline & \multicolumn{3}{|c|}{ Stainless steel holder $\left(\times 10^{9} \mathrm{~m}^{-1} / \mathrm{min}\right)$} & \multicolumn{3}{|c|}{ Rubber backing $\left(\times 10^{9} \mathrm{~m}^{-1} / \mathrm{min}\right)$} \\
\hline & $\begin{array}{c}\text { Fouling } \\
\text { rate }\end{array}$ & Mean & $\begin{array}{l}\text { Standard } \\
\text { deviation }\end{array}$ & $\begin{array}{c}\text { Fouling } \\
\text { rate }\end{array}$ & Mean & $\begin{array}{l}\text { Standard } \\
\text { deviation }\end{array}$ \\
\hline \multirow{3}{*}{ Membrane tank 1} & 4.74 & \multirow{3}{*}{5.14} & \multirow{3}{*}{2.39} & 6.68 & \multirow{3}{*}{6.20} & \multirow{3}{*}{0.461} \\
\hline & 2.97 & & & 5.76 & & \\
\hline & 7.70 & & & 6.18 & & \\
\hline \multirow{3}{*}{ Membrane tank 2} & 7.02 & \multirow{3}{*}{5.87} & \multirow{3}{*}{1.89} & 6.52 & \multirow{3}{*}{5.77} & \multirow{3}{*}{0.825} \\
\hline & 3.69 & & & 4.88 & & \\
\hline & 6.90 & & & 5.89 & & \\
\hline \multirow{3}{*}{ Membrane tank 3} & 5.93 & \multirow{3}{*}{5.61} & \multirow{3}{*}{2.43} & 4.33 & \multirow{3}{*}{5.55} & \multirow{3}{*}{1.24} \\
\hline & 3.03 & & & 6.81 & & \\
\hline & 7.85 & & & 5.50 & & \\
\hline \multirow{3}{*}{ Membrane tank 4} & 3.51 & \multirow{3}{*}{4.81} & \multirow{3}{*}{1.27} & 4.60 & \multirow{3}{*}{5.90} & \multirow{3}{*}{4.04} \\
\hline & 6.05 & & & 2.67 & & \\
\hline & 4.86 & & & 10.4 & & \\
\hline
\end{tabular}

Table 7.4: ANOVA results of the stainless steel holder and the rubber backing fiber mounting methods comparison experiment at 95\% confidence interval $(\alpha=0.05)$

\begin{tabular}{|l|c|c|}
\hline \multicolumn{1}{|c|}{ Factor } & F-value & P-value \\
\hline Membrane tank & 0.05 & 0.98 \\
\hline Fiber mounting method & 0.33 & 0.57 \\
\hline Interaction & 0.15 & 0.93 \\
\hline
\end{tabular}

\subsubsection{Conclusion}

There was no statistically significant difference in membrane fouling when using the stainless steel holder and rubber backing fiber mounting methods for filtration under the no shear condition in a $0.2 \mathrm{~g} / \mathrm{L}$ bentonite solution. Fouling rates in a $0.2 \mathrm{~g} / \mathrm{L}$ bentonite solution were the same for the four membrane tanks that operated in parallel, indicating that the performance of the four membrane tanks was consistent.

Filtration with shear applied had better fouling control than filtration without shear. The high peak shear condition had the best fouling control compared to the other shear stress conditions. Results showed that the modified system was able to produce shear conditions that were similar to the original design in Chan et al., 2011.

Table 7.5: Fouling rates $\left(\times 10^{10} \mathrm{~m}^{-1} / \mathrm{min}\right)$ of filtration using the stainless steel holder fiber mounting methods under different shear stress conditions in a $0.2 \mathrm{~g} / \mathrm{L}$ bentonite solution at the 
60-80 min time interval (triplicate runs were performed for each shear stress condition and the fouling rates of triplicate runs for each shear stress condition are also shown in the table)

\begin{tabular}{|c|c|c|c|}
\hline $\begin{array}{l}\text { Shear Stress } \\
\text { Condition }\end{array}$ & $\begin{array}{c}\text { Fouling Rate } \\
\left(\times 10^{10} \mathrm{~m}^{-1} / \mathrm{min}\right)\end{array}$ & $\begin{array}{c}\text { Mean } \\
\left(\times 10^{10} \mathrm{~m}^{-1} / \mathrm{min}\right)\end{array}$ & $\begin{array}{l}\text { Standard Deviation } \\
\left.\qquad \times \mathbf{1 0}^{10} \mathrm{~m}^{-1} / \mathrm{min}\right)\end{array}$ \\
\hline \multirow{3}{*}{ No shear } & 1.78 & \multirow{3}{*}{1.74} & \multirow{3}{*}{0.141} \\
\hline & 1.59 & & \\
\hline & 1.86 & & \\
\hline \multirow{3}{*}{ High Peak } & 0.408 & \multirow{3}{*}{0.425} & \multirow{3}{*}{0.028} \\
\hline & 0.457 & & \\
\hline & 0.408 & & \\
\hline \multirow{3}{*}{ Low Peak } & 0.787 & \multirow{3}{*}{1.08} & \multirow{3}{*}{0.371} \\
\hline & 1.5 & & \\
\hline & 0.962 & & \\
\hline \multirow{3}{*}{ Sustained Peak } & 1.04 & \multirow{3}{*}{0.979} & \multirow{3}{*}{0.061} \\
\hline & 0.922 & & \\
\hline & 0.970 & & \\
\hline
\end{tabular}

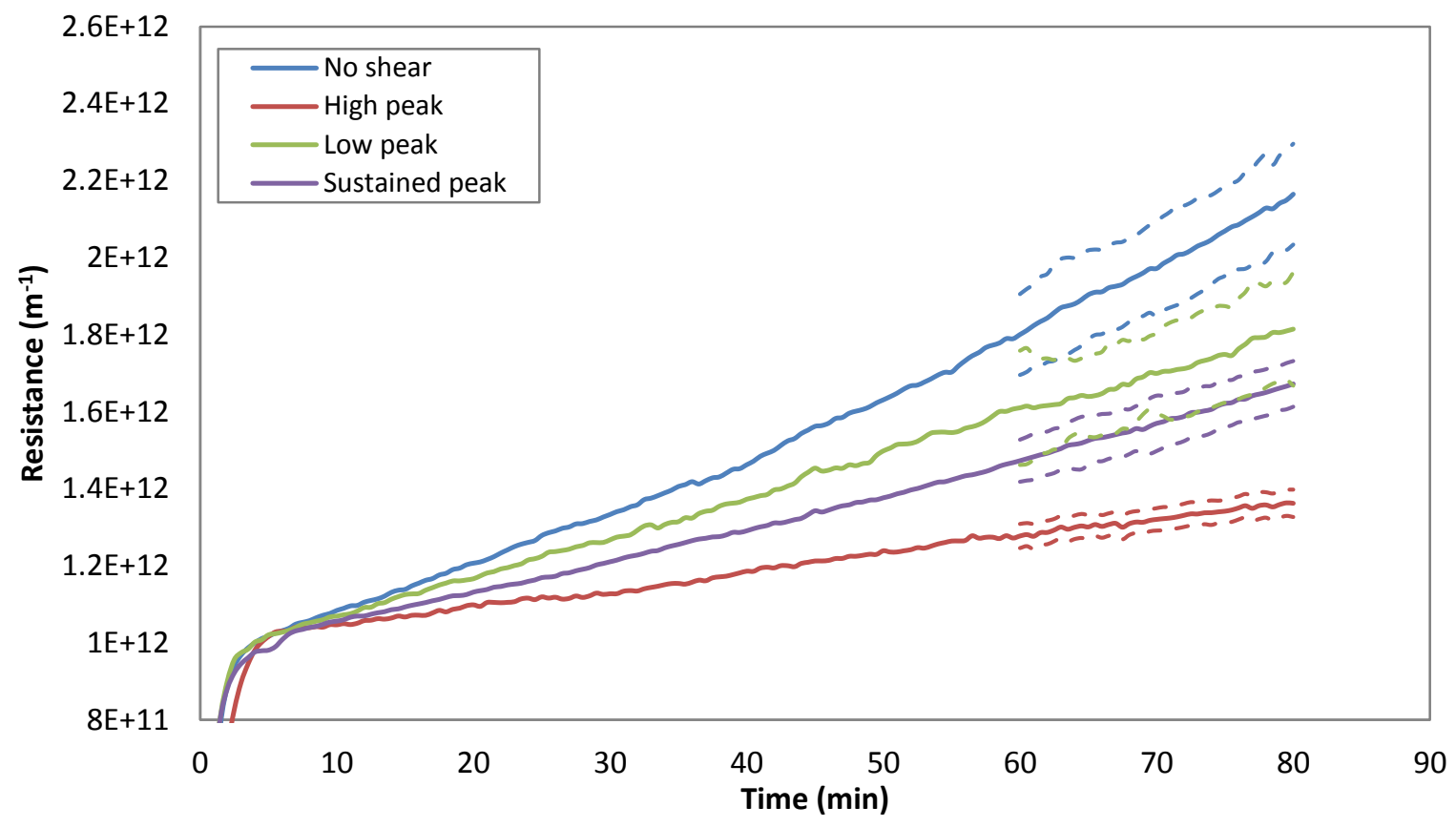

Figure 7.3: Resistance curves of filtration using the stainless steel fiber holder method under different shear stress conditions in a $0.2 \mathrm{~g} / \mathrm{L}$ bentonite solution (dash lines represent the $95 \%$ confidence interval at the 70-80 min filtration interval) 


\subsection{Flow Rate Adjustment}

The hollow fiber UF membrane used in Chan et al., 2011 was $20 \mathrm{~cm}$ long and was attached to a piece of rubber backing using epoxy. Approximately $40 \%$ of the fiber surface area was covered by epoxy and the available permeation area was estimated to be $600 \mathrm{~mm}^{2}$. In the current study, a $25 \mathrm{~cm}$-long stainless steel holder was installed in the interior wall of the membrane tank and was used as the new fiber mounting method. The hollow fiber UF membrane was also $25 \mathrm{~cm}$ long and all surface area was permeable. This resulted in a total permeable area of approximately $1250 \mathrm{~mm}^{2}$. In Chan et al., 2011, a volumetric flow rate of $0.5 \mathrm{~mL} / \mathrm{min}$ was applied to achieve a permeate flux of $50 \mathrm{~L} / \mathrm{m}^{2} / \mathrm{h}$. With the increase in permeation area, the volumetric flow rate was adjusted to $1 \mathrm{~mL} / \mathrm{min}$ to achieve the same permeate flux of $50 \mathrm{~L} / \mathrm{m}^{2} / \mathrm{h}$ :

$$
\begin{aligned}
\text { new flow rate }(\mathrm{mL} / \mathrm{min}) & =1250 \mathrm{~mm}^{2} \times 50 \frac{\mathrm{L}}{\mathrm{m}^{2} \mathrm{~h}} \times \frac{1000 \mathrm{~mL}}{1 \mathrm{~L}} \times \frac{1 \mathrm{~m}^{2}}{10^{6} \mathrm{~mm}^{2}} \times \frac{1 \mathrm{~h}}{60 \mathrm{~min}} \\
& =1.0 \mathrm{~mL} / \mathrm{min}
\end{aligned}
$$

\subsection{ANOVA Results of all experiments using natural water matrices}

ANOVA was performed at $95 \%$ confidence interval; $p$-values should be $<0.05$ for the data sets to be considered as statistically significant.

Table 7.6: Three-way ANOVA results for the experiments

\begin{tabular}{|c|c|c|}
\hline Factor & F-value & P-value \\
\hline Effect of water matrix & 115.66 & $<\mathbf{0 . 0 0 0 1}$ \\
\hline Effect of shear condition & 55.02 & $<\mathbf{0 . 0 0 0 1}$ \\
\hline Effect of backwash frequency & 24.88 & $<\mathbf{0 . 0 0 0 1}$ \\
\hline $\begin{array}{c}\text { Interaction between water matrix and } \\
\text { shear condition }\end{array}$ & 17.24 & $<\mathbf{0 . 0 0 0 1}$ \\
\hline $\begin{array}{c}\text { Interaction between water matrix and } \\
\text { backwash frequency }\end{array}$ & 9.62 & $\mathbf{0 . 0 0 0 6}$ \\
\hline $\begin{array}{c}\text { Interaction between shear condition } \\
\text { and backwash frequency }\end{array}$ & 5.59 & $\mathbf{0 . 0 0 0 5}$ \\
\hline
\end{tabular}

ANOVA analysis was performed at $95 \%$ confidence interval; bold font indicates a significant difference at $\alpha=0.05$ 
Table 7.7: Two-way ANOVA results for the experiments in Otonabee River water

\begin{tabular}{|c|c|c|}
\hline Factor & F-value & P-value \\
\hline Effect of shear condition & 37.10 & $<\mathbf{0 . 0 0 0 1}$ \\
\hline Effect of backwash frequency & 33.21 & $<\mathbf{0 . 0 0 0 1}$ \\
\hline $\begin{array}{c}\text { Interaction between shear } \\
\text { condition and backwash frequency }\end{array}$ & 5.87 & $\mathbf{0 . 0 0 4 6}$ \\
\hline
\end{tabular}

ANOVA analysis was performed at $95 \%$ confidence interval; bold font indicates a significant difference at $\alpha=0.05$

Table 7.8: One-way ANOVA comparing irreversible fouling rates at different backwash frequencies with the same shear stress conditions for experiments in Otonabee River water

\begin{tabular}{|c|c|c|}
\hline Shear condition & F-value & P-value \\
\hline No shear & 30.48 & $\mathbf{0 . 0 1 0}$ \\
\hline Low peak & 22.42 & $\mathbf{0 . 0 1 6}$ \\
\hline Sustained peak & 2.21 & 0.26 \\
\hline High peak & 1.90 & 0.29 \\
\hline
\end{tabular}

ANOVA analysis was performed at $95 \%$ confidence interval; bold font indicates a significant difference at $\alpha=0.05$

Table 7.9: One-way ANOVA comparing irreversible fouling rates at different shear stress conditions with the same backwash frequency for experiments in Otonabee River water

\begin{tabular}{|c|c|c|}
\hline Backwash frequency $(\mathbf{h})$ & F-value & P-value \\
\hline 0.5 & 30.08 & $\mathbf{0 . 0 0 3}$ \\
\hline 2 & 9.66 & $\mathbf{0 . 0 2 6}$ \\
\hline 6 & 16.21 & $\mathbf{0 . 0 1 1}$ \\
\hline
\end{tabular}

ANOVA analysis was performed at $95 \%$ confidence interval; bold font indicates a significant difference at $\alpha=$ 0.05

Table 7.10: Two-way ANOVA results for the experiments in Lake Simcoe water

\begin{tabular}{|c|c|c|}
\hline Factor & F-value & P-value \\
\hline Effect of shear condition & 48.50 & $<\mathbf{0 . 0 0 0 1}$ \\
\hline Effect of backwash frequency & 21.04 & $\mathbf{0 . 0 0 0 1}$ \\
\hline $\begin{array}{c}\text { Interaction between shear condition } \\
\text { and backwash frequency }\end{array}$ & 4.77 & $\mathbf{0 . 0 1 0 4}$ \\
\hline
\end{tabular}

ANOVA analysis was performed at $95 \%$ confidence interval; bold font indicates a significant difference at $\alpha=0.05$ 
Table 7.11: One-way ANOVA comparing irreversible fouling rates at different backwash frequencies with the same shear stress conditions for experiments in Lake Simcoe water

\begin{tabular}{|c|c|c|}
\hline Shear condition & F-value & P-value \\
\hline No shear & 189.73 & $\mathbf{0 . 0 0 0 7}$ \\
\hline Low peak & 6.62 & 0.079 \\
\hline Sustained peak & 2.03 & 0.28 \\
\hline High peak & 0.13 & 0.89 \\
\hline
\end{tabular}

ANOVA analysis was performed at $95 \%$ confidence interval; bold font indicates a significant difference at $\alpha$ $=0.05$

Table 7.12: One-way ANOVA comparing irreversible fouling rates at different shear stress conditions with the same backwash frequency for experiments in Lake Simcoe water

\begin{tabular}{|c|c|c|}
\hline Backwash frequency (h) & F-value & P-value \\
\hline 0.5 & 4.78 & 0.082 \\
\hline 2 & 9.39 & $\mathbf{0 . 0 2 8}$ \\
\hline 6 & 362.68 & $<\mathbf{0 . 0 0 0 1}$ \\
\hline
\end{tabular}

ANOVA analysis was performed at $95 \%$ confidence interval; bold font indicates a significant difference at $\alpha=$ 0.05

\subsection{Sample Calculation for Tukey's HSD Test}

Tukey's HSD test was performed for data sets that were identified as significantly different by one-way ANOVA using the method described in Section 3.6.1. Irreversible fouling rates of experiments associated with the $6 \mathrm{~h}$-backwash frequency using Lake Simcoe water were used as an example in this sample calculation:

$$
H S D=Q_{[\alpha, k, f]} \sqrt{\frac{M S E}{n}}
$$

where $Q=$ the studentized range critical value

$\alpha=0.05$ (at $95 \%$ confidence interval)

$\mathrm{k}=$ number of factor levels (4)

$\mathrm{f}=$ degrees of freedom for error (4)

$\mathrm{n}=$ number of replicates in means (2)

$\mathrm{MSE}=$ mean squared error 
The MSE was obtained from the one-way ANOVA using Design Expert, which was $1.08 \times 10^{10}$. In Design Expert, MSE is calculated as follow:

$$
M S E=\frac{\sum_{i=1}^{k} \sum_{t=1}^{n i}\left(y_{i t}-\bar{y}_{l}\right)^{2}}{k(n-1)}
$$

where $\mathrm{y}=$ response variable (irreversible fouling rate)

$\mathrm{k}=$ number of factor levels (4)

$\mathrm{n}=$ number of replicates in means (2)

$\mathrm{i}=$ level of treatment factor (1-4)

$\mathrm{t}=$ replicate number $(1-2)$

For irreversible fouling rates in Lake Simcoe water at different shear stress conditions and 6-h backwash frequency, HSD was calculated as:

$$
H S D=Q_{[0.05,4,4]} \sqrt{\frac{M S E}{n}}=5.76 \times \sqrt{\frac{6.9731 \times 10^{18}}{2}}=1.08 \times 10^{10}
$$

Tukey's HSD results for the experiments are presented in Tables 7.13-7.19.

Table 7.13: Tukey's HSD table $\left(\times 10^{7}\right)$ for irreversible fouling rates at 0.5 -h backwash frequency in Otonabee River water

\begin{tabular}{|c|r|r|r|r|}
\hline Shear condition & High peak & Sustained peak & Low peak & No shear \\
\hline No shear & $\mathbf{7 . 4 9}$ & $\mathbf{7 . 1 5}$ & 0.087 & \\
\hline Low peak & $\mathbf{7 . 4 0}$ & $\mathbf{7 . 0 6}$ & & \\
\hline Sustained peak & 0.34 & & & \\
\hline
\end{tabular}

Tukey's HSD $=4.41 \times 10^{7}$ 
Table 7.14: Tukey's HSD table $\left(\times 10^{8}\right)$ for irreversible fouling rates at 6 -h backwash frequency in Otonabee River water

\begin{tabular}{|c|r|r|r|r|}
\hline Shear condition & High peak & Sustained peak & Low peak & No shear \\
\hline No shear & $\mathbf{2 . 1 8}$ & $\mathbf{1 . 8 5}$ & 1.14 & \\
\hline Low peak & 1.04 & 0.71 & & \\
\hline Sustained peak & 0.33 & & & \\
\hline
\end{tabular}

Tukey's HSD $=1.38 \times 10^{8}$

Table 7.15: Tukey's HSD table $\left(\times 10^{8}\right)$ for irreversible fouling rates under no shear condition in Otonabee River water

\begin{tabular}{|c|r|r|r|}
\hline Backwash frequency & \multicolumn{1}{|c|}{$0.5 \mathrm{~h}$} & $2 \mathrm{~h}$ & $6 \mathrm{~h}$ \\
\hline $6 \mathrm{~h}$ & 1.76 & 1.72 & \\
\hline $2 \mathrm{~h}$ & 0.035 & & \\
\hline
\end{tabular}

Tukey's HSD $=1.08 \times 10^{8}$

Table 7.16: Tukey's HSD table $\left(\times 10^{7}\right)$ for irreversible fouling rates under low peak shear condition in Otonabee River water

\begin{tabular}{|c|r|c|c|}
\hline Backwash frequency & $0.5 \mathrm{~h}$ & $2 \mathrm{~h}$ & $6 \mathrm{~h}$ \\
\hline $6 \mathrm{~h}$ & 6.26 & 6.01 & \\
\hline $2 \mathrm{~h}$ & 0.25 & & \\
\hline
\end{tabular}

Tukey’s HSD $=4.43 \times 10^{7}$

Table 7.17: Tukey's HSD table $\left(\times 10^{8}\right)$ for irreversible fouling rates at 2 -h backwash frequency in Lake Simcoe water

\begin{tabular}{|c|r|r|r|r|}
\hline Shear condition & High peak & Sustained peak & Low peak & No shear \\
\hline No shear & $\mathbf{4 . 4 9}$ & 2.64 & 1.96 & \\
\hline Low peak & 2.53 & 0.68 & & \\
\hline Sustained peak & 1.85 & & & \\
\hline
\end{tabular}

Tukey's HSD $=3.49 \times 10^{8}$

Table 7.18: Tukey's HSD table $\left(\times 10^{7}\right)$ for irreversible fouling rates at 6 -h backwash frequency in Lake Simcoe water

\begin{tabular}{|c|r|r|r|r|}
\hline Shear condition & High peak & Sustained peak & Low peak & No shear \\
\hline No shear & $\mathbf{5 7 . 2}$ & $\mathbf{4 5 . 4}$ & $\mathbf{4 5 . 0}$ & \\
\hline Low peak & $\mathbf{1 2 . 2}$ & 0.38 & & \\
\hline Sustained peak & $\mathbf{1 1 . 8}$ & & & \\
\hline
\end{tabular}

Tukey's HSD $=7.63 \times 10^{7}$ 
Table 7.19: Tukey's HSD table $\left(\times 10^{7}\right)$ for irreversible fouling rates under no shear condition in Lake Simcoe water

\begin{tabular}{|c|c|c|c|}
\hline Backwash frequency & $0.5 \mathrm{~h}$ & $2 \mathrm{~h}$ & $6 \mathrm{~h}$ \\
\hline $6 \mathrm{~h}$ & 40.5 & 13.7 & \\
\hline $2 \mathrm{~h}$ & 26.8 & & \\
\hline
\end{tabular}

Tukey's HSD $=8.84 \times 10^{7}$

\subsection{Cost Estimation Procedure}

Cost savings for each experimental condition were scaled up to a membrane train per year (29MLD with permeable area of $24000 \mathrm{~m}^{2} /$ train). Costs were divided into operating and membrane replacement costs. Operating costs were further grouped into energy costs associated with permeation, backwash and air sparging. Values used in the calculation are presented in Table 3.3. Irreversible fouling was plotted against total filtration time for the costs calculation (Figures 7.5-7.6).

Step 1 Determine the number of filtration-backwash cycles per day

Number of filtration-backwash cycles per day varied based on the backwash frequency:

$$
\text { number of cycle per day }=\frac{1}{\text { permeation duration }+ \text { backwash duration }}
$$

where permeation and backwash durations were in days.

\section{Step 2 Determine annual permeation energy consumption}

Assumptions:

1. Rate of total resistance increase was linear and constant for every cycle

2. Irreversible fouling rate was linear

3. Reversible fouling was constant for every cycle

4. $75 \mathrm{~kW} /$ train permeation power consumption (Table 3.3) was the energy required for permeation when the membrane was clean

5. $60 \%$ pump efficiency 
(a)

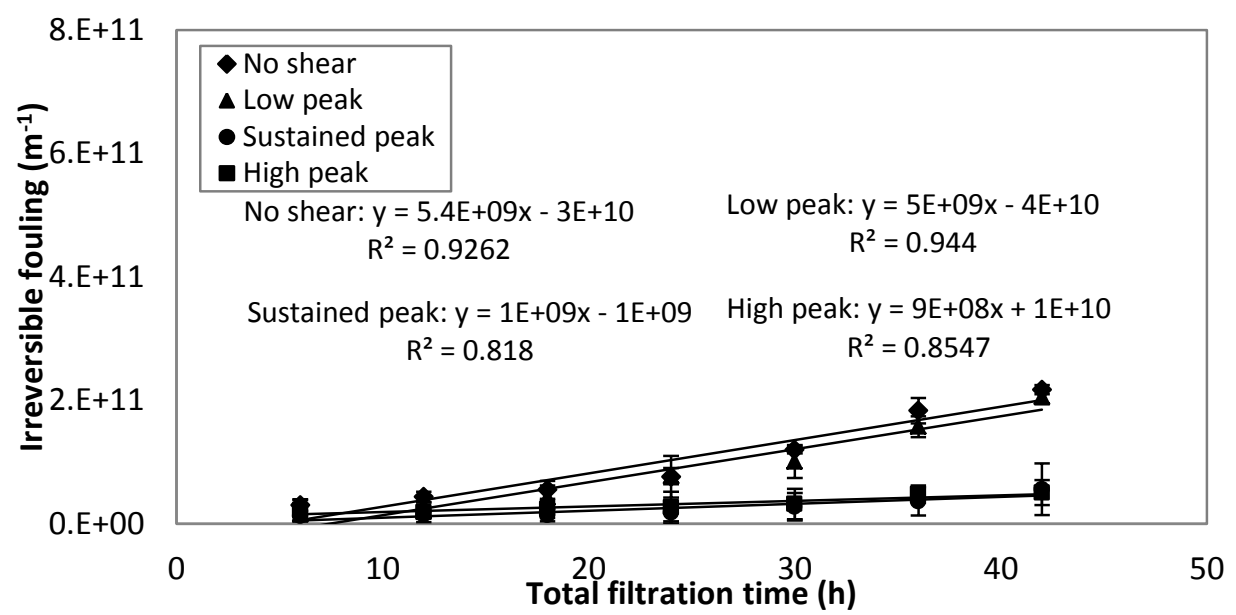

(b)

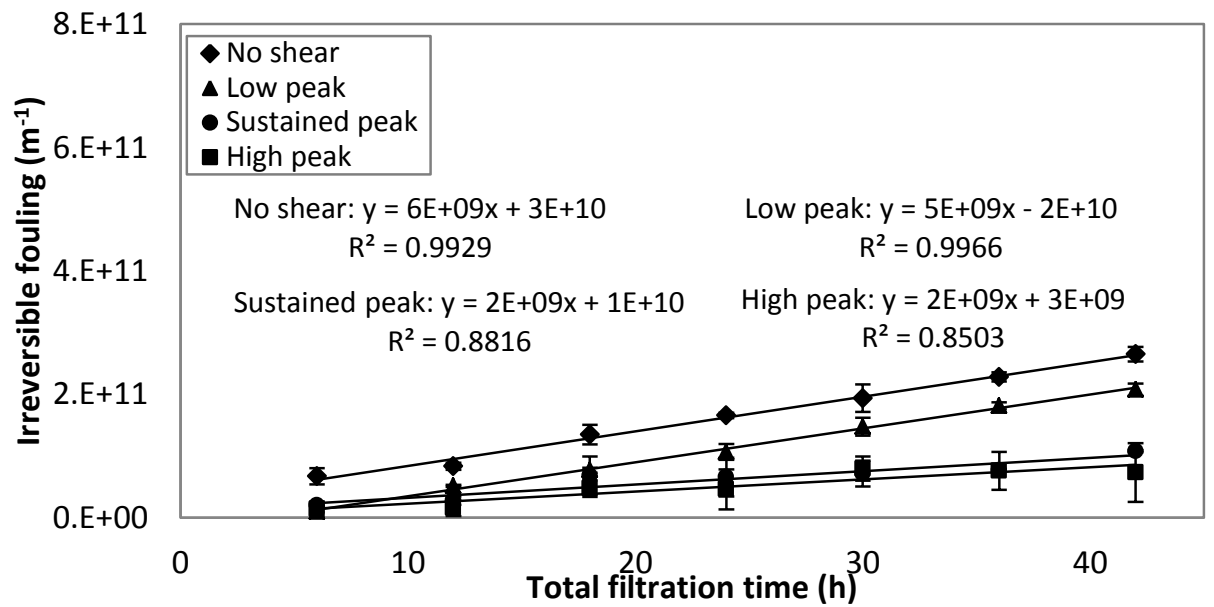

(c)

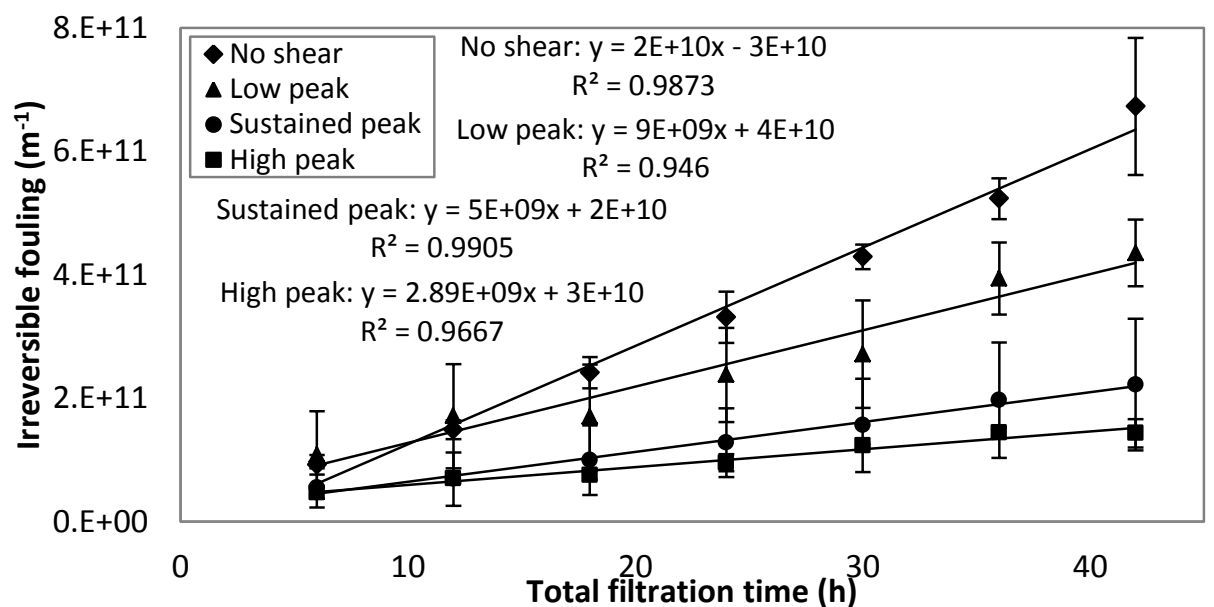

Figure 7.4: Impact of backwash frequency and shear stress condition on irreversible fouling during ultrafiltration of Otonabee River water with respect to total filtration time. (a) $0.5 \mathrm{~h}$, (b) 2 $\mathrm{h}$, and (c) $6 \mathrm{~h}$ (data represents average values of duplicate runs for each condition, vertical bars represent maximum and minimum values observed) 
(a)

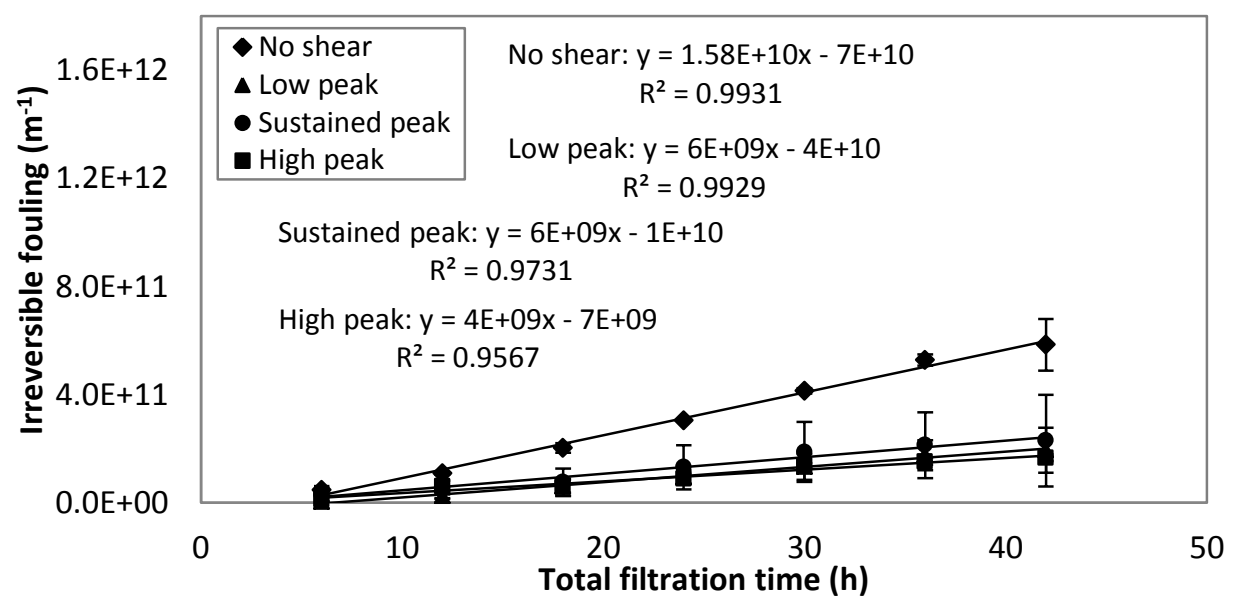

(b)

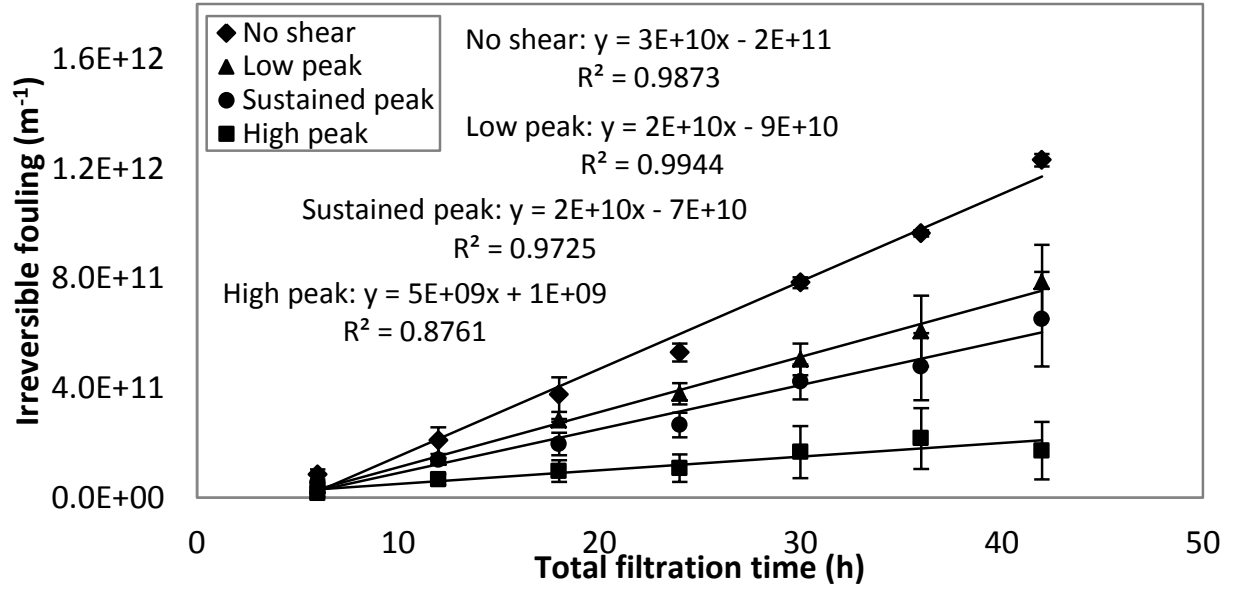

(c)

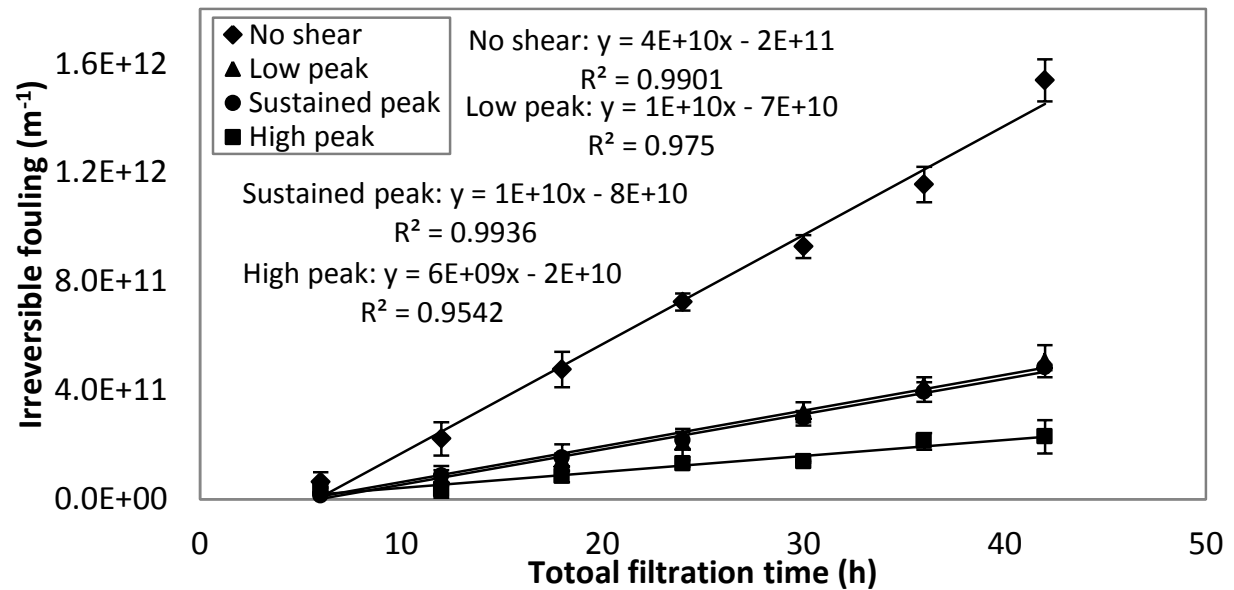

Figure 7.5: Impact of backwash frequency and shear stress condition on irreversible fouling during ultrafiltration of Lake Simcoe water with respect to total filtration time. (a) $0.5 \mathrm{~h}$, (b) $2 \mathrm{~h}$, and (c) $6 \mathrm{~h}$ (data represents average values of duplicate runs for each condition, vertical bars represent maximum and minimum values observed) 
Pumping power increases as the TMP increased due to fouling. Extra power requirement and change in TMP has the following relationship:

$$
\text { Power }=\frac{\triangle P Q}{\eta}
$$

where power is in $\mathrm{kW}, \Delta \mathrm{P}$ is the TMP $(\mathrm{kPa}), \mathrm{Q}$ is the volumetric flowrate $\left(\mathrm{m}^{3} / \mathrm{s}\right)$, and $\eta$ is the pump efficiency. Fouling was expressed in resistance $\left(\mathrm{m}^{-1}\right)$ in this study. TMP was then converted into resistance (R) using Equation 3.1 and scaled up to one membrane train. Figure 7.4 shows the relationship between additional power input and $\Delta \mathrm{R}$.

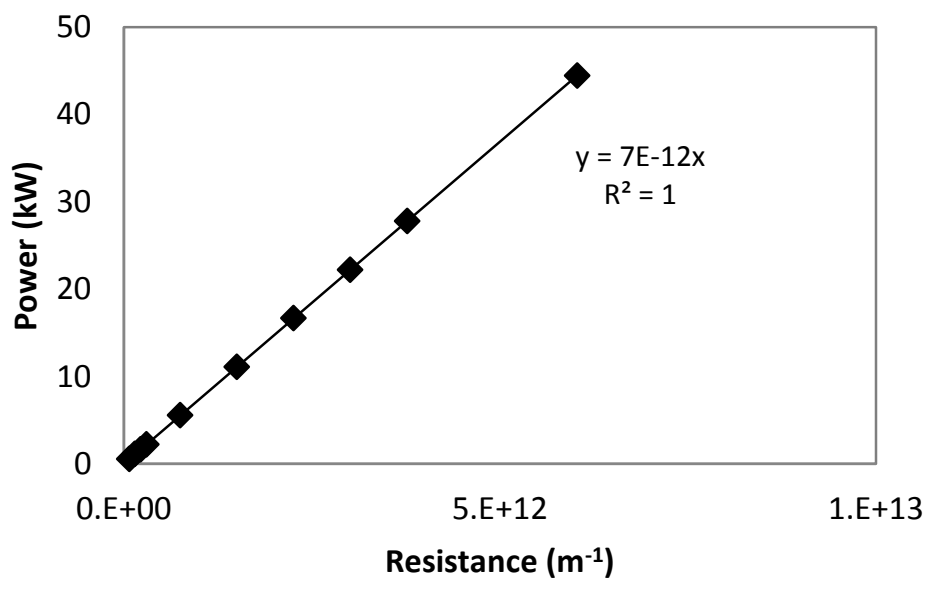

Figure 7.6: Relationship between additional power input and change in resistance

Since Power $=7 \times 10^{-12} \Delta \mathrm{R}$, and $\Delta \mathrm{R}$ was assumed to be linearly related to permeation time, additional power input due to fouling and permeation time had the following relationship:

$$
\text { Power }=7 \times 10^{-12} \times(\text { fouling rate }) \times t
$$

where $t$ is the permeation time $(\mathrm{h})$. Additional energy required per day to overcome the resistance increase due to fouling in order to maintain a constant flux of $50 \mathrm{~L} / \mathrm{m}^{2} \cdot \mathrm{h}$ was calculated in two parts:

1. Additional energy consumption (energy $y_{\text {irr }}$ ) due to irreversible fouling: it was calculated by integrating Equation 7.7 over permeation time per day (Equation 7.8). Irreversible fouling rate was calculated by linear regression (Figures 7.5-7.6). 


$$
\text { energy }_{\text {irr }}=\int 7 \times 10^{-12} \times(\text { irreversibile fouling rate }) \times t d t
$$

Example:

For filtration with $0.5 \mathrm{~h}$-backwash frequency under no air sparging condition in Lake Simcoe water, the irreversible fouling rate was $1.58 \times 10^{10} \mathrm{~m}^{-1} / \mathrm{h}$. After integration, Equation (7.8) became:

$$
\text { energy }_{\text {irr }}=0.0553 t^{2}
$$

Total permeation time, $\mathrm{t}=18 \mathrm{~h}$ :

$$
\text { energy }_{\text {irr }}=0.0553 \times 18^{2}=17.92 \mathrm{kWh} / \text { day }
$$

2. Additional energy consumption due to reversible fouling: this increase in energy was calculated by multiplying the difference between total fouling and irreversible fouling for each cycle by the number of cycles per day for a given filtration condition. Total fouling rate for each cycle was calculated as the average $\Delta \mathrm{R}$ of the filtration cycles in the first $24 \mathrm{~h}$ over filtration time of each cycle, since chemically enhanced backwash is to be performed every $24 \mathrm{~h}$.

\section{Example:}

For filtration with $0.5 \mathrm{~h}$-backwash frequency under the no air sparging condition in Lake Simcoe water (Figure 3.9) with the increase in resistance graph), the average increase in total resistance per filtration cycle for the first $24 \mathrm{~h}$ (i.e. the first 36 cycles) was $9.54 \times 10^{10} \mathrm{~m}^{-1}$. Total fouling rate was calculated as:

$$
\text { total fouling rate }=\frac{9.54 \times 10^{10} \mathrm{~m}^{-1}}{0.5 \mathrm{~h}}=1.91 \times 10^{11} \mathrm{~m}^{-1} / \mathrm{h}
$$

By applying integration of Equation 7.7 and subtract it by the additional energy required due to irreversible fouling per cycle, the additional energy required due to reversible fouling $\left(\right.$ energyr $_{\mathrm{ev}}$ ) per day was calculated as: 


$$
\begin{aligned}
\text { energy }_{\text {rev }} & =\int 7 \times 10^{-12} \times(\text { total fouling rate }- \text { irreversibile fouling rate }) t d t \\
\text { energy }_{\text {rev }} & =\int 7 \times 10^{-12} \times\left(1.91 \times 10^{11}-1.58 \times 10^{10}\right) t d t \\
\text { energy }_{\text {rev }} & =0.61 t^{2}
\end{aligned}
$$

where $\mathrm{t}=0.5 \mathrm{~h}$ and there are 36 cycles per day for the operation with $0.5 \mathrm{~h}$-backwash frequency. Additional energy required due to reversible fouling was:

$$
\text { energy }_{\text {rev }}=0.61 \times(0.5)^{2} \times 36=5.49 \mathrm{kWh} / \text { day }
$$

Energy required per day for permeation at $50 \mathrm{~L} / \mathrm{m}^{2} / \mathrm{h}$ using clean membrane was calculated as:

$$
\text { energy }=75 \mathrm{~kW} \times \text { total permeation time }
$$

Example:

For the $0.5 \mathrm{~h}$-backwash frequency, total permeation time was $18 \mathrm{~h} / \mathrm{day}$ :

$$
\text { energy }=75 \mathrm{~kW} \times 18 \mathrm{~h} / \text { day }=1350 \mathrm{kWh} / \text { day }
$$

Total permeation energy required per year per train was the sum of energy required for permeation using the virgin membrane and the additional permeation energy required due to irreversible and reversible fouling. Example:

For the filtration with $0.5 \mathrm{~h}$-backwash frequency under the no air sparging condition in Lake Simcoe water:

$$
\begin{aligned}
\text { total permeation energy } & =(17.92+5.49+1350) \mathrm{kWh} / \text { day } \times 365 \text { days } \\
& =501295 \mathrm{kWh} / \text { year }
\end{aligned}
$$

\section{Step 3 Determine annual aeration energy consumption}

Power requirements for different air sparging conditions are listed in Table 3.3. Annual aeration energy consumption for a given air sparging condition was calculated as the product of aeration power requirement and total aeration duration per year. 
Step 4 Determine annual backwashing energy consumption

Power requirement for backwash is listed in Table 3.3. Annual backwashing energy consumption for a given backwash frequency was calculated as the product of backwashing power requirement and total backwashing duration per year.

\section{Step 5 Determine annual operating energy costs}

Cost of electricity was assumed to be $\$ 0.118 / \mathrm{kWh}$ (Table 3.3). Annual operating energy costs were calculated as the product of electricity cost and the sum of the annual permeation, aeration and backwashing energy consumption calculated in Steps 2-4.

Step 6 Determine the annual costs for membrane replacement

Membrane replacement costs were estimated based on value associated with the extended/shortened membrane life due to less/more frequent chemical cleans resulted from irreversible fouling reduction/increase, relative to the baseline case.

Assumptions:

1. Chemically enhanced backwash (CEB) was performed daily for $30 \mathrm{~min}$ for all conditions investigated in this study

2. Cleaning in place (CIP) frequency for the baseline case $(0.5 \mathrm{~h}$-backwash frequency with no air sparging during filtration) was 8.7 times/year and the duration was $6 \mathrm{~h}$ (Barrie Surface Water Treatment Plant, Ontario, Canada)

3. CEB used $100 \mathrm{mg} / \mathrm{L}$ (ppm) sodium hypochlorite and CIP used $500 \mathrm{mg} / \mathrm{L}$ (ppm) sodium hypochlorite and $200 \mathrm{mg} / \mathrm{L}(\mathrm{ppm})$ citric acid (Table 3.3)

4. Membrane would be replaced when chemical exposure reached 500,000 ppm·h (Cote et al., 2012)

CIP frequency was linearly extrapolated from baseline case into equivalent longer or shorter operating times between two CIP based on the irreversible fouling reduction or increase resulting from different air sparging conditions and backwash frequencies. Example:

For operation with 6 h-backwash frequency and high peak shear condition (i.e. large pulse bubble sparging) in Otonabee River water, the average irreversible fouling rate is $2.89 \times 10^{9}$ $\mathrm{m}^{-1} / \mathrm{h}$, and the baseline case in Otonabee River water has an average irreversible fouling rate of 
$5.4 \times 10^{9} \mathrm{~m}^{-1} / / \mathrm{h}$ (Figure 7.5). The CIP frequency for the $6 \mathrm{~h}$-backwash frequency with high peak shear condition was calculated as:

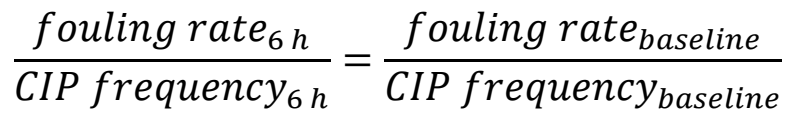

$$
\begin{aligned}
& \text { CIP frequency }_{6 h}=\frac{2.89 \times 10^{9} \mathrm{~m}^{-1} / \mathrm{h} \times 8.7 \text { times } / \text { year }}{5.4 \times 10^{9} \mathrm{~m}^{-1} / \mathrm{h}}=4.7 \text { times } / \text { year }
\end{aligned}
$$

Membrane life for the 6 h-backwash frequency with high peak shear condition was then calculated based on the amount of chemical exposure:

CIP chemical exposure

$=$ CIP frequency $\times$ CIP chemical concentration $\times$ CIP duration

$=4.7$ times $/$ year $\times(500+200) p p m \times 6 h$

$=19740 \mathrm{ppm} \cdot \mathrm{h} /$ year

CEB chemical exposure

$=C E B$ frequency $\times C E B$ chemical concentration $\times C E B$ duration

$=365$ times $/$ year $\times 100 \mathrm{ppm} \times 0.5 \mathrm{~h}$

$=18250 \mathrm{ppm} \cdot \mathrm{h} /$ year

membrane life $=\frac{500000 \mathrm{ppm} \cdot \mathrm{h}}{(19741+18250) \mathrm{ppm} \cdot \mathrm{h} / \text { year }}=13$ years

Annual membrane replacement costs was the costs for a membrane train (Table 3.3) averaged over the membrane life:

$$
\text { membrane replacement costs }=\frac{\$ 1428571}{13 \text { years }}=\$ 108091 / \text { year }
$$

Step 7 Determine the value of water produced per year

Cost of water was assumed to be $\$ 0.08 / \mathrm{m}^{3}$ (Table 3.3):

value of water $=\$ 0.08 / \mathrm{m}^{3} \times($ water permeated - water consumed during backwash $)$ 
Step 8 Calculate annual cost savings per membrane train

Annual cost savings were calculated using values obtained from Steps 5, 6 and 7:

cost savings $=$ value of water - operating energy costs - membrane replacement costs 


\subsection{Raw Experimental Data}

(a)

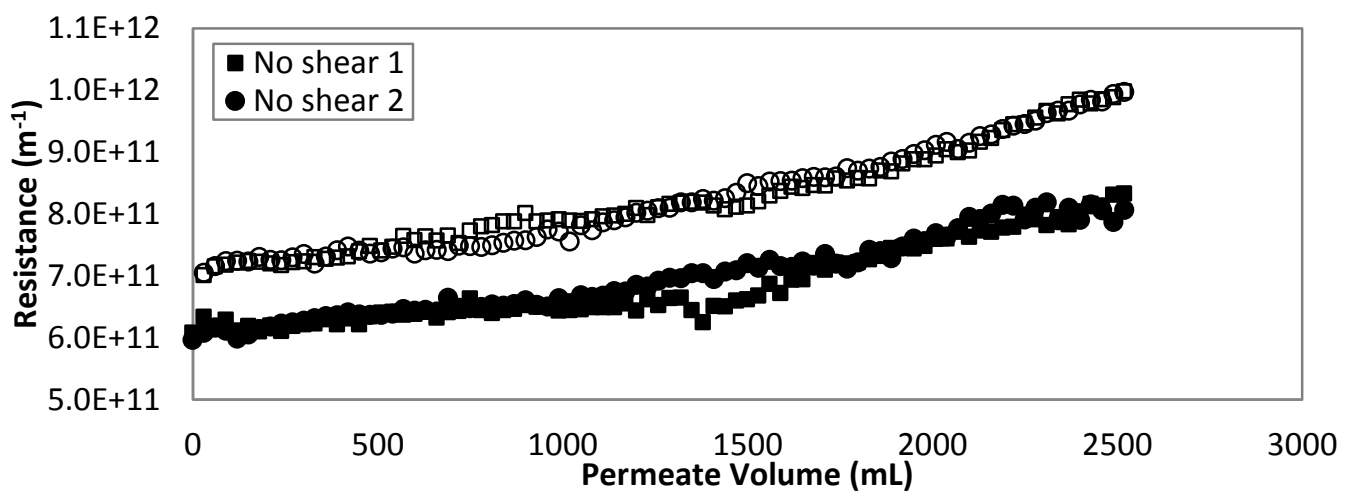

(b)

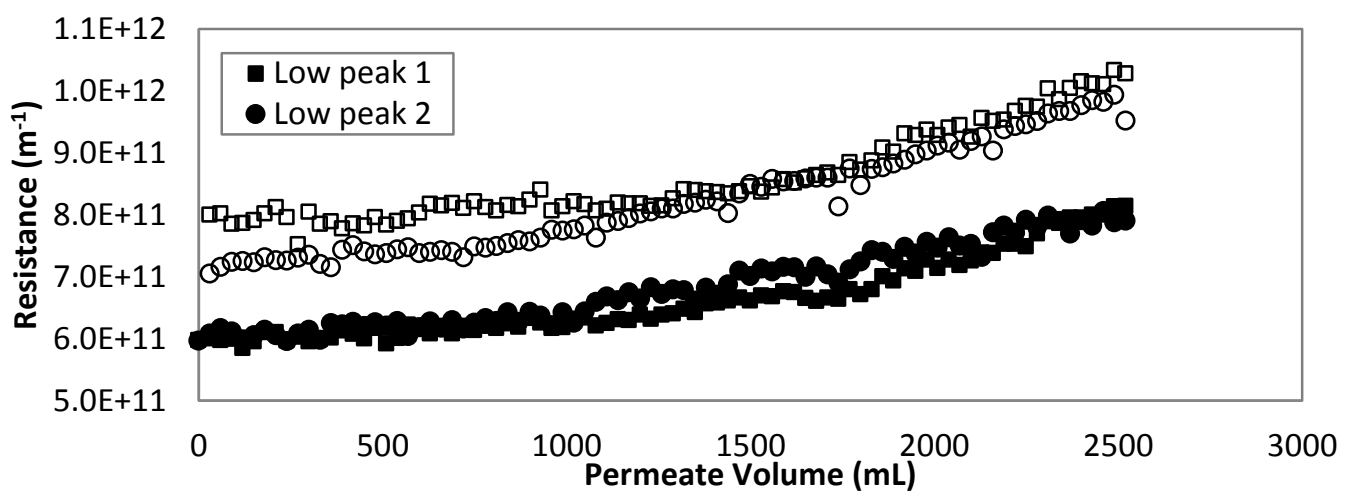

(c)

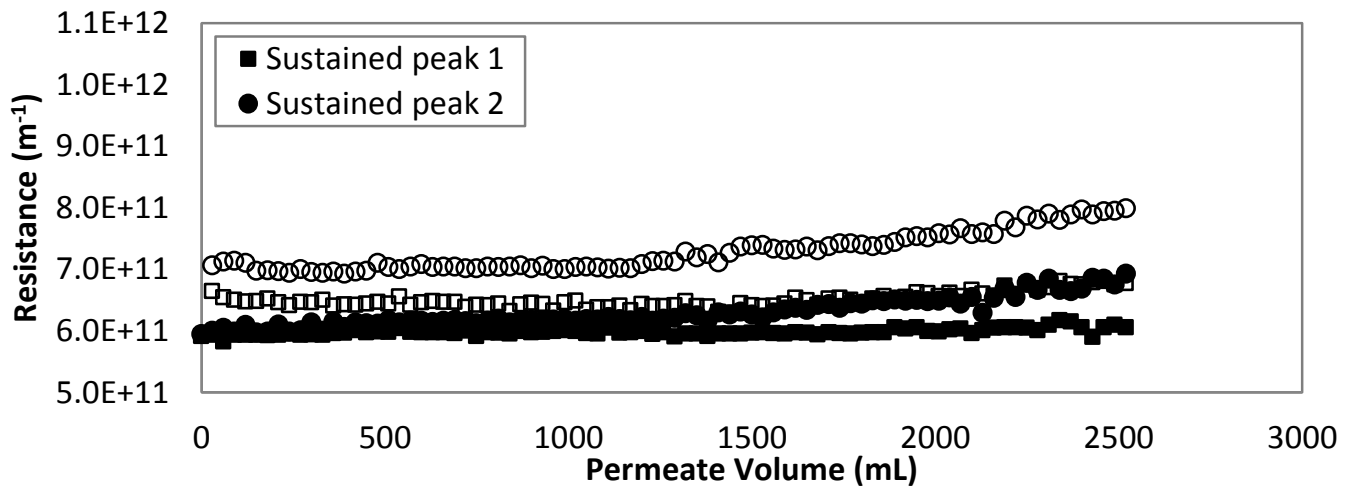


(d)

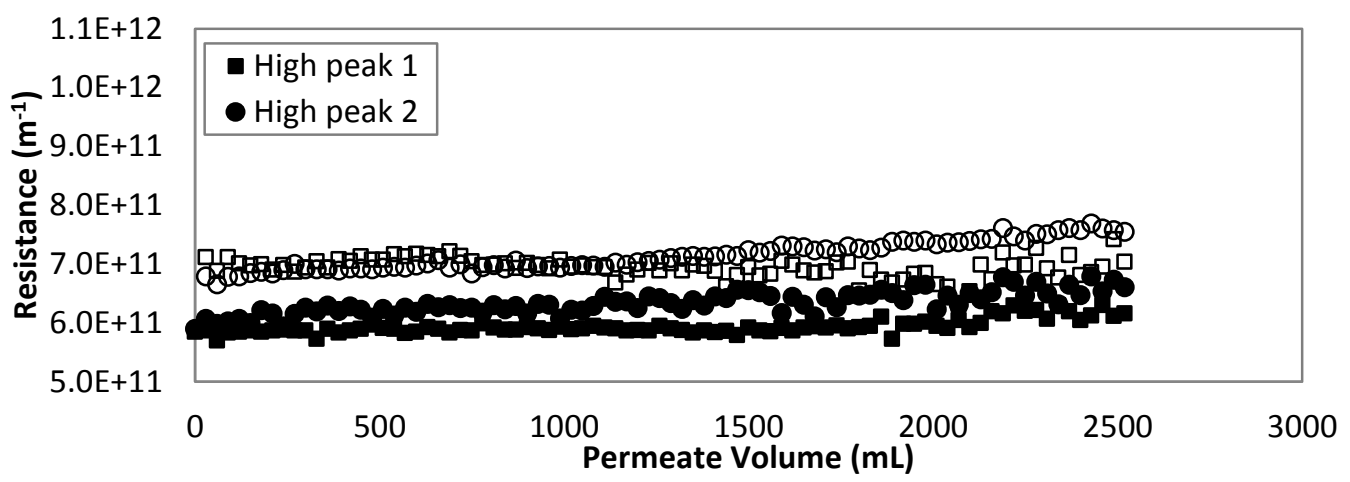

Figure 7.7: Resistance graphs showing the initial and final resistance of each cycle for experiments with the $0.5 \mathrm{~h}$-backwash frequency in Otonabee River water. Solid markers are the initial resistance and hollow markers are the final resistance. Data shows duplicate runs for each shear condition. (a) no shear, (b) low peak, (c) sustained peak, (d) high peak 
(a)

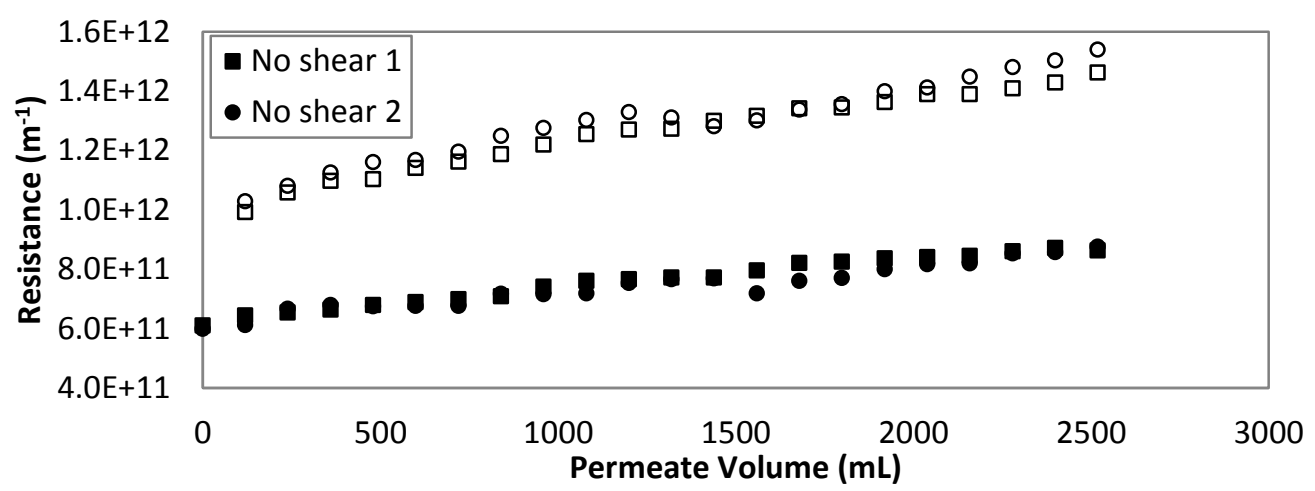

(b)

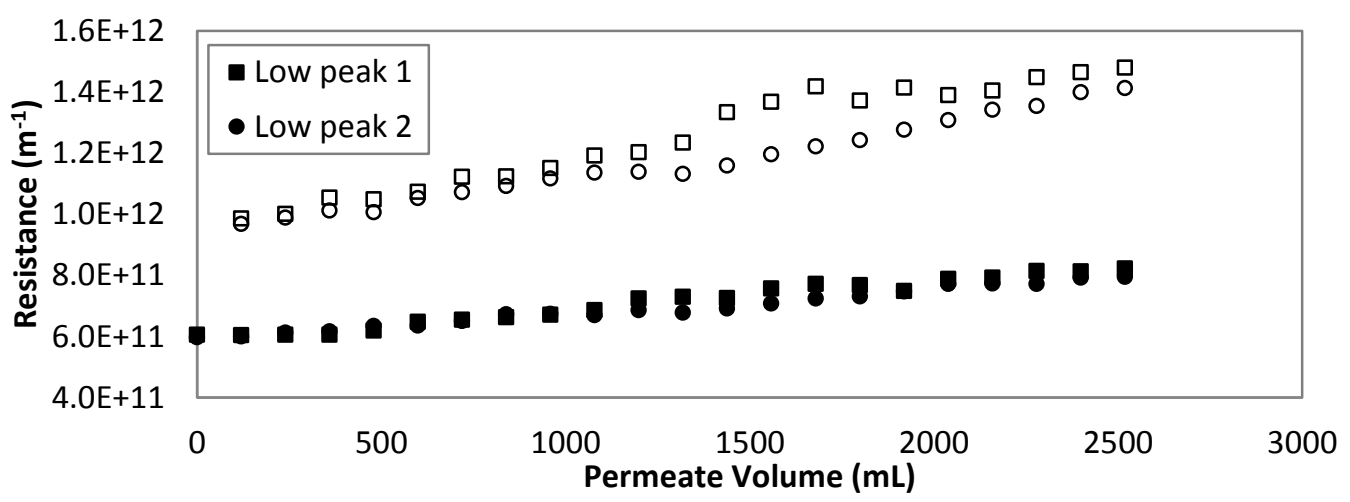

(c)

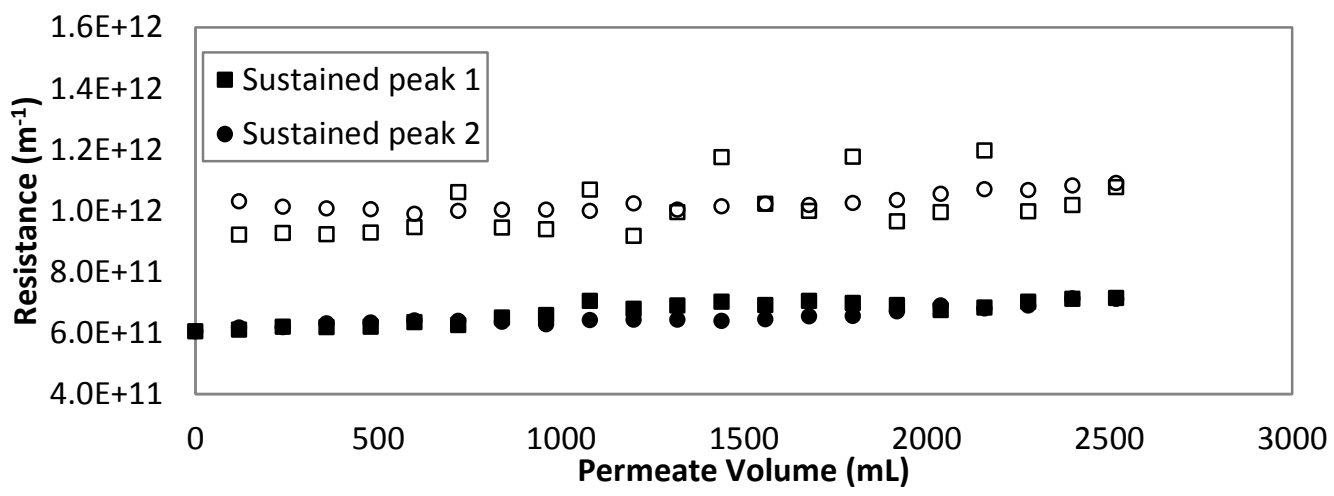


(d)

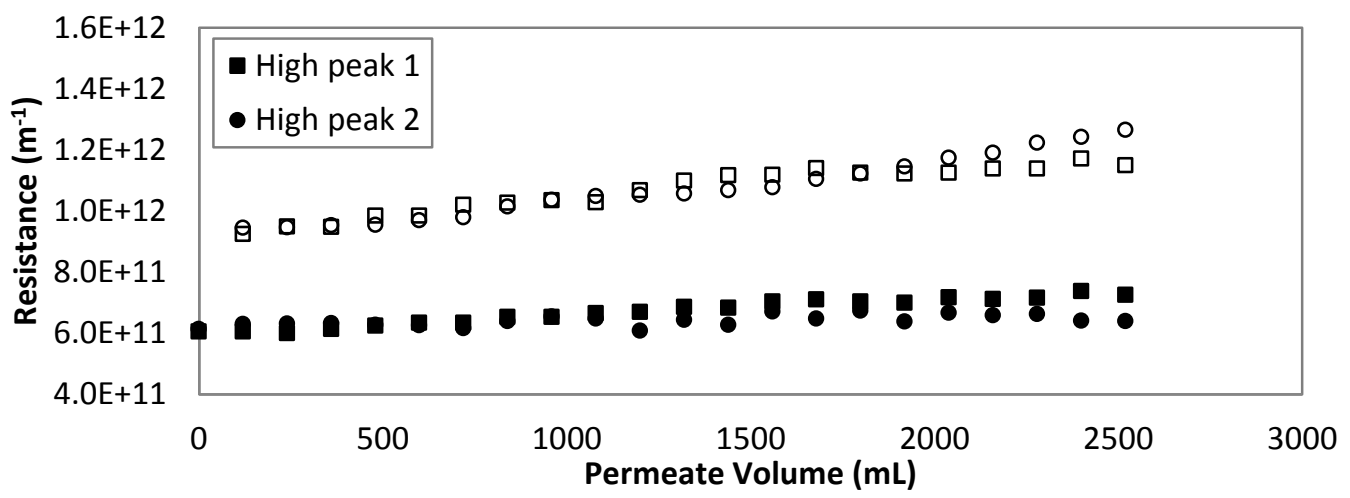

Figure 7.8: Resistance curves showing the initial and final resistance of each cycle for experiments with the $2 \mathrm{~h}$-backwash frequency in Otonabee River water. Solid markers are the initial resistance and hollow markers are the final resistance. Data represents duplicate runs for each shear condition. (a) no shear, (b) low peak, (c) sustained peak, (d) high peak 
(a)

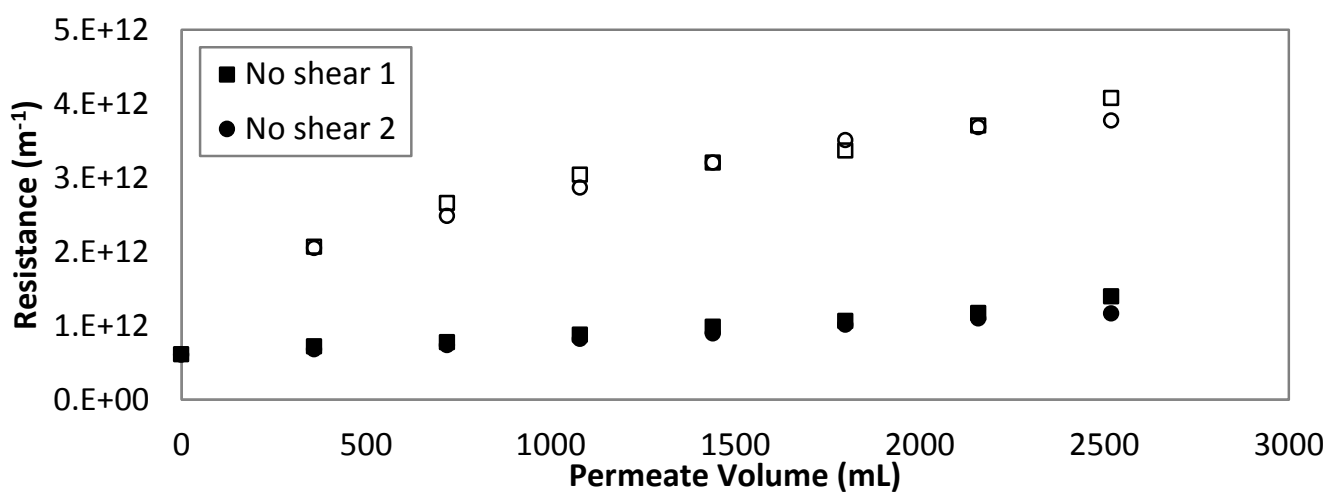

(b)

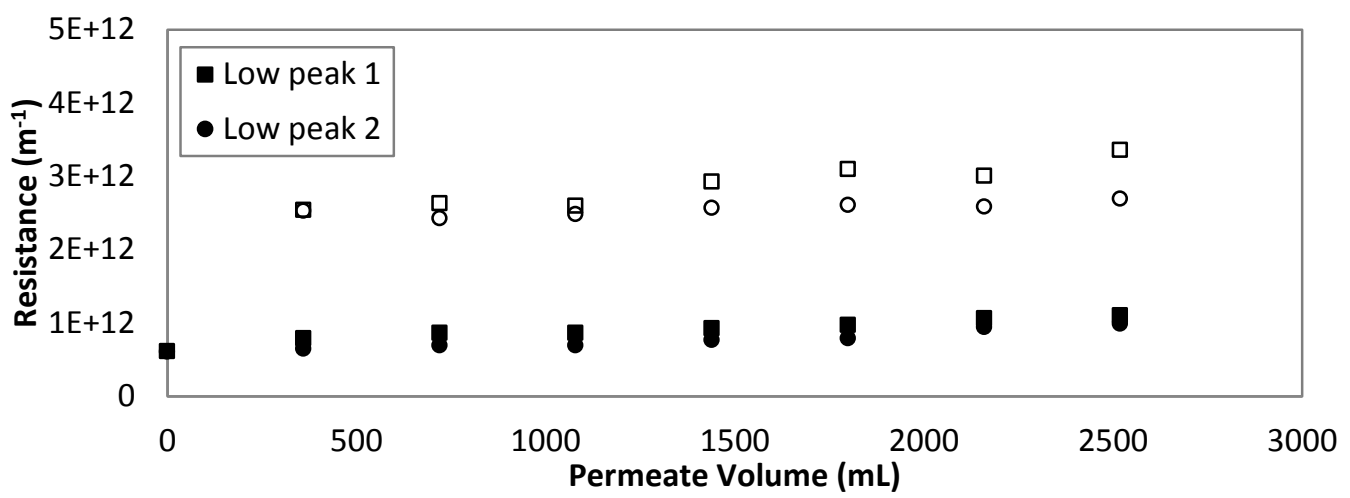

(c)

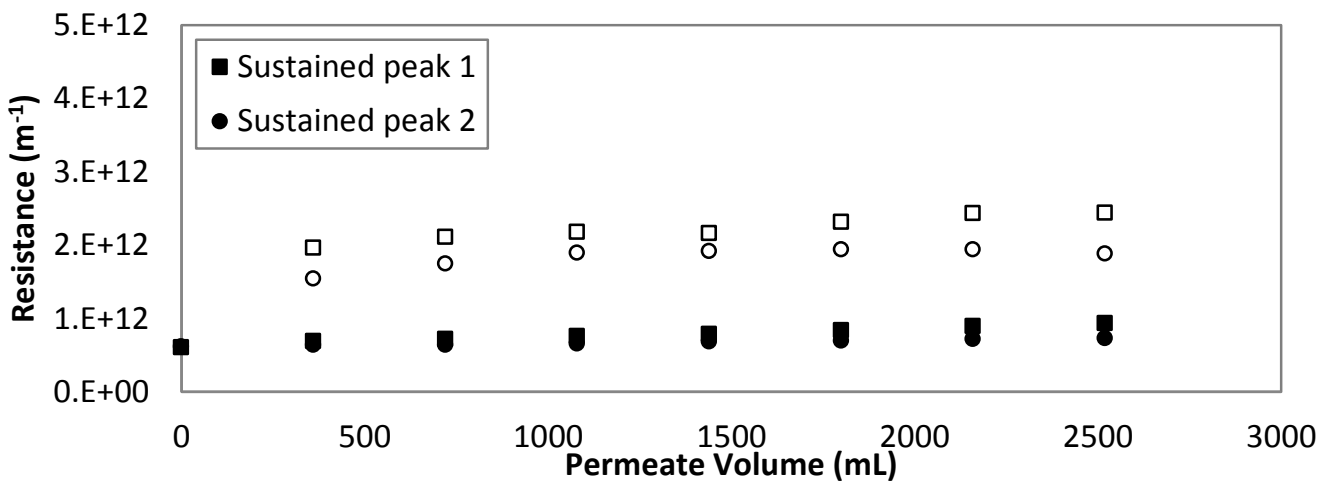


(d)

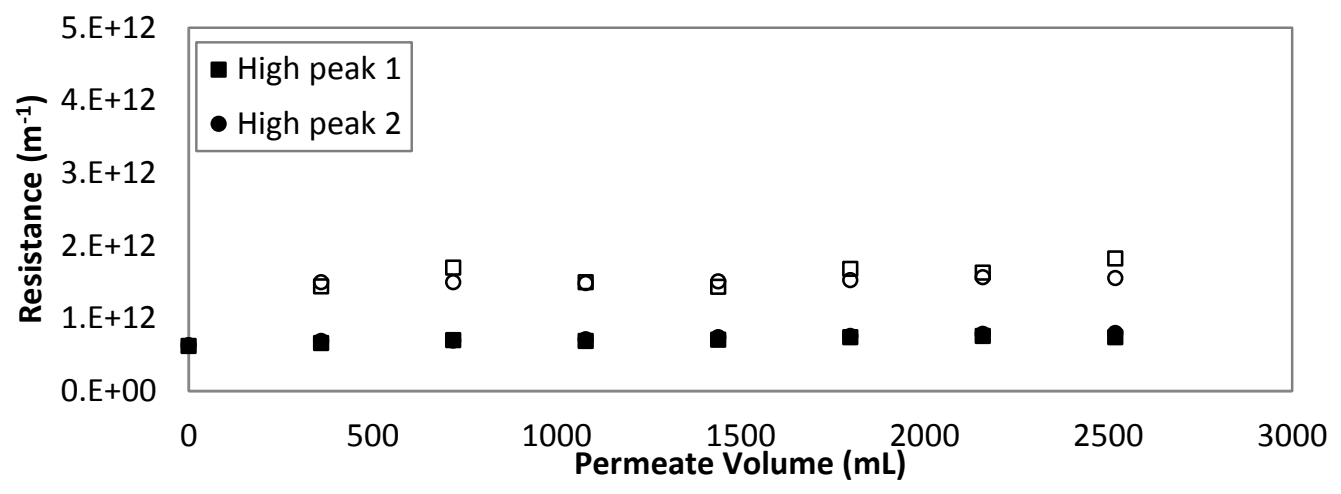

Figure 7.9: Resistance curves showing the initial and final resistance of each cycle for experiments with the $6 \mathrm{~h}$-backwash frequency in Otonabee River water. Solid markers are the initial resistance and hollow markers are the final resistance. Data represents duplicate runs for each shear condition. (a) no shear, (b) low peak, (c) sustained peak, (d) high peak 
(a)

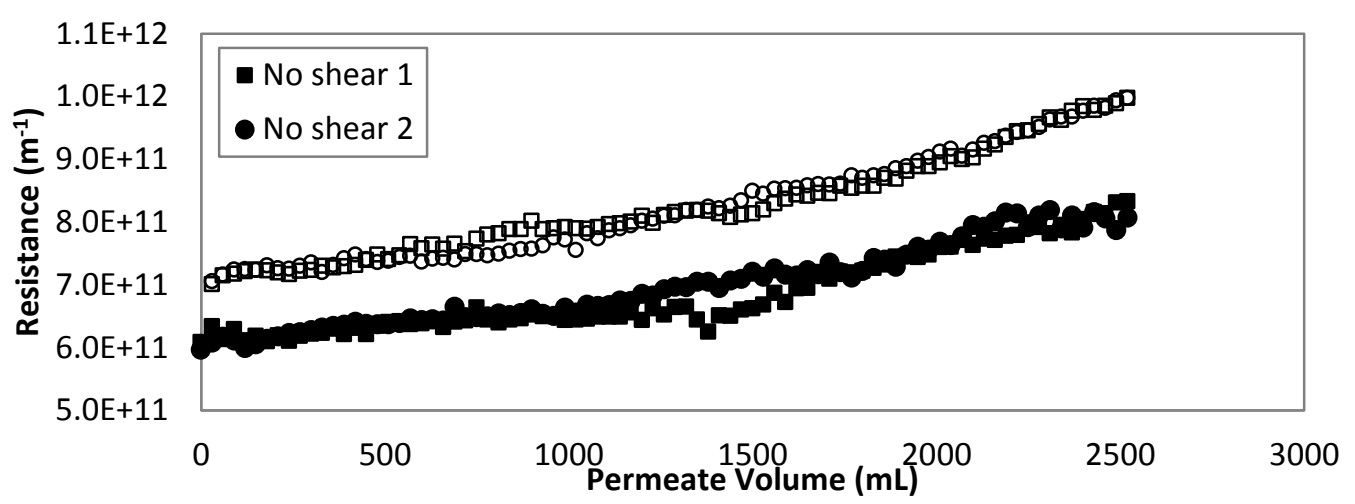

(b)

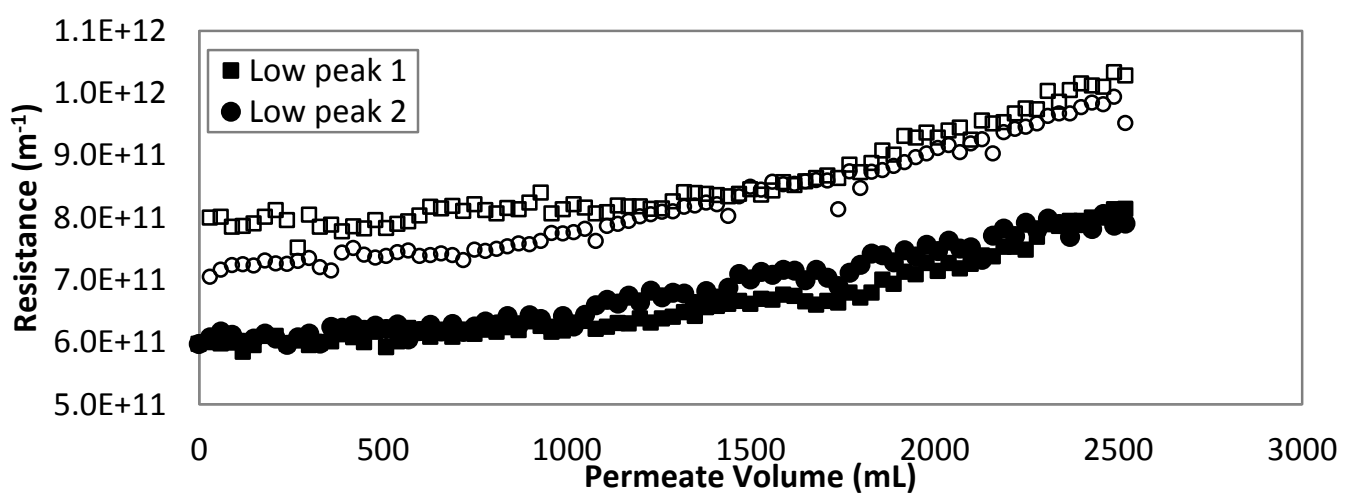

(c)

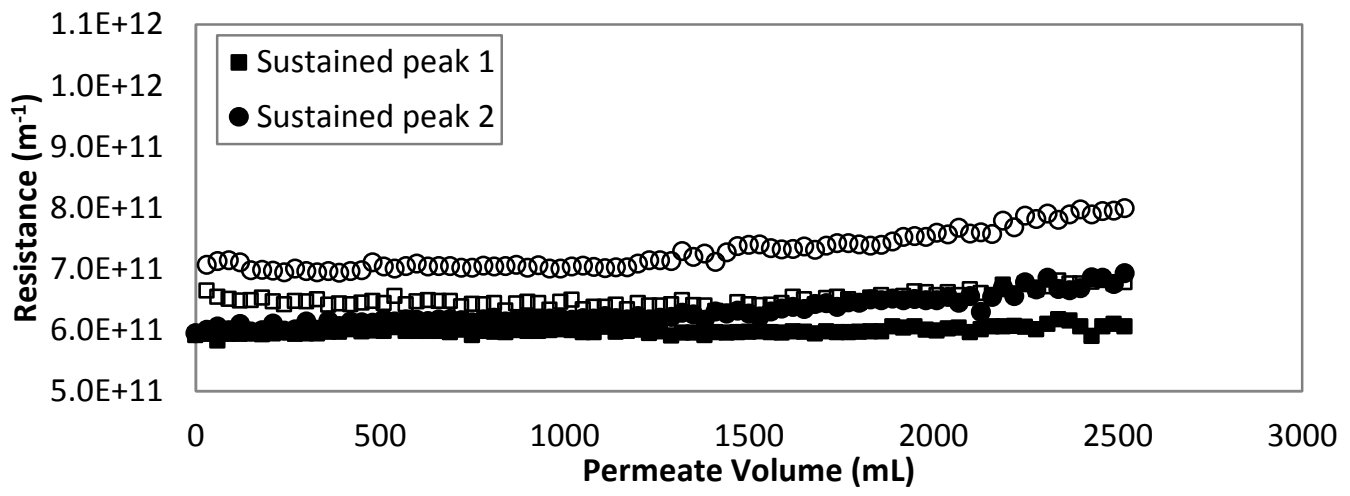


(d)

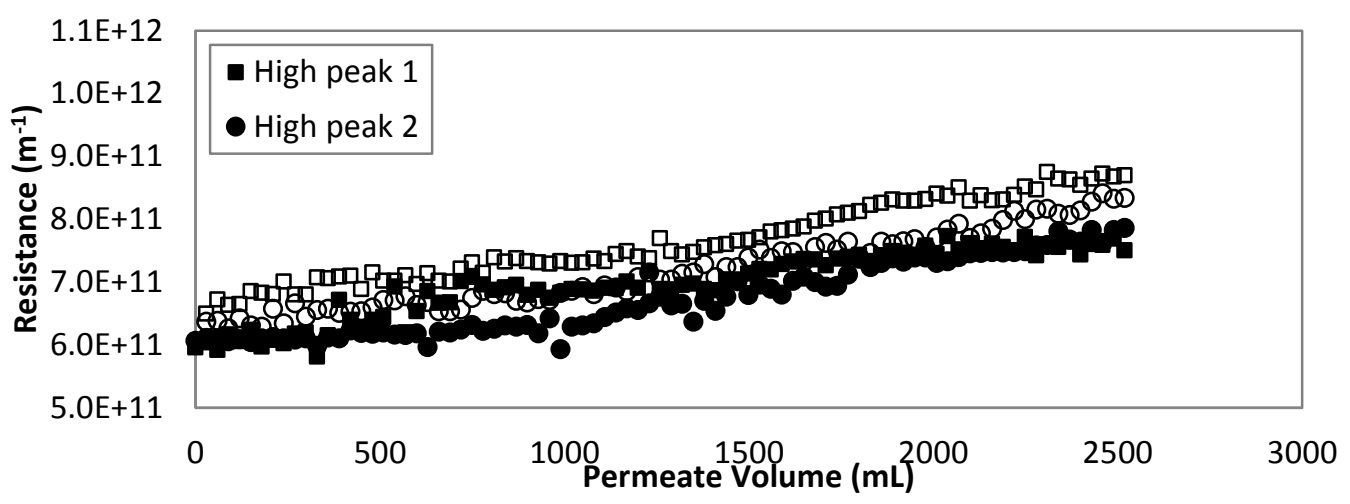

Figure 7.10: Resistance curves showing the initial and final resistance of each cycle for experiments with the $0.5 \mathrm{~h}$-backwash frequency in Lake Simcoe water. Solid markers are the initial resistance and hollow markers are the final resistance. Data represents duplicate runs for each shear condition. (a) no shear, (b) low peak, (c) sustained peak, (d) high peak 
(a)

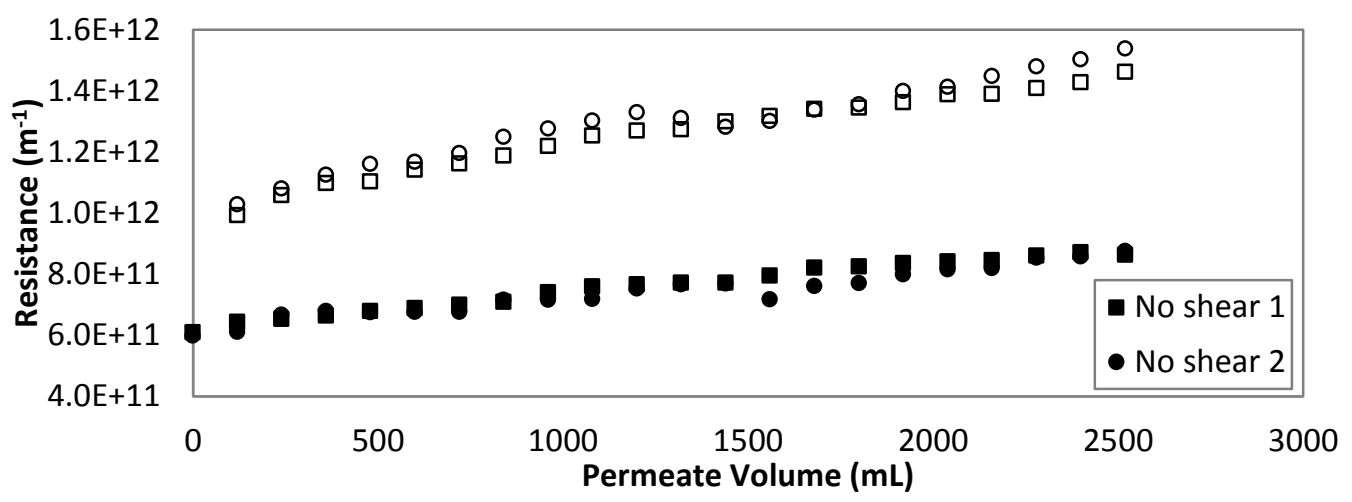

(b)

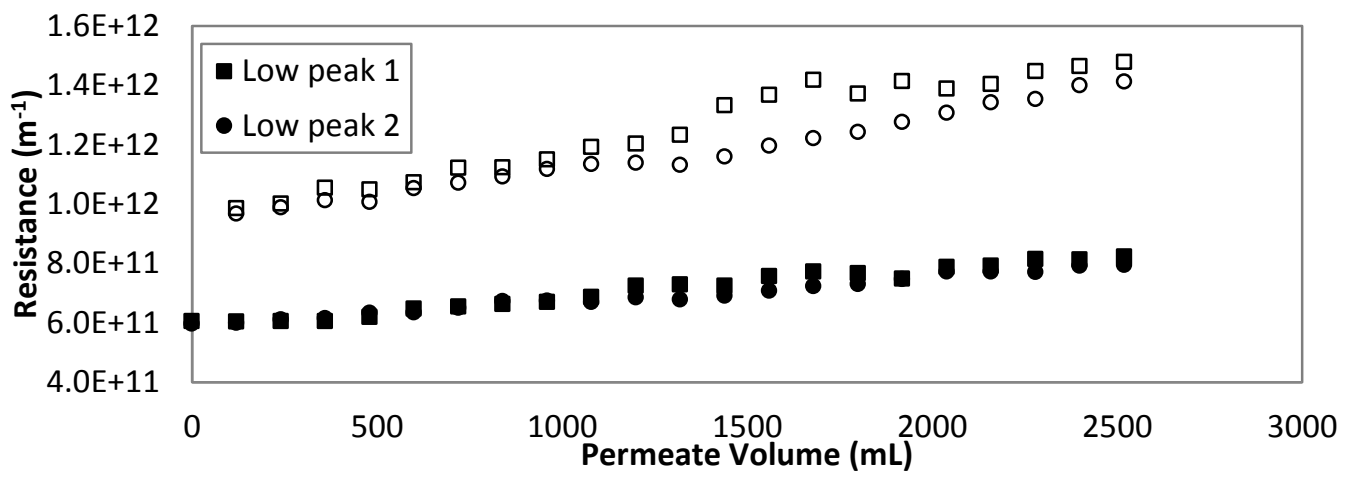

(c)

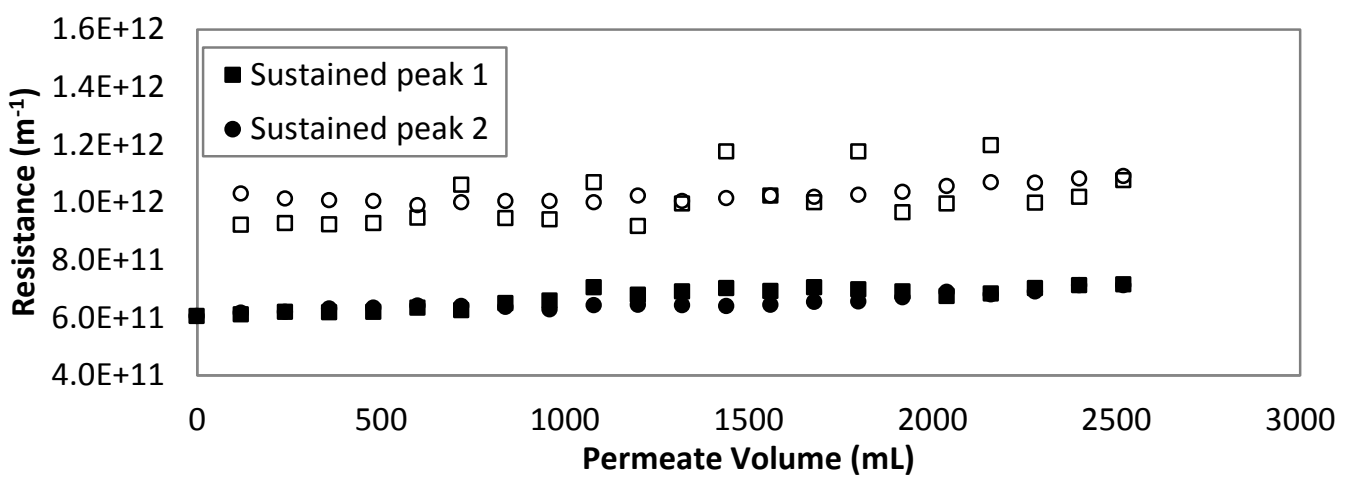


(d)

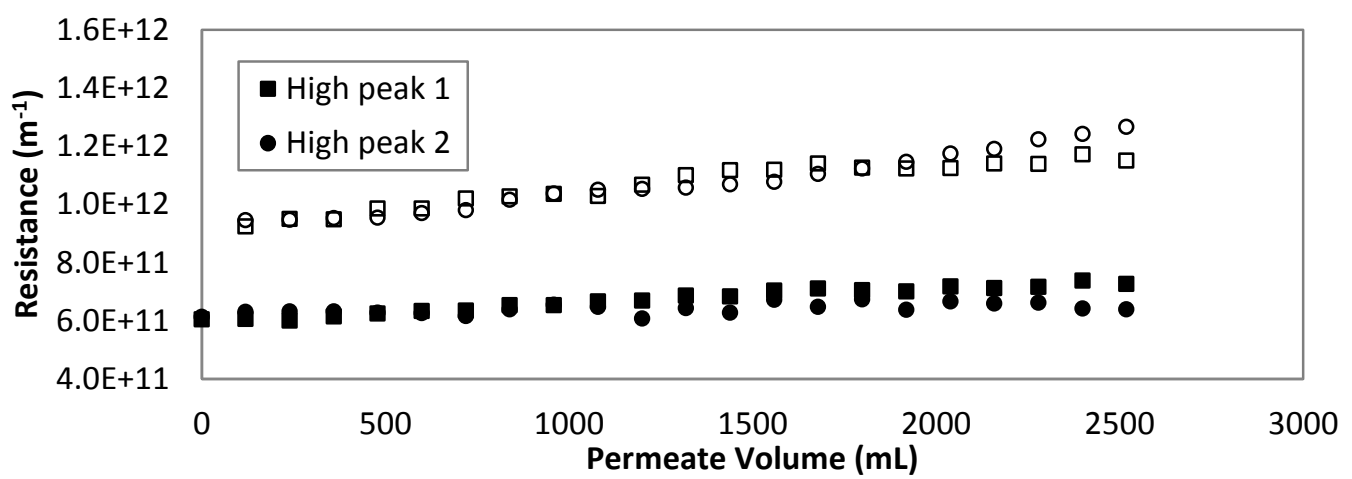

Figure 7.11: Resistance curves showing the initial and final resistance of each cycle for experiments with the $2 \mathrm{~h}$-backwash frequency in Lake Simcoe water. Solid markers are the initial resistance and hollow markers are the final resistance. Data represents duplicate runs for each shear condition. (a) no shear, (b) low peak, (c) sustained peak, (d) high peak 
(a)

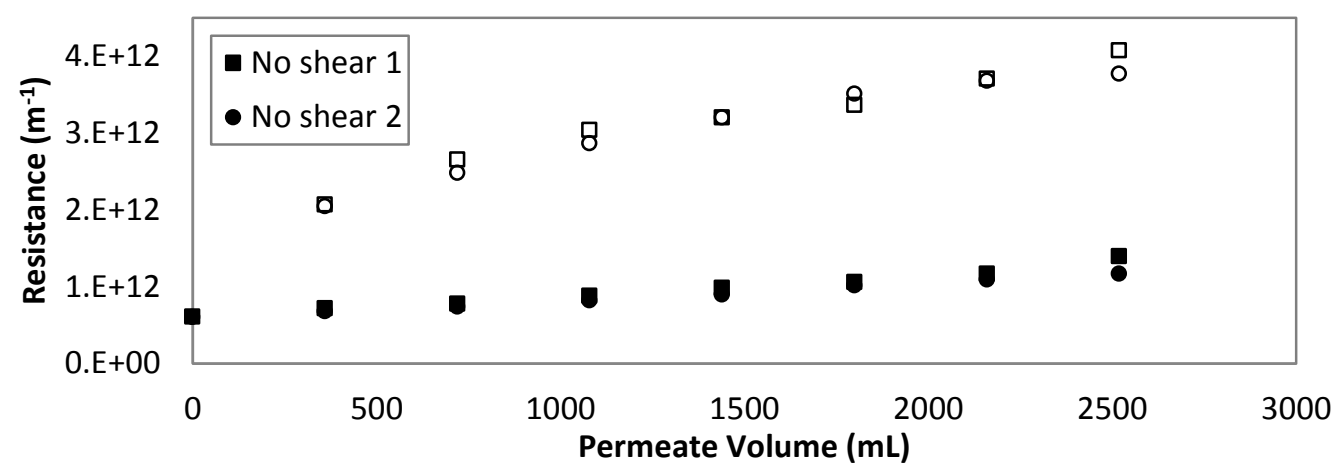

(b)

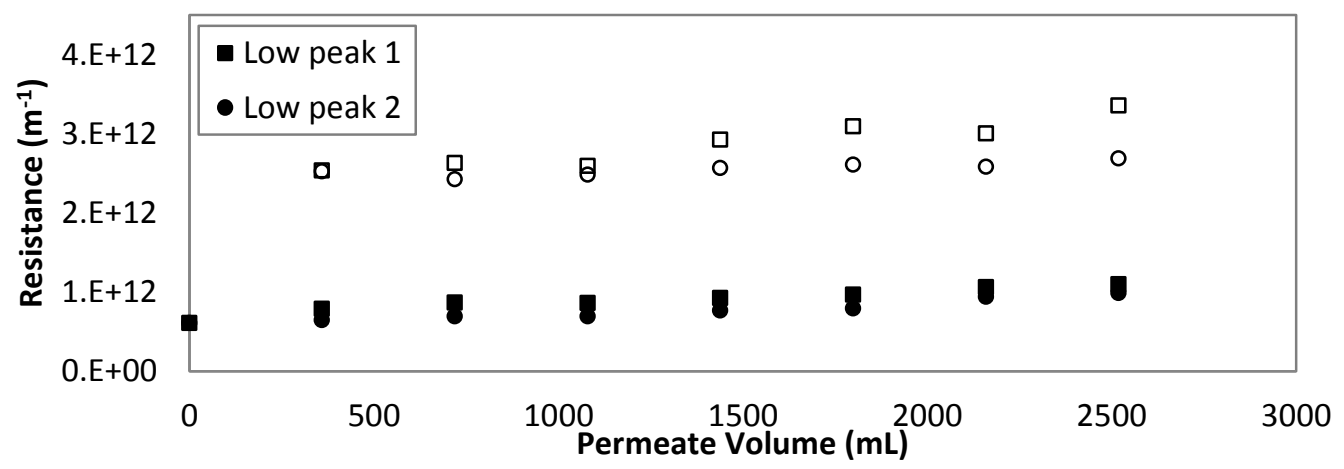

(c)

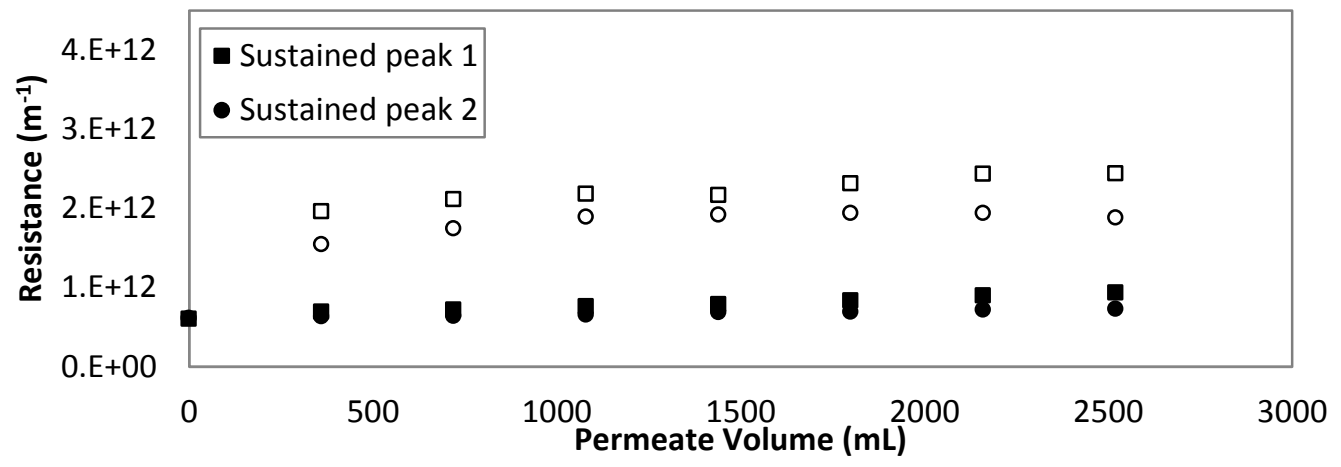


(d)

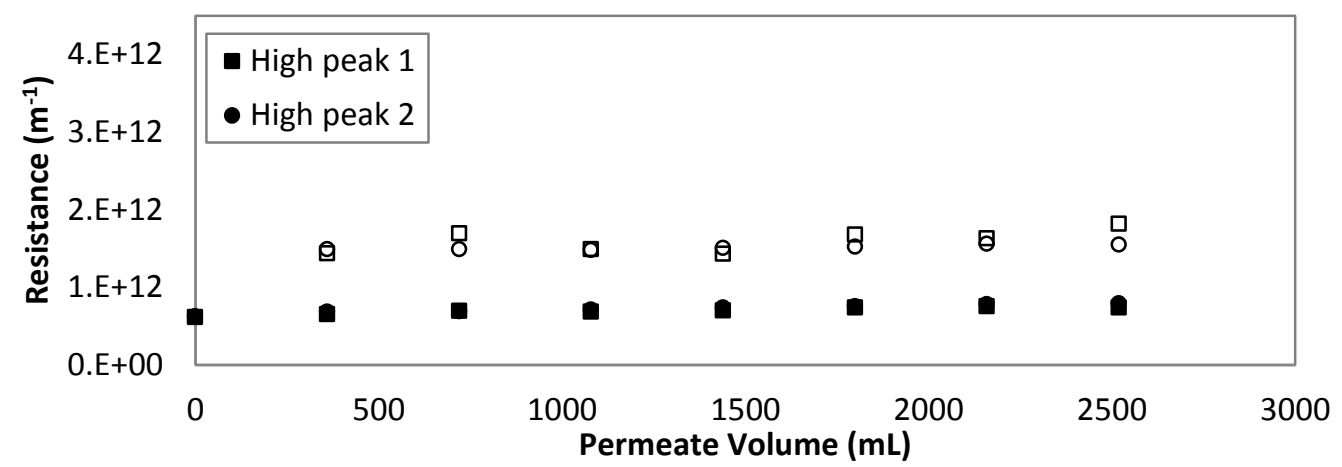

Figure 7.12: Resistance curves showing the initial and final resistance of each cycle for experiments with the 6 h-backwash frequency in Lake Simcoe water. Solid markers are the initial resistance and hollow markers are the final resistance. Data represents duplicate runs for each shear condition. (a) no shear, (b) low peak, (c) sustained peak, (d) high peak 